\title{
Deshkan Ziibi Conservation Impact Bond Project: On Conservation Finance, Decolonization, and Community-Based Participatory Research
}

Deshkan Ziibi Conservation Impact Bond Project: On Conservation Finance, Decolonization, and Community- Based Participatory Research,

Diane-Laure Arjaliès

Ivey Business School, darjalies@ivey.ca

Follow this and additional works at: https://ir.lib.uwo.ca/impact-bond

Part of the Business Commons

\section{Recommended Citation}

Arjaliès, Diane-Laure (2021) "Deshkan Ziibi Conservation Impact Bond Project: On Conservation Finance, Decolonization, and Community- Based Participatory Research," Deshkan Ziibi Conservation Impact Bond Project: On Conservation Finance, Decolonization, and Community-Based Participatory Research: Vol. 1 : Iss. 1 , Article 1.

Available at: https://ir.lib.uwo.ca/impact-bond/vol1/iss1/1

This Article is brought to you for free and open access by Scholarship@Western. It has been accepted for inclusion in Deshkan Ziibi Conservation Impact Bond Project: On Conservation Finance, Decolonization, and CommunityBased Participatory Research by an authorized editor of Scholarship@Western. For more information, please contactwlswadmin@uwo.ca. 


\section{Deshkan Ziibi Conservation Impact Bond Project: On Conservation Finance, Decolonization, and Community- Based Participatory Research,}

\section{Cover Page Footnote}

Deshkan Ziibi Conservation Impact Bond Leadership Team (2021), The Deshkan Ziibi Conservation Impact Bond Project: On Conservation Finance, Decolonization, and Community- Based Participatory Research, Western University, London, Canada, DOI: https://doi.org/10.5206/101121ipib, 114 pages. 


\section{Table of Contents}

\author{
FOREWORD \\ Deshkan Ziibiing - Restoring our Relationships.............................vi \\ PREFACE............................................................... ix \\ A Message from the Leadership Team..................................... ix \\ A Message from the Research Team Lead...................................... $\mathrm{xi}$ \\ ACKNOWLEDGEMENTS ....................................................... \\ Land Acknowledgement ................................................... \\ The Deshkan Ziibi Conservation Impact Bond Leadership Team.................xiv

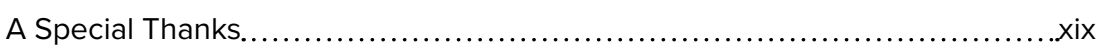 \\ LIST OF ABBREVIATIONS .......................................................

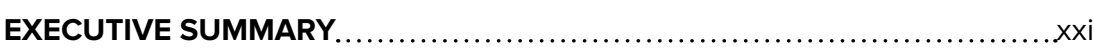

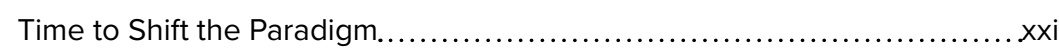 \\ The Carolinian Canada Conservation Impact Bond Model...................xxii \\ The Deshkan Ziibi Conservation Impact Bond............................xxiii \\ What is in this Report?....................................................
}

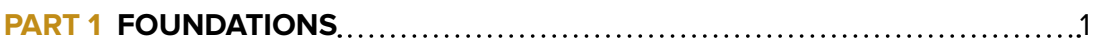

CHAPTER 1 Time to Shift the Paradigm.................................... 2

The Urgency of the Biodiversity and Climate Crises.............................2

Transforming how Societies and Economies Value Nature ....................... 5

CHAPTER 2 On the need to Decolonize Relationships with Nature.............9
The Legacy of the European Enlightenment on

Human Relationships with Nature.

Embracing Indigenous Worldviews and their

Relational Approaches to Nature.

CHAPTER 3 Canada's Commitments to the Ecological

Crises and Indigenous Peoples.

Climate and Biodiversity: International Frameworks and

National Commitments in Canada...............................................18

Commitment to the Process of Truth and Reconciliation.........................21

CHAPTER 4 The Conservation Finance Funding Gap.......................27

CHAPTER 5 Conservation Finance Mechanisms and Strategies..............31

Mechanisms of Conservation Finance...................................... 31

Conservation Finance Models............................................. 36

PART 2 CAROLINIAN CANADA CONSERVATION IMPACT BOND

CHAPTER 6 The Carolinian Zone and Carolinian Canada Coalition 44

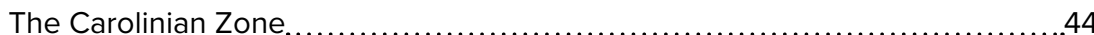

CHAPTER 7 The Carolinian Canada Conservation Impact Bond Model and the Deshkan Ziibi Pilot Project .......................................... 50

The Carolinian Canada Conservation Impact Bond Model.........................50

The Deshkan Ziibi Conservation Impact Bond Pilot Project.....................53

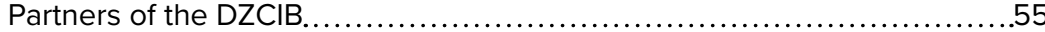




\section{CHAPTER 8 Assessing the impact of the Deshkan Ziibi}

Conservation Impact Bond.

Using a Theory of Change Framework to Assess Impact

Impacts.

Outcomes.

Outputs/Impact Metrics.

Using Impact Metrics to Assess Holistic Impact.

Selected Pay-for-Success Metrics.

Evaluating the Success of the DZCIB.

\section{CHAPTER 9 The Cross-cultural Collaborative Processes of the}

Deshkan Ziibi Conservation Impact Bond.

Towards Plural Valuations of Nature, Ecosystems, and

Ecosystem Services.

Plural Valuation
Operationalizing Plural Valuations and

Decolonizing Principles in the DZCIB

Ongoing Collaboration and Relationship-Building.............................85

CHAPTER 10 Reflections and Next Steps 89

Scaling the Carolinian Canada CIB to Other Contexts.............................89

Adapting to Evolving Conditions and Considerations for the Future .............90

CONCLUDING REFLECTION

List of References 


\section{Focus Points}

The Biosphere and Biodiversity.

The United Nations' Decade on Ecosystem Restoration......................... 5

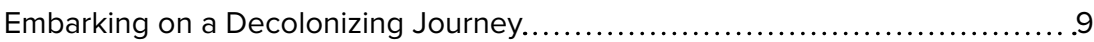

Anishinaabe Prophecy of the Seven Fires.....................................12

The Success of Indigenous Land Management................................13

Embracing a Wide Diversity of Human-Nature Relational Models.................15

High Ambition Coalition for Nature and People 30x30 Target....................19

Nature-Based Solutions and Indigenous Participation...........................20

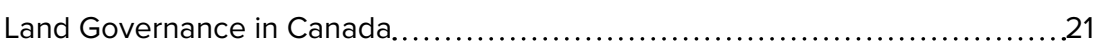

Haida Law of Gina 'Waadluxan Gud Ad Kwaagiida and

Indigenous Rights in Conservation Finance.

Defining Conservation Finance.

Raven Indigenous Capital Partners and the Argument for Community Driven Outcomes Contracts

DC Water Environmental Impact Bond

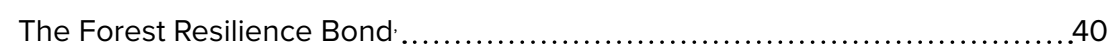

The Rhino Impact Investment Project" ........................................40 40

The Land Degradation Neutrality Fund.......................................4 41

HSBC Pollination Climate Asset Management Funds...........................41

The Carolinian Canada Coalition and the Healthy Landscape Strategy...........46

Coming Together in Ethical Space........................................ 51

The In the Zone Habitat Tracker............................................5 57

Special Note on Outcome Payers............................................58

The Deshkan Ziibi Conservation Impact Bond: A Systems Approach............61

Connecting Outcomes to Impact...........................................67

Acknowledging the Agency of Nature through the use of

Ecological Health Indicators.................................................. 75

Suggested Model for Assessing the Evaluation Pillars of the DZCIB.............77

Examples of DZCIB Pilot Habitat Projects and Impact to Date....................77

DZCIB Connecting knowledge / Circling and Learning Workshops...............87 


\section{Figures}

Figure 1: Chippewas of the Thames First Nation flag................................vi

Figure 2: Treaties in southern Ontario .............................................. vii

Figure 3: Deshkan Ziibi.............................................................ii

Figure 4: The Planetary Boundaries ................................................. 3

Figure 5: Global Wealth per Capita, 1992-2014....................................6

Figure 6: 'Ego-Eco' Diagram: Humankind is Embedded in the

Ecosystem, not apart from it nor above it.......................................... 14

Figure 7: How Worldviews Shape Social-Ecological Outcomes.....................16

Figure 8: Contemporary Conservation Funding Models............................36

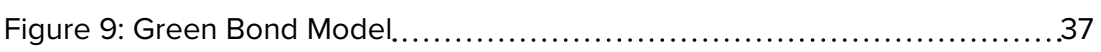

Figure 10: Pay-for-Success/Impact Bond Model...................................38

Figure 11: The Carolinian Zone.....................................................44

Figure 12: Indigenous Territories of the Carolinian Zone...........................45

Figure 13: The "Big Picture" Vision Map........................................... 47

Figure 14: Carolinian Canada Conservation Impact Bond Partner Groups......... 51

Figure 15: Carolinian Canada Conservation Impact Bond Model...................52

Figure 16: Partners of the Deshkan Ziibi Conservation Impact Bond...............54

Figure 17: Deshkan Ziibi Conservation Impact Bond Theory of Change...........64

Figure 18: Connecting Outcomes to Impact: The Process of

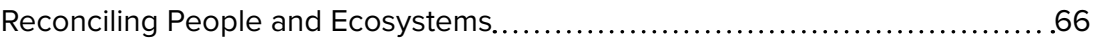

Figure 19: Evaluation Pillars of the DZCIB and a Suggested Model to

Visualize Thresholds of Impact...................................................77

Figure 20: Ongoing Collaboration and Relationship Building Through the

Development and Management Processes of the DZCIB..

Figure 21: "First Light, a Two-Row Poem by Peter Blue Cloud.. .99

Figure 22: Two-Row Wampum.

\section{Tables}

Table 1: Mechanisms of Conservation Finance. 32

Table 2: Evaluation Pillars and Impact Metrics

Table 3: The Environmental and Social Conditions to Consider for Future Implementations of the CIB

Table 4: The Challenges Within the Financial Industry to Consider for Future Implementations of the CIB. 


\section{The Deshkan Ziibi Conservation Impact Bond Project: On Conservation Finance, Decolonization, and Community-Based Participatory Research}

\section{CONTACTS:}

Ivey Business School, Research Team Lead

Dr. Diane-Laure Arjaliès: darjalies@ivey.ca

Ivey Business School, Research Assistant

Michelina Aguanno: maguanno.phd@ivey.ca

Chippewas of the Thames First Nation,

Senior Environment Officer

Emma Young: eyoung@cottfn.com I 519-289-5555 ext. 254

Ivey Business School, Research Assistant

Melanie Issett: missett@ivey.ca

\section{Carolinian Canada, Executive Director}

Michelle Kanter: mkanter@carolinian.org

Carolinian Canada, Outcome Partnerships Specialist

Daniel Fuentes: dfuentes@carolinian.org

Carolinian Canada, Conservation Impact Bond Facilitator

André Pawan Vashist: avashist@carolinian.org

Chippewas of the Thames First Nation, Director of Treaty, Lands and Environment

Kelly Riley: kriley@cottfn.com I 519-289-5555

\section{TO CITE THIS REPORT:}

Deshkan Ziibi Conservation Impact Bond Leadership Team (2021), The Deshkan Ziibi Conservation Impact Bond Project:

On Conservation Finance, Decolonization, and Community-

Based Participatory Research, Western University, London,

Canada, DOI: https://doi.org/10.5206/101121ipib, 114 pages.

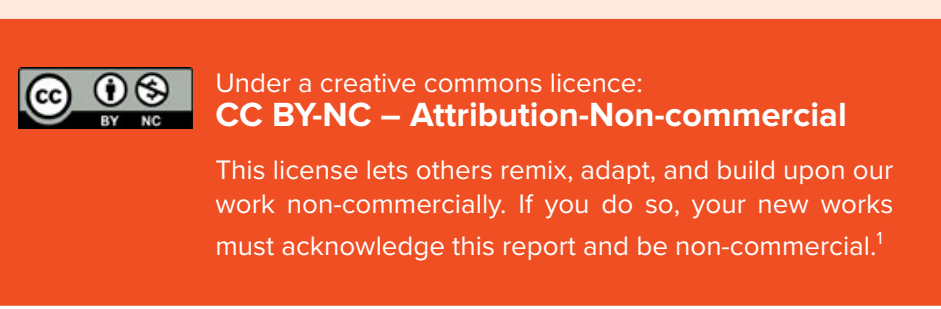

1 More information here: https://creativecommons.org/licenses/ 


\section{FOREWORD}

\section{Deshkan Ziibiing - \\ Restoring our Relationships}

\section{BY EMMA YOUNG, \\ CHIPPEWAS OF THE THAMES FIRST NATION}

Deshkan Ziibiing edbendaagzijig "those that belong to Antler River" (Chippewas of the Thames First Nation), have called the watersheds of southwestern Ontario home for millennia.

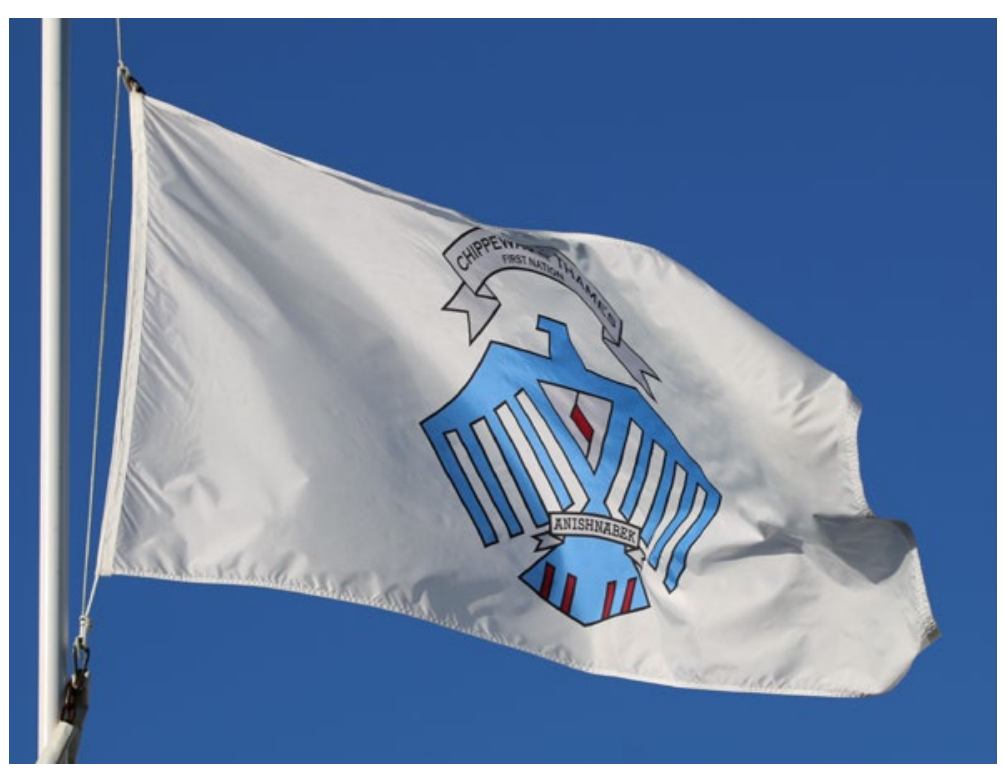

Figure 1: Chippewas of the Thames First Nation flag
Widespread archaeological evidence of the "Western Basin Late Woodland Tradition" confirms our traditional oral history teachers' accounts of this lengthy Anishinaabe dwelling in our territory of Waawayaatanong, or "Round Lake." This region is known as the third stopping place of the Water Drum on its sacred journey to Madeline Island, centuries before the era of colonization.

We have continued to dwell here despite the disruptions stemming from conflicts with other Anishinaabe Nations also dwelling near the Great Lakes, from the wars between various settler powers between 1757 and 1815, and from the imposition of Britain's, then the United States', and Canada's colonial rule. Historically, we managed portions of our territory in common with other Anishinaabe Nations, and at times in partnership with the Haudenosaunee.

Nevertheless, the lands bordering the northern bank of Deshkan Ziibi "Antlered River" (Thames River) have been solely in the stewardship and possession of Deshkan Ziibiing since before the treaty era. 


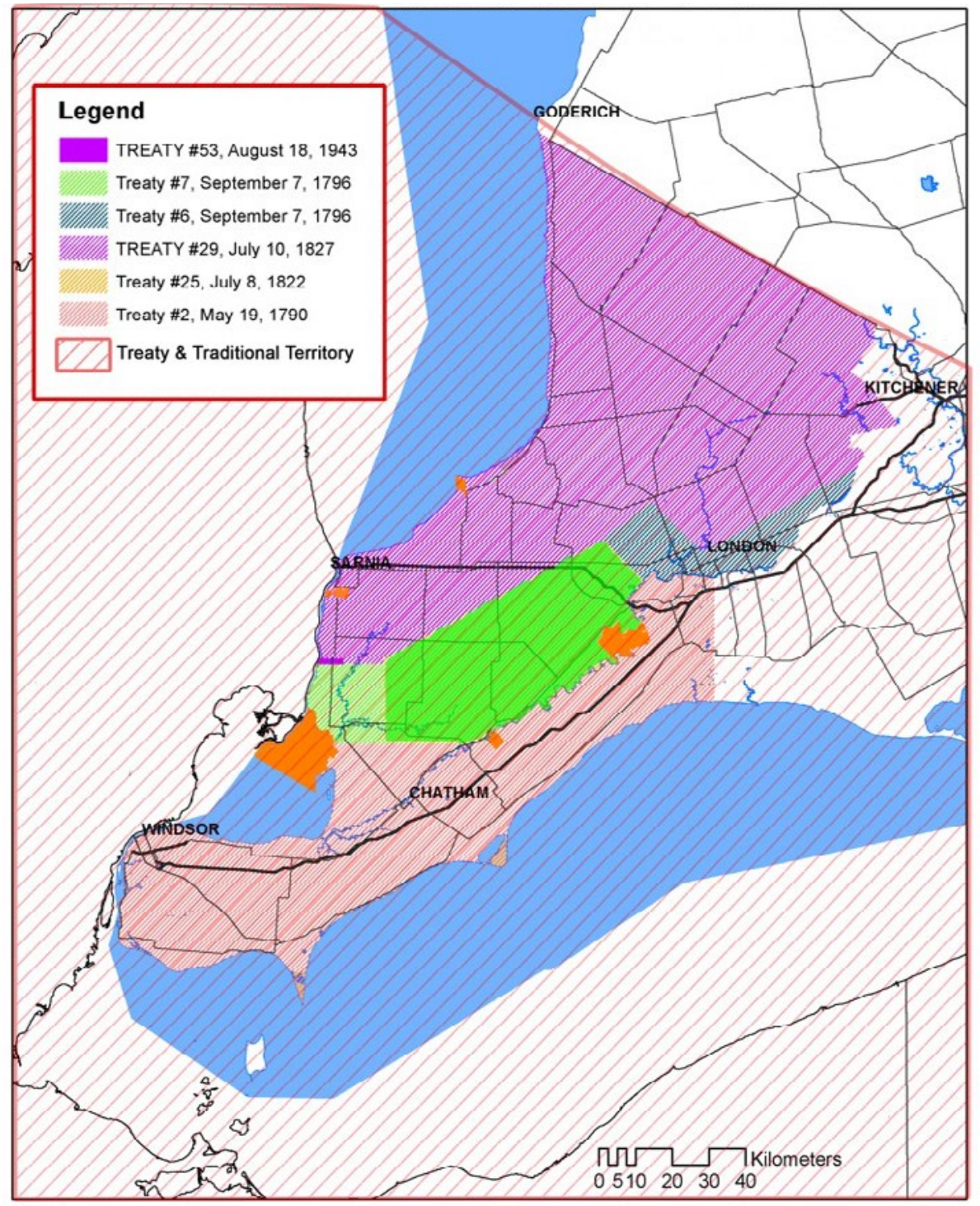

Figure 2: Treaties in southern Ontario
Deshkan Ziibiing has been a partner in developing the Conservation Impact Bond since its early inception. Deshkan Ziibiing has an interest in conservation activities within the Carolinian Zone as this ecoregion spans both our Treaty and Traditional Territory.

Working from the standpoint of including the importance of relational accountability, Deshkan Ziibiing puts forth the perspective that we must restore our relationships with the land in order for conservation to have long-term success. This includes removing humans from the top of the chain and moving to look at the environment more holistically, as an interconnected web of which humans are only a piece.

Through this project, we are able to help fulfill the responsibilities given to us by the Creator to protect and steward the lands and waters. The name Deshkan Ziibi comes from the original Anishinaabemowin name given to the Thames River which translates to "antlered or horned river."

This name was given to the river by the Anishinabeg for two possible reasons. One reason is the name is a reference to how the river forks in London, Ontario, resembling antlers or horns. A second reason is in reference to a horned serpent which is known to dwell within the river. As a Conservation Impact Bond partner, we felt it important that the original name of the river be used rather than its modern colonial name. 


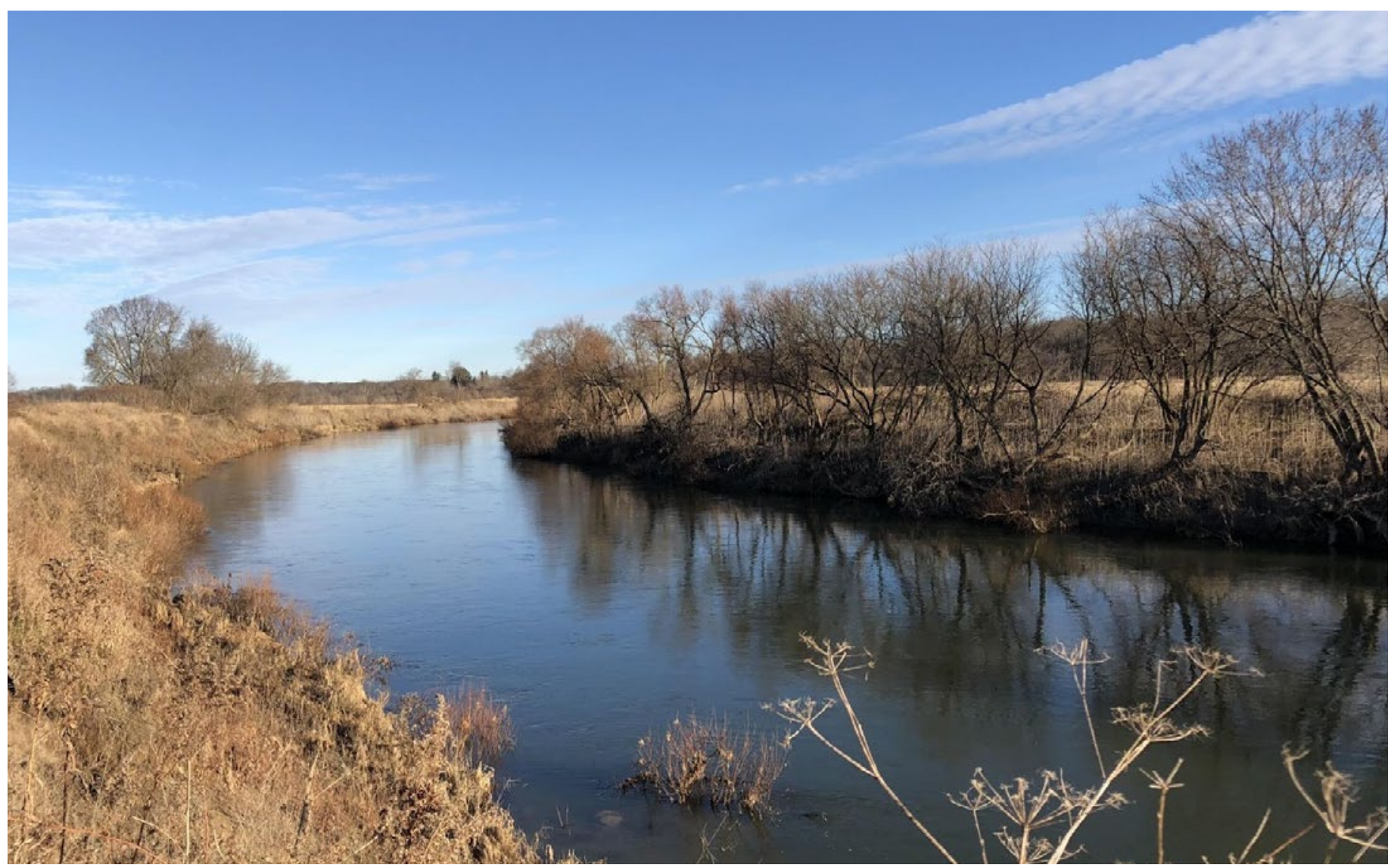

We encourage those working on Indigenous territories to learn whose territories and treaty lands they are on. It's important to take the time necessary to build relationships, to listen, to learn and eventually trust one another when embarking on collaborative work.
Indigenous people have been stewarding the land on the Turtle Island since time immemorial and it is imperative that the conservation sector begins to acknowledge and work collaboratively with Indigenous Nations who hold vital knowledge on maintaining and revitalizing local ecosystems. 


\section{PREFACE}

\section{A Message from the Leadership Team}

This report includes elements of Indigenous and Western forms of knowledge to share a holistic story of the Deshkan Ziibi Conservation Impact Bond (DZCIB). The authors sought to write this report being guided by a "Two-Eyed Seeing" perspective", bringing together Indigenous and Western ways of knowing, seeing, and being. As a reader, you are implored to reflect on the colonial legacy which continues to disempower Indigenous value systems and ways of life. You are encouraged to approach this report with an open mind and heart, challenge your base assumptions, and embrace the integration of diverse value systems and worldviews.

This project was conducted in the spirit of reconciliation, decolonization, and indigenization. All three are recognized as continuous processes that occur on many levels including: intrapersonal, interpersonal, community, organizational, and national.

\begin{abstract}
"Reconciliation is about establishing and maintaining a mutually respectful relationship between [Indigenous] and [non-Indigenous] peoples in this country. In order for that to happen, there has to be awareness of the past, an acknowledgment of the harm that has been inflicted, atonement for the causes, and action to change behaviour."
\end{abstract}

Truth and Reconciliation Commission of Canada ${ }^{2}$
Decolonization is the process of deconstructing colonial biases and ideologies which inhibit Indigenous perspectives and ways of life. It involves actively dismantling the societal structures that perpetuate the superiority of Western thought to allow for the promotion of Indigenous ways of knowing, being, and seeing. ${ }^{3}$ Decolonization is a process that brings about the repatriation ${ }^{2}$ of Indigenous land and life. ${ }^{4}$ Notably, the word 'decolonization' has been critiqued for its use in certain contexts as a metaphor for improving societies and institutions. The use of the term as a metaphor has been challenged because it may have objectives that are incommensurable with decolonization and enables its use as an evasion technique for settler guilt. ${ }^{5}$

Indigenization is a process of naturalizing Indigenous knowledge systems and making them accessible and understood. Indigenization is not the replacement of a Western way of thinking with an Indigenous way, but rather the weaving of the two distinct knowledge systems in ways that allow for building mutual understanding and capacities for appreciating both ways of life. ${ }^{6}$

The Leadership Team intends to be transparent with their use of reconciliation, decolonization, and indigenization terminology, recognizing that these terms hold important meanings and exist with more significant implications in contexts broader than the project discussed in this report. The Leadership Team's focused engagement with the processes of reconciliation, decolonization, and indigenization stem from a recognition of the detrimental impacts of colonization on Indigenous peoples and ecosystems in Canada and the colonizing undertones of land

\footnotetext{
2 Rematriation. The authors want to acknowledge the Indigenous-led movement of Rematriation, 'the act or process of returning the Sacred to the Mother'. (https://rematriation.com/) 
governance and the financialization of nature, both concepts present in this project. This project actively strives to support the processes of reconciling, decolonizing, and indigenizing in its structure and engagements with partners and non-human living beings.

Supporting Indigenous leadership is a vision adopted by the Leadership Team to align with and support a range of goals and priorities defined by local First Nations. Embedded in this vision is an acknowledgement that Indigenous ways of knowing and being are essential to reconciliation processes that can promote healthier landscapes and healthier communities. This project was undertaken with engagement from key Indigenous partners to support deconstructing colonial assumptions of nature and its management on a personal and project level and create collaborative spaces for integrating the influences of Indigenous worldviews, values, and knowledge systems. The Leadership Team understands that non-Indigenous people have an essential role to play in advancing the processes of reconciliation, decolonization, and indigenization through a conscientious commitment to learning, understanding, relationship building, and capacity development. At the time of this report, important first steps have been taken that are integral to the reconciliation journey ahead.

The Deshkan Ziibi Conservation Impact Bond Leadership Team 


\section{A Message from the Research Team Lead}

This report explains the motivations and theoretical foundations of the processes, governance, and impact metrics employed to co-develop the Deshkan Ziibi Conservation Impact Bond (DZCIB). The DZCIB is an outcomes-based financial instrument focused on reconciling peoples and ecosystems by building capacity for growing healthy landscapes with nature-based solutions and Indigenous leadership.

This first-of-its-kind financial instrument is facilitated by Carolinian Canada, a non-profit network of leaders that collaborate for healthy ecosystems in the Carolinian Zone, Canada's southernmost ecoregion spanning from Toronto to Windsor. The structure of the DZCIB is similar to social impact bonds with facilitators, investors, and outcome payers.

In the first phase of the DZCIB, due to conclude in 2023 , a social finance firm provided the upfront investment, and government, a multinational company, and non-profit acted as the outcome payers, paying out the principal and return of the DZCIB if the targeted outcomes are achieved. Impact metrics were determined collaboratively with the DZCIB Leadership Team and partners including: the research team, Carolinian Canada, habitat partners, Indigenous communities, and investors; in ways that attempted to embrace both Indigenous and Western worldviews.
The DZCIB is the first pilot project of the Carolinian Canada Conservation Impact Bond (CIB). This report focuses on the DZCIB's development over its first two years since partners began meeting (January 2019 - July 2021). Further updates on the project will be given in the future, with the hope that our journey will help spur further similar initiatives across Canada and around the world.

Because we believe that knowledge should not be privately appropriated and to support as many communities as we can through our shared experience, we decided to publish this report in the format of an electronic book in an open access format. This creative commons license lets others remix, adapt, and build upon our work non-commercially. If you do so, your new works must acknowledge this report and be non-commercial.

A research team from Ivey Business School wrote this report with input and approval from the members of the DZCIB Leadership Team. We aimed to acknowledge the diverse perspectives in the team, notably by closely involving our Indigenous partners, throughout the process. Despite our best efforts, we might have maintained at times a Westernized bias, for which we apologize.

The viewpoints expressed in this report are ours and should not be attributed to others. 


\section{WHAT IS COMMUNITY-BASED PARTICIPATORY RESEARCH?}

Canadian university research agendas have often neglected the knowledge of Indigenous peoples, misinterpreted their teachings, and 'othered' their culture, positioning it as inferior, illiterate, and uncivilized. Canadian universities must now engage in a process of decolonization, which aims to reverse the negative and disempowering nature of colonialism in research and education. Researchers must also improve Indigenous peoples' access and experience within the university system. Engaging Indigenous peoples in the production of research is im portant as it contributes to building relationships and meaningful dialogue between Indigenous and non-Indigenous peoples and is an integral part of the reconciliation process.

This project relies on community-based participatory research (CBPR) which is a research method that relies on building relationships between academics and community partners, with principles of co-learning, mutual benefit, and long-term commitment. ${ }^{8}$ CBPR emerges with a topic that matters to the community and involves academics with the aim of combining knowledge and action to trigger change that contributes to improving the community. Rather than a specific set of research methods or techniques, CBPR involves a systematic effort to involve community practices throughout the research process.

CBPR has been praised by Indigenous scholars for its ability to contribute to the process of decolonizing research by empowering communities to meet their goals of self-determination. ${ }^{9}$ Not only does CBPR require that Indigenous communities participate actively in the research from the very start, but it also implies that the research will have direct benefits to their lives. This approach is a significant turn from previous involvement of researchers into Indigenous contexts. While broadly used in disciplines attuned to engage in Indigenous contexts, such as geography, anthropology, or Indigenous studies, ${ }^{10}$ CBPR has rarely been used in business schools.

CBPR involves several challenges, including issues of power, domination, and sustained col- laborative engagement. ${ }^{11}$ To maintain an ethica research partnership, two elements have been identified as essential: relational accountability and mindful reciprocity. ${ }^{12,13}$ Relational accountability requires that consistent attention be given by the researchers to the relationships involved in the project. Mindful reciprocity requires that researchers participate in thoughtful and compassionate relationships with the people involved in the collaboration.

All the academic researchers involved in this project are non-Indigenous, which requires cultural sensitivity and a constant, conscientious effort to engage in decolonizing themselves and their research practices, in accordance with the CBPR method. The research protocol was designed and has been constantly adjusted accordingly with all the members of the team. Ethics approval was obtained both from Western University Non-Medical Research Ethics Board and project partners at the Chippewas of the Thames First Nation.

\section{Dr. Diane-Laure Arjaliès}

Ivey Business School, Research Team Lead
To conduct this research, the Ivey research team received funding from the Smart Prosperity Institute, the CPA-Ivey Centre for Accounting \& the Public Interest, the Ivey Business School and Western University. The authors have no conflict of interest to declare. 


\section{ACKNOWLEDGEMENTS}

\section{Land Acknowledgement}

The Deshkan Ziibi Conservation Impact Bond Leadership Team acknowledges that our work, our team, and our partners are located and living on the traditional territories of many Indigenous Nations including the Anishinaabe, the Haudenosaunee, the Lunaapeew, the Attawandaron, the Wendat. We acknowledge all Indigenous peoples that still call this land home and the many diverse First Nations, Métis, and Inuit peoples who have moved here since.

We acknowledge the inherent rights and the treaty rights of the Indigenous peoples of Turtle Island. We acknowledge the Royal Proclamation of 1763, which serves as the basis for the treaty-making process and is the first legal recognition of aboriginal rights and titles, and all the treaties that have been signed related to this land.
With this, we respect the longstanding relationships that Indigenous peoples have to this land, as they are the original caretakers. We acknowledge historical and ongoing injustices that Indigenous peoples (e.g., First Nations, Métis, and Inuit) endure in Canada, and the non-Indigenous peoples on the team accept the role we must play in Indigenous reconciliation and the responsibility to contribute towards revealing and correcting miseducation as well as renewing respectful, reciprocal relationships with Indigenous communities through our practices and community service. We are committed to building relationships and working with Indigenous Nations. We are also committed to creating safe spaces for Indigenous and non-Indigenous perspectives to meet and discuss the issues that matter to everyone. 


\section{The Deshkan Ziibi Conservation}

\section{Impact Bond Leadership Team}

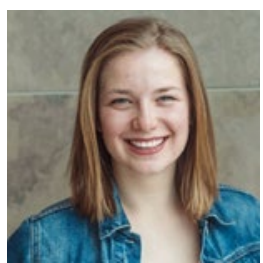

\author{
Michelina Aguanno \\ Ivey Research Team,
}

Research Assistant

Michelina is a PhD Student at the Ivey Business School, Western University (Canada), where she also holds a bachelor's degree in Honours Business Administration (HBA). Michelina's passion for the innovative change potential at the intersection of business and sustainability drove her to pursue research in conservation finance. Michelina is a European descendant of Italian heritage whose family settled in Canada in the mid-1900s. In her spare time, Michelina can be found outdoors connecting with nature through activities such as camping, hiking, and canoeing.

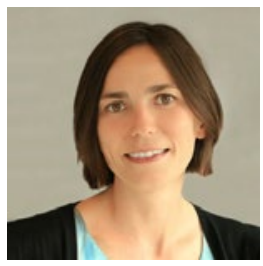

\section{Dr. Diane-Laure Arjaliès}

Ivey Research Team,

Lead

Diane-Laure is an Associate Professor at the Ivey Business School, Western University (Canada). An ethnographer, she aims to push the boundaries of knowledge and practice by investigating how the fashioning of devices and collective actions can help transform financial markets towards sustainable development. She leads the Ivey research team in the Deshkan Ziibi Conservation Impact Bond Project, including the community-based participatory research and the writing of this report. A settler of French origin, she moved from Paris to what is now called Canada in 2015.

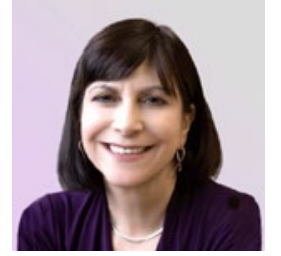

\section{Lina Bowden}

VERGE Capital,

Impact Investor
Lina Bowden, FCPA, FCMA, MA is the catalyst behind VERGE Capital, a community-led collaborative that creates local investment for local impact in London and southwestern Ontario. Her work in social finance has helped create two place-based impact funds and engaged local impact investors and community stakeholders. She is also an impact investor and advisor with several social enterprises. Lina has a $30+$ year career in the financial services industry, leading finance, marketing, product management and client service teams. She is a fellow of the Society of Management Accountants and Chartered Professional Accountants and she holds a Masters in Development Policy and Practice from the University of New Hampshire.

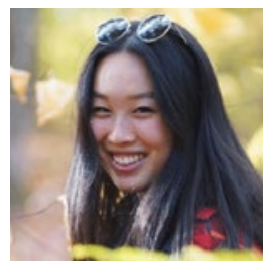

\section{Celina Chen}

Ivey Research Team, Research Assistant

Celina is a recent graduate of the Honours Business Administration program with the Sustainability Certificate at the Ivey Business School at Western University. With a passion for the intersection of sustainability, social impact, and business, she will continue her involvement in the space as a nominated Fellow for the Sustainability Certificate, to support and rapidly scale the program at Ivey's Centre for Building Sustainable Value. She is a first-generation immigrant to Canada and is originally from China. 


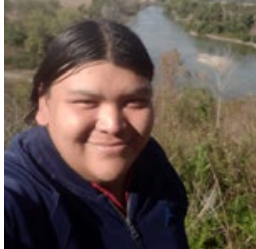

\section{Brandon Doxtator}

Oneida Nation of the Thames,

Environment and Consultation Coordinator

Brandon Doxtator is a bear clan member from the Oneida Nation of the Thames. Brandon currently sits on the Association of Iroquois and Allied Indians (AIAI) Youth Council, as well as working for the Oneida Nation as the Environment and Consultation Coordinator. In 2016, Brandon served a two-year term as an Elected Councillor for the Oneida Nation of the Thames, and ever since has been passionate about working with youth and protecting and enhancing critical habitat within Southwestern Ontario. Through his school, professional and life experiences, Brandon is always interested in talking about Anthropology, History, Indigenous issues, Treaty and Inherent rights and Consultation practices and protocols.

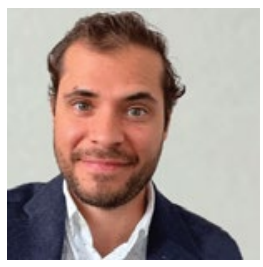

\section{Daniel Fuentes}

Carolinian Canada,

Outcome Partner Specialist

Daniel is leading the Outcome Partner Strategy for Carolinian Canada's Conservation Impact Bond: "an excellent example of Canadian leadership in pay-for-success models." ${ }^{4}$ In 2017, with funding from Cambia Development Foundation, Daniel led the internal capacity building of Carolinian Canada's corporate strategy to pioneer and build partnerships at the nexus between finance and conservation. He designed Carolinian Canada's Resilience Mechanism: an outcomes-based partnership model that has served as the foundation of the Deshkan Ziibi Conservation Impact Bond Project and the overall Carolinian Canada's conservation finance strategy. Daniel is a new immigrant to Canada and is originally from Ciudad Juárez, Mexico.

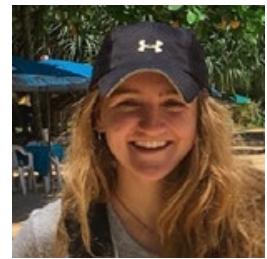

\section{Melanie Issett}

Ivey Research Team,

Research Assistant

Melanie Issett is a recent graduate of the undergraduate dual degree program at Western University where she received an Honours B.Sc. in Environmental Science and Honours Business Administration degree from the Ivey Business School. Passionate about finding ways for societies and economies to operate within planetary boundaries, Melanie will be continuing her studies pursuing a master's degree at the School of Environment, Enterprise, and Development (SEED) at the University of Waterloo in the Fall. She is a descendant of European origin whose family settled in Canada in the early 1900s.

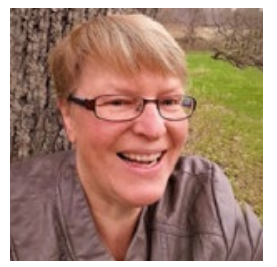

\section{Michelle Kanter \\ Carolinian Canada,}

Executive Director

Michelle Kanter is the Executive Director of Carolinian Canada, since 2003. With 35 years of experience in wildlife research and conservation, she has worked with diverse species and stakeholders from the Carolinian Zone to the Arctic and Australia. She has led the co-development and implementation of the Conservation Impact Bond and other multi-partner platforms with a strong and diverse team. She specializes in cross-sector collaborations for healthy ecosystems using a range of innovative tools including collective impact, social finance, social marketing, and green business. She sits on the Ontario Biodiversity Council and lives in the Dorchester swamp where she found her love of local nature as a second-generation settler of European immigrants. 


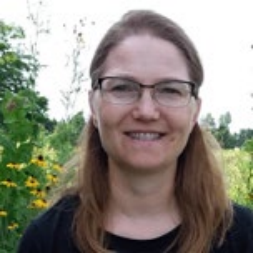

\section{Daria Koscinsk}

Thames Talbot Land Trust,

Habitat Partner

Daria is the Executive Director of Thames Talbot Land Trust. Daria has been actively involved in conservation and land stewardship in Ontario since 2000 through her education, work, and volunteer experience with environmental groups. Daria received her BSc and MSc from Queen's University and her PhD from Western University with a focus on ecology, population genetics, and habitat fragmentation. Daria enjoys spending time in nature, restoring habitats, and sharing her enthusiasm for local biodiversity through educational programs. Daria emigrated from Poland to Canada in 1986 and has been nurturing her relationship with land and nature near her home and work in southwestern Ontario.

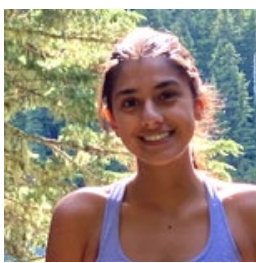

\section{Baani Mann}

\section{Ivey Research Team,}

Research Assistant

Baani became involved with the Conservation Impact Bond after taking a class in Social Finance at the Ivey Business School taught by Professor Diane-Laure Arjaliès. She recently graduated from Western University with a dual degree in Business and Political Science and is fascinated by the intersection of policy and environmental outcomes.

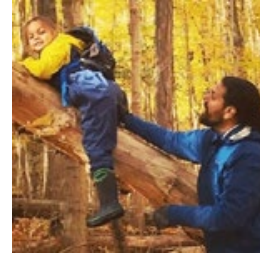

\section{André Pawan Vashist}

Carolinian Canada,

Conservation Impact Bond Facilitator

André was invited to support the development of the Conservation Impact Bond as a social innovation specialist and social finance leader. As the Founding Manager of VERGE Capital and Director of Social Innovation at Pillar Nonprofit Network, André facilitated relationship building across sectors and nurtured collaboration that supported our team's vision of developing a bioregional conservation finance model, including the first Outcome Partner. André decided to continue supporting this work by leading the facilitation of the Deshkan Ziibi Leadership Team and by supporting the scaling of the Conservation Impact Bond into new bioregions. As a collaborationist and equity seeker, André is focused on cultural knowledge and structures that can honour our relationships with the land, all our relatives and our human family.

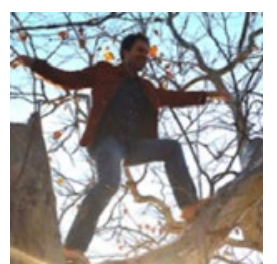

\section{Ben Porchuk}

Carolinian Canada,

Carolinian Zone Ecologist

Ben Porchuk has over two decades of experience in wildlife biology and ecology, non-profit management, environmental consulting, and sustainable living. Working with rural threatened ecosystems in southern Ontario and in densely populated urban centres, Ben has become both a highly experienced practitioner on ecological systems recovery and a strong agent for restoring urban ecology to greater resiliency. Now living in the densely populated area of London, Ontario, Ben's property consists of over 150 species of native plants, including a wetland, all visited by many rare species of wildlife, seldom observed in the downtown of a city. 


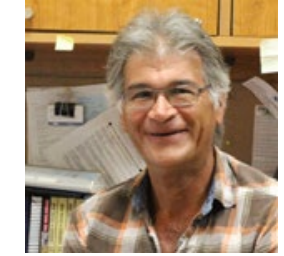

\section{Kelly Riley}

Chippewas of the Thames First Nation,

Director of Treaty, Lands and Environment

Born and raised in Chippewas of the Thames First Nation, Kelly has extensive experience in the area of lands and has graduated from the University of Saskatchewan's Indigenous Peoples Resource Management Program (IPRMP) and is a Certified Lands Manager. Kelly also has a background in Specific Claims and Treaty Research and is grounded in lands issues from a historical perspective. Due to his former political career, Kelly has practical intergovernmental affairs experience with First Nations, municipalities, and federal and provincial governments. Currently, Kelly works as the Director of the Treaty, Lands and Environment Department where he oversees and provides guidance to this multidisciplinary department.

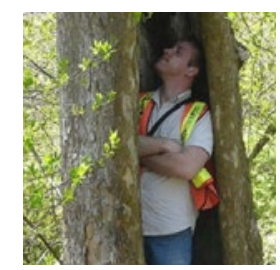

\section{Stefan Weber}

Carolinian Canada,

Restoration Biologist/Botanist

Stefan is a plant ecologist and horticulturalist with a keen interest in rare native plants, seed conservation and ecosystem restoration. In addition to his role with Carolinian Canada, Stefan is the director and co-founder of the Ontario Plant Restoration Alliance, a small not-for profit organization that helps create ex-situ 'Seed Conservation Orchards' to support the restoration of uncommon and threatened plants. Stefan is in the final writing stages of a PhD in Ecology at McMaster University, where he studies grassland restoration, invasion biology, and climate adaptation in wildflowers. He has also worked as a Botanist for the Toronto Botanical
Garden, the Biodiversity Institute of Ontario, and the St. Williams Ecology Centre. Stefan has propagated over 200 species of native plants from seed and curates several garden collections of these species in Norfolk County and Niagara region.

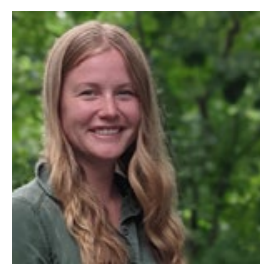

\section{Koral Wysocki}

ALUS, Partnerships Manager

(Former Program Director at Carolinian Canada)

Koral's engagement in conservation and community development internationally on several continents has rooted her strong understanding of the connections between respectful community interaction and transformative approaches to environmental restoration. In her role as Partnerships Manager at ALUS, Koral draws on these experiences to build effective networks of collaborators which support ALUS' portfolio of place-based projects. Koral is on the board of directors of the Global Institute of Forest Therapy (GIFT) and is a PhD candidate in Geography and Indigenous Health under the supervision of Dr. Chantelle Richmond at the University of Western Ontario. Koral is a Canadian settler of European descent based in Hamilton, Ontario and finds hope in work that moves us toward decolonised relationships with the places we call home. 


\section{Emma Young}

Chippewas of the Thames First Nation,

Senior Environment Officer

Emma is a Chippewas of the Thames First Nation (COTTFN) community member and works out of the Treaty, Lands and Environment Department as the Senior Environment Officer. Emma has a Bachelor of Arts Degree in Geography from the University of Guelph and is currently completing her Masters of Arts in Geography from the University of Toronto. Since joining the Environment Department, Emma has been involved in establishing a water monitoring regime, assist-

ing to complete a source water protection project with the Canadian
Environmental Law Association and has established a wide network of collaborative partners on environmental initiatives throughout COTTFN's treaty and traditional territory. A large part of Emma's work involves actively pursuing and creating opportunities for COTTFN that enhance the environment at both the community and broader territory level. 


\section{A Special Thanks}

This report and project was made possible through the collaborative vision, effort, and support of the Deshkan Ziibi Conservation Impact Bond Leadership Team (identified with photos and bios above). We would also like to thank other key contributors to the development of this report: Dr. Lara Liboni (Carolinian Canada), James Chan (VERGE Capital), Maya Ghandi (Ivey Research Team), Valeria Widjaja (Ivey Research Team), and Brennan Vogel (Chippewas of the Thames First Nation).

Additionally, we want to thank several other groups and individuals who have supported the broader co-development and implementation of the Deshkan Ziibi Conservation Impact Bond over the last two years. Many thanks to Leslee White-Eye (Chippewas of the Thames First Nation), Brandon
Doxtator (Oneida Nation of the Thames), Danielle Hill (Oneida Nation of the Thames), Anthea Rowe (3M Canada), Diane Piedade (3M Canada), and Adam Spence (SVX). Deep thanks to Chippewas of the Thames First Nation who hosted and enabled an ethical space of engagement for partners to come together for initial project discussions. Thank you to the Board of Directors of the Carolinian Canada Coalition, led by Chairs, Don Pearson and Dr. Dawn Bazely, and Treasurer, Chris Turner. Also, thank you to Jarmo Jalava, previous Director of Ecosystem Recovery, who fostered the direction of the DZCIB project. A big thank you to all our diverse DZCIB partners and dedicated team members who, despite the major challenges of a global pandemic, continued to advance and adaptively manage their commitments in the DZCIB. 


\section{LIST OF ABBREVIATIONS}

\begin{tabular}{|c|c|c|c|}
\hline ALUS & Alternative Land Use Services & Leadership Team & Deshkan Ziibi Conservation Impact Bond \\
\hline C & Celsius & & Leadership Team \\
\hline CAD & Canadian Dollar & LTVCA & Lower Thames Valley Conservation Authority \\
\hline \multirow[t]{5}{*}{ Carolinian Zone } & A popular name for Canada's southernmost & NGOs & Non-governmental organizations \\
\hline & ecoregion, also known as the Carolinian Life & Raven & Raven Indigenous Capital Partners \\
\hline & Zone, stretching form Windsor to Toronto. The & SIB & Social Impact Bond \\
\hline & technical name is Lake Erie Lowland Ecoregion & SDG & Sustainable Development Goal \\
\hline & (federally) or Region 7E3 (provincially). & TCFD & Task Force for Climate-related Financial \\
\hline Carolinian Canada & Carolinian Canada Coalition & & Disclosures \\
\hline CDOC & Community-driven outcome contracts & TNFD & Task Force on Nature-Related Financial \\
\hline $\mathrm{CIB}$ & Carolinian Canada Conservation Impact Bond & & Disclosures \\
\hline COTTFN & Chippewas of the Thames First Nation & TRC & Truth and Reconciliation Commission \\
\hline COP & Conference of the Parties & TTLT & Thames Talbot Land Trust \\
\hline DZCIB & Deshkan Ziibi Conservation Impact Bond & UN & United Nations \\
\hline EIB & Environmental Impact Bond & UNFCCC & United Nations Framework Convention on \\
\hline ESG & Environmental, Social, and Governance & & Climate Change \\
\hline ICE & Indigenous Circle of Experts & UNDRIP & United Nations Declaration on the Rights of \\
\hline \multirow[t]{2}{*}{ IPBES } & Intergovernmental Platform on Biodiversity & & Indigenous Peoples \\
\hline & and Ecosystem Services & USD & United States Dollar \\
\hline IPCAs & Indigenous Protected and Conserved Areas & VERGE & VERGE Capital \\
\hline IPCC & Intergovernmental Panel on Climate Change & WWF & World Wildlife Fund \\
\hline IUCN & International Union for Conservation of Nature & & \\
\hline \multirow[t]{2}{*}{ LCIB } & Long Point Walsingham Conservation Impact & & \\
\hline & Bond & & \\
\hline LDN & Land Degradation Neutrality & & \\
\hline
\end{tabular}




\section{EXECUTIVE SUMMARY}

\section{TIME TO SHIFT THE PARADIGM}

We are in the Anthropocene epoch, characterized by human activity detrimentally impacting the biosphere and shifting the state and functioning of the Earth system. Today's ecological crises of climate change and biodiversity loss are consequences of human activities placing demands on the environment that exceed the Earth's regenerative capacities.

Our current economic systems have not adequately accounted for the value of nature, and thus, do not sufficiently capture the impact and risks posed by environmental degradation. Additionally, worldviews that value nature above an exploitable resource and honour a relational value of nature are marginalized through our current ways of measuring economic value. There is a fundamental disconnect between the way nature is addressed in mainstream economics and the intrinsic life-sustaining value it provides. It is time to shift the paradigm on how ecosystems and ecosystem services are valued.

European Enlightenment ideology, spread through colonization, has influenced the philosophical foundations which Western society is built upon today. A human-centric focus on individualism justified the decoupling of humans from the rest of nature and pursuits such as industrialization and urbanization, which come at the expense of non-human forms of nature. A positive relationship exists between human connectedness with nature and favourable conservation attitudes and behaviours, making this anthropocentric disconnect hold implications for long-term sustainability.

Indigenous philosophies do not make the same distinction as Western philosophies regarding the value of nature. Indigenous worldviews of nature hold humans as equal in significance to other life forms which all exist in a harmonic and mutually life-sustaining balance. Through an Indigenous lens, the value of nature is relational and with this relationality comes an ethic of ecological stewardship. These underpinning philosophies support sustainability and conservation as is evident through Indigenous successes in environmental stewardship. Interweaving Indigenous and Western philosophies in a Two-Eyed Seeing approach is integral to reconciling the dissonance between largely Westernized societies and the ecosystems in which they are embedded.

Indigenous peoples have been living harmoniously with the land since time immemorial and sustainable development discourses have increasingly begun recognising the value and ethics of Indigenous ways of knowing and being. Given the cultural significance of connection to the land for Indigenous cultures and peoples, land dispossession and environmental degradation can be interpreted as colonial acts that have further separated Indigenous peoples from traditional sources of knowledge and culture. As part of Canada's broader commitment to truth and reconciliation and in accordance with its national conservation targets, investing in Indigenous-led conservation and collaborating through reciprocal restoration projects is integral to responding to our ecological crises and empowering the human-nature relationship. 
The field of conservation finance is emerging in response to many of the above issues as it provides mechanisms for realigning financial resources with the maintenance of the biosphere and incentives for achieving nature conservation and restoration outcomes. To effectively protect and restore habitat for ecological biodiversity, meet global conservation targets, and reduce atmospheric greenhouse gases through nature-based solutions, an estimated CAD \$741-\$1,021 billion is needed in annual funding over the next critical decade. Historically, public funding, grants, and transfers have been the primary sources of funding for conservation. Although these sources remain important, they do not currently provide enough funding, flexibility, or accountability to rapidly respond to the ecological crises and drive sustainable place-based projects. Thus, innovative financial instruments that mobilize alternative sources of capital are needed.

\section{THE CAROLINIAN CANADA CONSERVATION IMPACT BOND MODEL}

The Carolinian Canada Conservation Impact Bond (CIB) model was developed as a novel approach to conservation finance building on components of existing conservation funding models. The CIB model responds to the urgent need for piloting reconciliatory and cross-cultural ways of collaborating with Indigenous communities to diversify investment partnerships and redirect capital to conservation efforts that promote the regeneration of land and reciprocal and respectful relationships in southern Ontario.
The CIB is a financial instrument that facilitates cross-cultural collaboration by providing a common goal amongst a diverse set of sectors, partners, and worldviews to promote healthy landscapes and empower relationships between people and ecosystems. By leveraging financial incentives, this model aims to engage partners who may not have otherwise been attracted to conservation efforts. By tying financial returns to impact metrics of holistic landscape health that incorporate Indigenous worldviews and values of nature, this innovative instrument seeks to contribute towards shifting the conservation finance paradigm more broadly by engaging in the ongoing process of decolonizing the financialization of nature.

THE KEY PARTNERS IN THIS MODEL INCLUDE:

» First Nations Partners who help to co-develop the community-driven evaluation framework and implement the Two-Eyed Seeing approach while ensuring the CIB activities are beneficial to the holistic wellbeing of Indigenous communities and support the paths toward reconciliation and decolonization.

» Impact Investors who provide the upfront capital for the implementation of the Healthy Landscape Portfolio and receive a return on investment if the funded projects achieve the collectively agreed upon outcomes.

» Program Facilitator, in this case, Carolinian Canada, a non-profit conservation network that holds the prototype bond, manages cash flows, facilitates relationships among partners, and coordinates the habitat projects that align with the CIB objectives in the Healthy Landscape Portfolio. 
» Habitat Partners who implement habitat projects and on-the-ground ecosystem enhancement work based on agreements with the program facilitator. The impacts of these ecosystem projects are measured according to a predetermined community-driven evaluation framework which assesses social, ecological, and economic impacts.

" Outcome Payers who pay for the cost of implementing the Healthy Landscape Portfolio plus a premium if the projects achieve the collectively agreed upon outcomes.

» Research Team which helps co-develop the community-driven evaluation framework and study the financial model's efficiency in achieving beneficial social, ecological, and economic impacts.

\section{THE DESHKAN ZIIBI CONSERVATION IMPACT BOND}

Deshkan Ziibi Conservation Impact Bond (DZCIB) represents a five-year place-based project that began in 2019 to pilot the CIB financing model. The DZCIB pilot is engaged with 60 hectares (150 acres) of land in the Lake Erie Lowland Ecoregion (also known as the Carolinian Zone), Canada's southernmost ecoregion. The Carolinian Zone spans southern Ontario from Toronto to Windsor and includes the traditional territories of the Anishinaabe, Haudenosaunee, Lunaapeew, Wendat, and Attawandaron peoples.

The Carolinian Zone provides a unique setting in which to launch this project as it is home to many Indigenous $\mathrm{Na}$ tions, some of the country's most diverse flora and fauna, and approximately $25 \%$ of Canada's human population. The biodiversity potential of this region, coupled with large-scale human activities and Indigenous presence, represents an ideal space for the launch of a Conservation Impact Bond that is aimed at improving the coexistence among humans and ecosystems in the spirit and practice of reconciliation.

The DZCIB model presents five evaluation pillars that stand as guideposts for projects on the landscape and aim to track holistic impact. These include (1) connecting healthy habitats, (2) connecting opportunities, (3) connecting knowledge / circling and learning, (4) connecting our hearts and minds, and (5) connecting our bodies. Multiple metrics exist to evaluate the outcomes of each evaluation pillar; however, one pay-forsuccess metric was collaboratively selected for each pillar to be directly tied to defining project success, and consequently, outcome payer payment and investor return on investment.

The intent of the CIB financing model is to mobilize increased capital toward reversing the trend of habitat loss and accelerating the growth and long-term stewardship of healthy landscapes in the Carolinian Zone. Following the DZCIB pilot project, the goal is for the CIB model to scale to other regions within the Carolinian Zone and beyond. With scaling, the CIB seeks to preserve the essence of the bond, while remaining adaptable to local environmental conditions and community partner needs and priorities. To aid in the replicability of the CIB model, the five evaluation pillars contain multiple potential pay-for-success metrics that may be selected to tailor the outcomes of the bond to local community and environmental needs while remaining consistent with the five categories of holistic impact. 


\section{WHAT IS IN THIS REPORT?}

This report is presented in two parts. Part one serves to contextualize the development of the CIB model by providing foundational insights that led to the creation and design decisions for the CIB. Part one introduces the global ecological crises from an Earth system science perspective before exploring the philosophical roots that are suspected to have contributed to the crises. It then provides an overview of commitments made to the climate and biodiversity crises as well as Indigenous Nations, both internationally and in Canada. It then introduces the field of conservation finance and the conservation funding gap, emphasizing the need for an enabling regulatory environment and innovative tools to mobilize increased capital to fill this gap.

Part two of the report details the design, development, and implementation of the Carolinian Canada Conservation Impact Bond model and Deshkan Ziibi CIB pilot project. It begins by introducing the CIB model and Carolinian Canada's Healthy Landscape Strategy. It then dives into the case of the DZCIB pilot project including topics such as the co-development process, guiding principles, planning and implementation, ongoing process of impact evaluation, and future vision and goals.

This report intends to capture the design and early implementation phase of the DZCIB. It seeks to tell the story of the DZCIB project to date and share this collaborative and innovative approach with others who may be interested to learn more or are keen to implement a similar model in their own settings. Lessons learned from this pilot project will serve to support the design and implementation of future CIB projects in different regions. 


\section{PART 1 FOUNDATIONS}

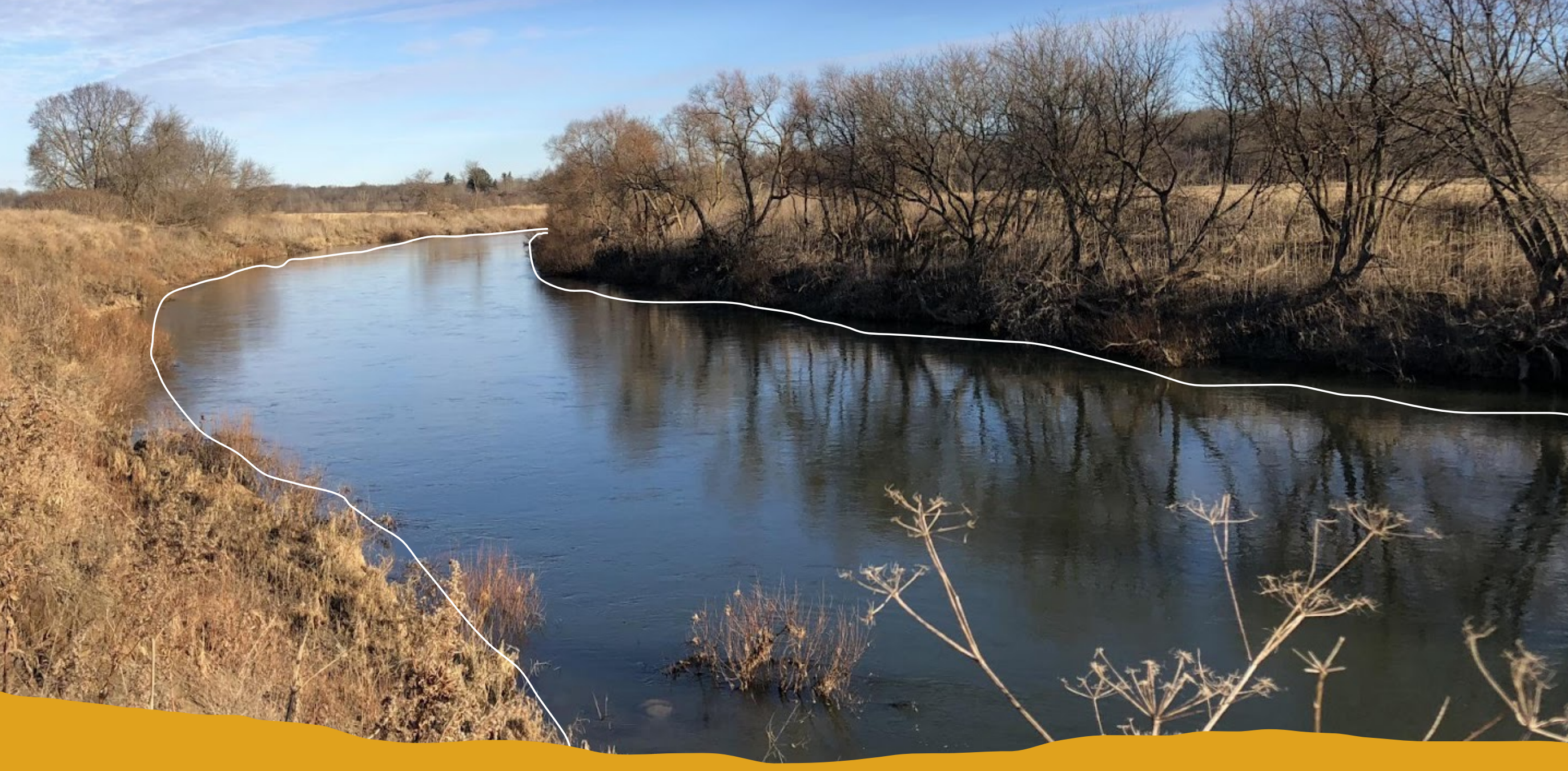




\section{Time to Shift the Paradigm}

\section{The Urgency of the Biodiversity and Climate Crises}

Biodiversity loss and climate change are the two most urgent issues for human societies in the Anthropocene..$^{15}$ The Anthropocene, defined as the current geologic epoch during which humans and human societies became a global geophysical force ${ }^{16}$ represents a fundamental shift in the state and functioning of the Earth system beyond the range of variability of the last 10,000 years of the Holocene epoch.17, 18

Since 1970, humanity's Ecological Footprint has exceeded the Earth's rate of regeneration, also referred to as biocapacity. ${ }^{19}$ Biocapacity is the underlying currency of all living systems on Earth; ${ }^{20}$ it supports humanity's economies, societies, and institutions, and regulates the environmental conditions that make human and much non-human life possible. Currently, humanity's Ecological Footprint exceeds Earth's biocapacity by $56 \%{ }^{21}$
Research over the last decade has sought to identify a "safe operating space for humanity." 22,23 This research has led to the development of the planetary boundaries framework (See Figure 4), which outlines nine biophysical thresholds within which humanity is expected to be able to safely operate..$^{24,25}$ As of today, four of nine interlinked planetary boundary thresholds have been exceeded: biosphere integrity, climate change, land-system change, and biogeochemical flows. ${ }^{26}$ 
PART 1 FOUNDATIONS

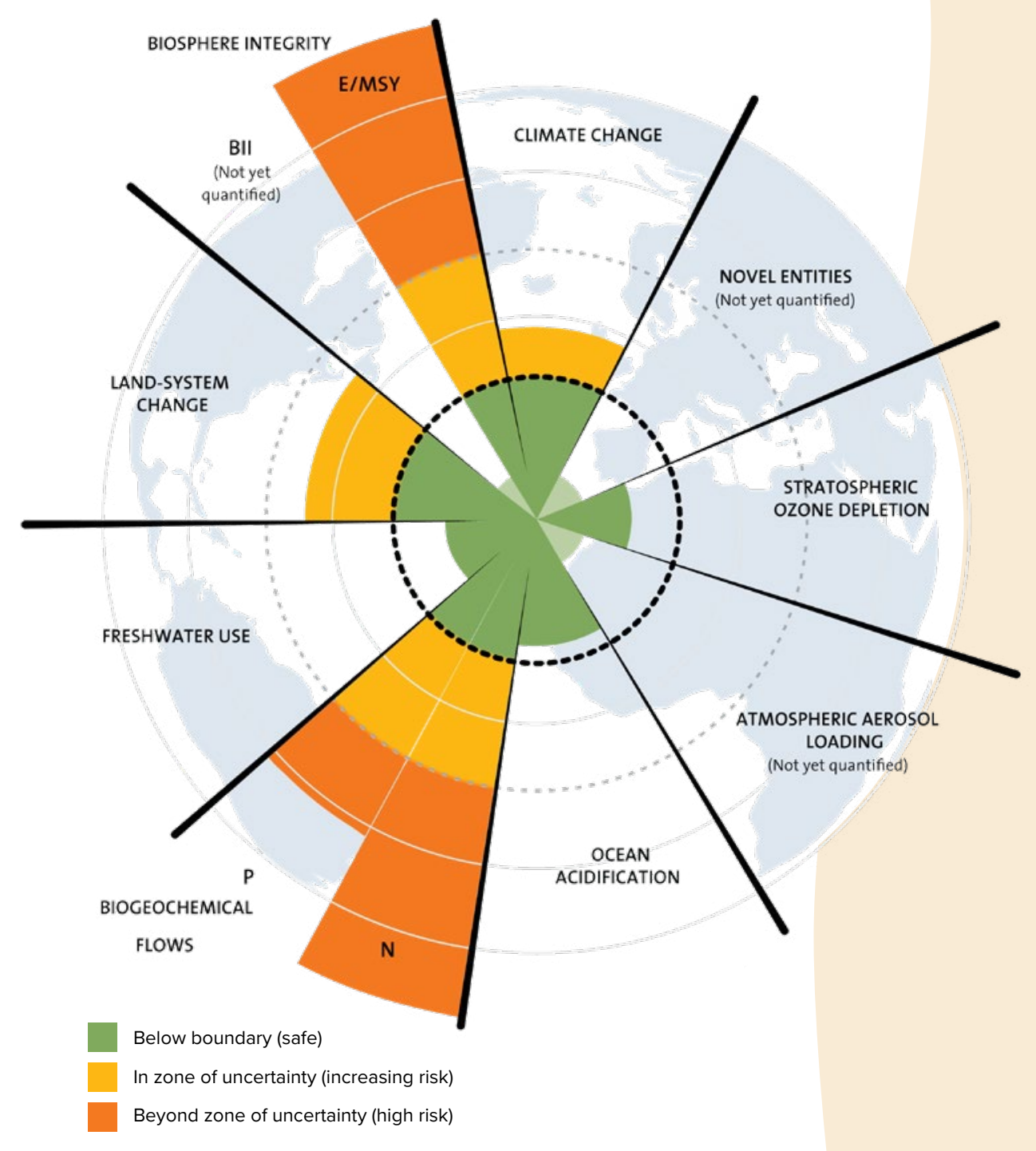

The Biosphere and Biodiversity

The biosphere is the zone of the Earth that is capable of supporting life..$^{28}$ Living organisms, humans, human societies, and economies (a social/cultural artifact of human societies) are embedded within the biosphere. The biosphere is a regenerative entity made up of living systems, or ecosystems, consisting of living, biotic, and non-living, abiotic, features. ${ }^{29}$ Wetlands, coral reefs, mangrove forests, agricultural fields, fisheries, lakes, and oceans are all examples of ecosystems. Each ecosystem is more than the sum of its parts and plays a critical role in maintaining the biosphere's ability to support life forms through diverse services including nourishment, security, nurture, and resilience.

Ecosystems are interconnected and have strong interactions among their

own biotic and abiotic constituents and weaker interactions with the constituents of other ecosystems; the loss or fragmentation of any component of an ecosystem affects the entire living system. ${ }^{30}$

Biological diversity, or biodiversity, is defined as the variability among living organisms from all sources and at various levels including genes, species, and ecosystems. ${ }^{31}$ Reductions in biodiversity disrupt biosphere processes and hold the strong potential to alter the functioning of ecosystems and the goods and services they provide to humanity. ${ }^{32}$ Increased biodiversity within ecosystems can increase average rates of productivity, nutrient retention, resilience, and adaptability. ${ }^{33}$

Figure 4: The Planetary Boundaries ${ }^{27}$

FIGURE CREDIT: J. LOKRANTZ/AZOTE BASED ON STEFFEN ET AL. 2015.

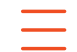


PART 1 FOUNDATIONS

In the last century, thousands of populations of critically endangered vertebrate animal species have been lost, indicating a sixth mass extinction caused by human activity. ${ }^{34}$ The Living Planet Index shows that from 1970 to 2016 populations of mammals, birds, amphibians, reptiles, and fish have decreased an average $68 \%{ }^{35}$ This rapid and accelerating loss of biodiversity has severe implications for society through the degradation of life-supporting systems. ${ }^{36}$

Additionally, more than 11,000 climate scientists from around the world have declared that planet Earth is facing a climate emergency. ${ }^{37}$ The concentration of carbon in the atmosphere has exceeded 415 ppm, beyond the 280 ppm that categorised the atmospheric concentration of the $18^{\text {th }}$ century, and the 350 ppm that has been identified as a 'safe' concentration in the planetary boundary framework. ${ }^{38,39}$ The current global atmospheric concentrations of carbon dioxide and other greenhouse gases including potent methane and nitrous oxide, are unprecedented in at least the last 800,000 years. ${ }^{40}$

From biosphere integrity to climate change and beyond, the implications of surpassing our planet's safe operating thresholds are already being experienced around the world in a range of ecological and health impacts including, but not limited to: increased intensity and frequency of extreme weather events such as heat waves, extreme precipitation, flooding, and fires; sea-level rise; altered crop growth; ocean acidification; and a pandemic linked to wildlife trade. ${ }^{41,42}$ Returning each of these boundaries to a safe operating space is critical to reduce the impact of further catastrophic events and avoid crossing ecological thresholds that trigger non-linear and abrupt changes in the Earth system. ${ }^{43}$
The climate and biodiversity crises are deeply intertwined issues sharing the common drivers of human activities. ${ }^{44}$ On the one hand, climate change is altering the function of the Earth system which is adversely affecting biodiversity, ecosystems, and the human societies dependent on them. On the other hand, human-induced changes in ecosystems and biodiversity impacts biosphere processes such as the carbon, water, and nitrogen cycles, which in turn affects the climate system. ${ }^{45}$ Therefore, resolving either one of these crises requires consideration of the other and the agencies of human activities to reduce detrimental ecological impacts.

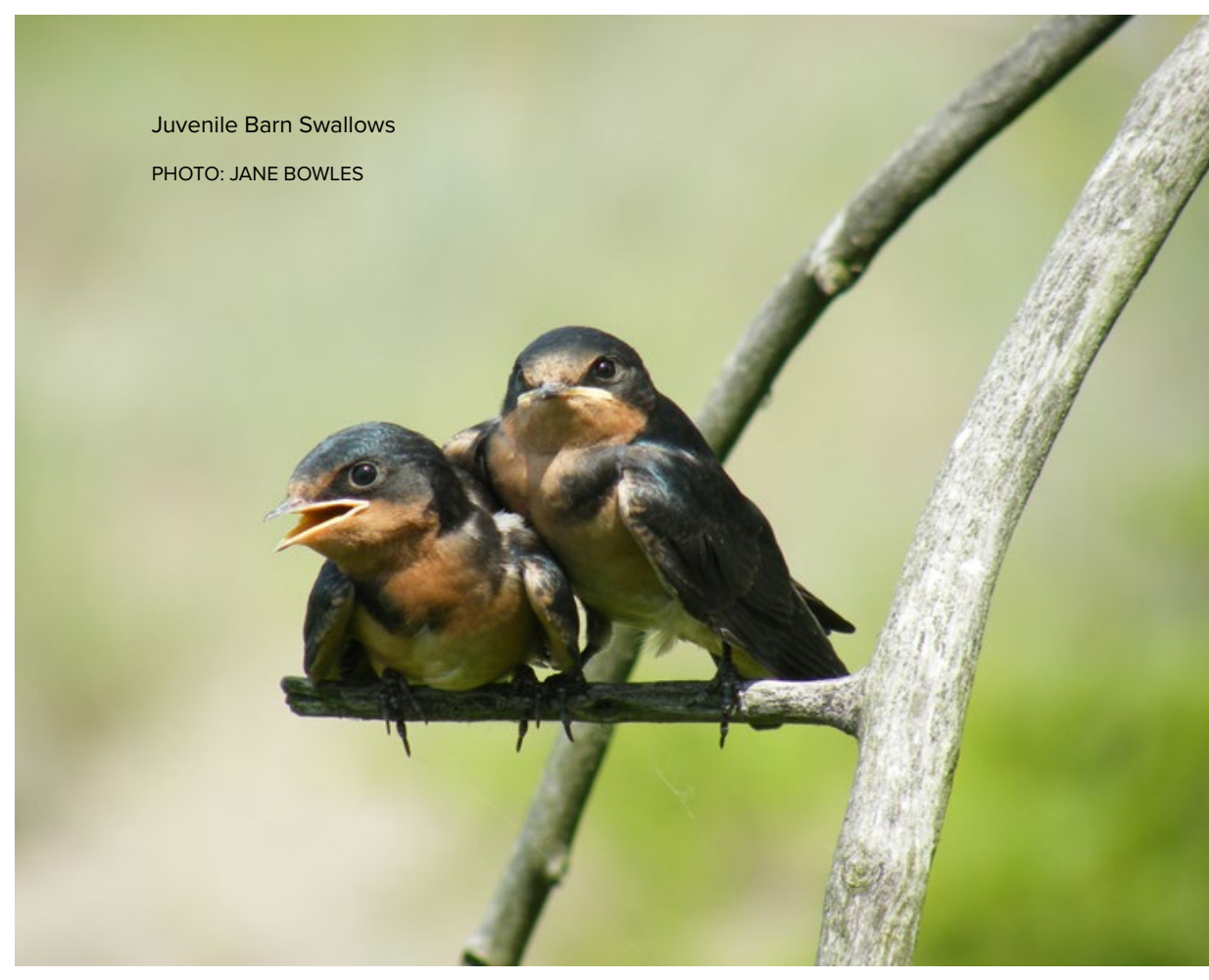

CHAPTER 1 I TIME TO SHIFT THE PARADIGM 


\section{The United Nations' Decade on Ecosystem Restoration ${ }^{46}$}

The UN Decade on Ecosystem Restoration runs from 2021 through 2030 , aligning with the timeline scientists have identified as the last chance to prevent catastrophic climate change and the deadline for the Sustainable Development Goals. The UN Decade on Ecosystem Restoration "is a rallying call for the protection and revival of ecosystems all around the world, for the benefit of people and nature. It aims to halt the degradation of ecosystems and restore them to achieve global goals. Only with healthy ecosystems can we enhance people's livelihoods, counteract climate change, and stop the collapse of biodiversity."

\section{Transforming how Societies and Economies Value Nature}

Since 1950, humanity has made notable achievements in material prosperity; the average life expectancy at birth was 43 years in 1950 and is now approximately 76 years, the proportion of the global population living in absolute poverty has decreased from $60 \%$ in 1950 to less than $10 \%$, and globally measured economic activity has increased 13 -fold in the past 70 years. ${ }^{47}$ Since 1970, the global human population doubled, the extraction of living materials from nature tripled, and economic indicators, such as Gross Domestic Product (GDP), quadrupled. ${ }^{48}$
The macroeconomic models which were developed during this time focused on produced capital (including roads, machines, infrastructure, buildings, and ports), and human capital (including skills, health, and education). ${ }^{49}$ Unfortunately, these models fail to adequately factor in environmental sustainability, ${ }^{50}$ and despite shifting circumstances, they have for the most part continued to operate as the engines informing the decisions made by policymakers, international organizations, and corporations. This has resulted in the prioritization of short-term economic growth and disguised the consequential losses suffered by our biosphere.

A third type of capital, natural capital, has historically been largely excluded from mainstream economic systems. 


\section{PART 1 FOUNDATIONS}

Natural capital refers to the planet's renewable and non-renewable resources (e.g., plants, animals, air, water, soils, and minerals) that collectively provide flows of goods, services, and other contributions to people that are wide-ranging and diverse. ${ }^{51}$ For example, some of the many benefits that trees provide include air filtration, greenhouse gas sequestration, reduced risk of flooding, biodiversity support, genetic resources, and social, cultural, and spiritual value. ${ }^{52}$ The collective benefits provided by natural capital and their processes are known as ecosystem goods and services. These benefits are also referred to as the positive aspects of "nature's contributions to people" which is a term that encompasses all contributions of nature, both positive and negative, to the quality of life for people. ${ }^{53}$

Natural capital is foundational to supporting all other forms of capital. It provides the resources with which economies, societies, and institutions are built and regulates the environmental conditions that make human life possible. ${ }^{54}$ Therefore, as natural capital erodes, economies, societies, institutions, and human lives are threatened.

From 1992 to 2014, globally produced capital per capita has doubled, human capital per capita has increased by approximately $13 \%$, but natural capital per capita has declined by nearly $40 \%$ (See Figure 5). ${ }^{55}$

Produced capital has grown in large part through the degradation and exploitation of natural capital. This has taken our planet beyond its boundaries and there is now an urgent need to invest in adaptation, conserve remaining natural capital, and enhance degraded natural capital.

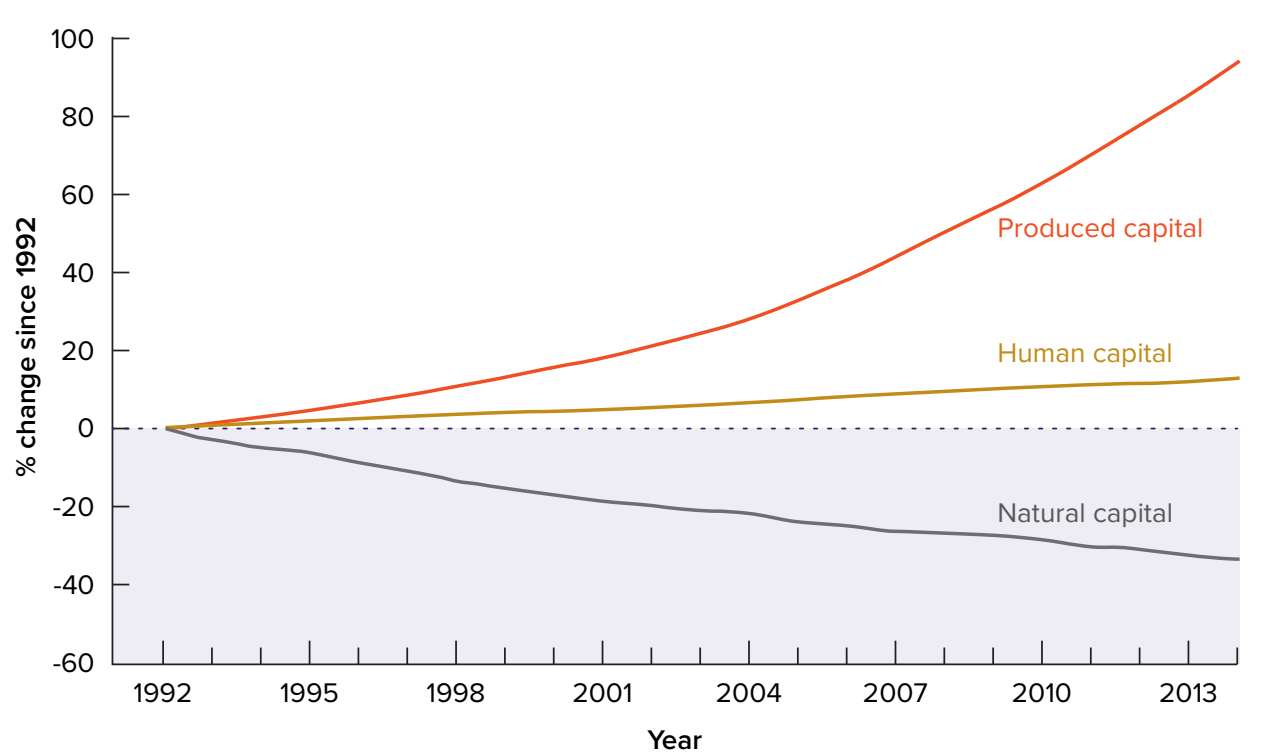

Figure 5: Global Wealth per Capita, 1992-2014 ${ }^{56}$

Investing in natural capital can offer a "triple dividend". ${ }^{57}$ The first dividend is loss avoidance from protecting infrastructure and communities from extreme weather events such as floods, storms, and heatwaves. The second dividend is economic gains from the creation of jobs to restore and protect nature, reducing risk, increasing food and water security, increasing productivity, increasing tourism and recreation value, and driving innovation. The third dividend comes from the numerous associated social and environmental benefits including cleaner air that improves human health, more habitat for endangered species, and climate change mitigation. ${ }^{58}$ Additionally, compared to produced capital, natural capital investments tend to 


\section{PART 1 FOUNDATIONS}

be more cost-effective, more sustainable in the long-term, and increase in holistic value over time as ecosystem productivity rises. ${ }^{59}$

Changing how economic "success" is measured and accounting for nature in decision-making serves to shift the paradigm and foster more sustainable and regenerative decision-making and practices. Language is fundamental in this shift. There is a mismatch between "economic grammar," which drives public and private policy, and "nature's syntax," which determines how the biosphere, and its life-sustaining processes, operate. ${ }^{60}$ This means that economic decision-makers are often unable or unwilling to understand and act on what biologists, conservationists, social scientists, and Indigenous communities are saying. This shift in language regarding nature needs to be seen in our economic systems, education systems, boardrooms, international negotiations, and beyond. Significant shifts will be a result of conversations and actions that move beyond the nature-economy capitalistic dualism to a relational ontology that reflects profound connections between humans and nature. ${ }^{61}$

"There is no choice but to transform how economies and societies value nature. We must put the health of the planet at the centre of all our plans and policies. The economics are clear."

Antonio Guterres, UN Secretary-General ${ }^{62}$

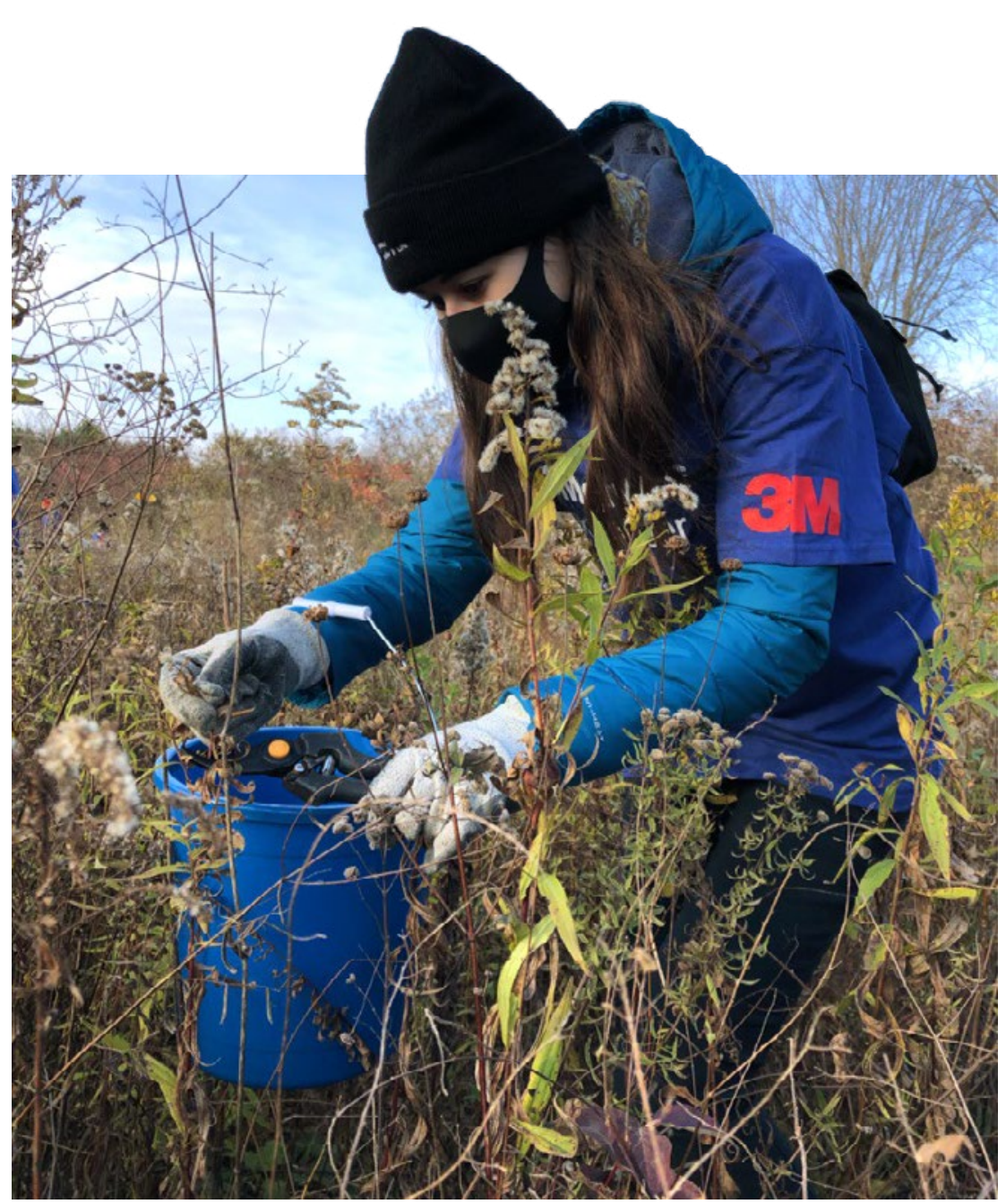

$3 \mathrm{M}$ volunteers collecting native seeds at Hawk Cliff Woods.

PHOTO: ANTHEA ROWE 


\section{KEY TAKEAWAYS}

\section{Time to Shift the Paradigm}

We are in the Anthropocene epoch, where human activity has become a global geophysical force capable of affecting the state and functioning of the Earth system.

The Earth's planetary boundaries have been exceeded and human societies are continuing to place demands on the Earth that exceed its biocapacity.

Current economic systems focus on human and produced capital, missing a key third component, natural capital.
It is possible to return to a safe operating space for humanity by responding to Earth system science, embedding economic models within the biosphere, and shifting our relationships with nature.

1) A fundamental mismatch between "economic grammar" and "nature's syntax" needs to be addressed. 


\section{On the need to Decolonize Relationships with Nature}

\section{Embarking on a Decolonizing Journey}

Exploiting, monetizing, and profiting from nature are Western economic concepts rife with colonial undertones. The capitalist perspective of prioritizing profits over the long-term stewardship of the Earth's life support mechanisms, a dominant perspective engrained in societies based on Western values and colonial ontologies, conflicts with Indigenous worldviews. By making the case for environmental protection and incorporation of Indigenous perspectives and values, the Deshkan Ziibi Conservation Impact Bond (DZCIB) provides an entry point for improving the valuations of nature while creating collaborative spaces for integrating Indigenous worldviews into the allocation and valuation of capital in ecosystem conservation efforts.
Since a foundational goal of colonization is to dispossess Indigenous peoples from their traditional territories and disrupt their relationships to land, ${ }^{63}$ processes of decolonization require active disengagement from colonial dispossession and exploitation to support strengthened connections to land. This includes promoting opportunities for cultural revitalization through access to land for traditional practices, ceremony, and land-based learning. Flows of capital can also play a role in decolonization through the realignment of investment capital to serve the broader goals of Indigenous communities, ${ }^{64}$ including conservation and the sustainability of shared environmental resources.
The DZCIB seeks to participate in a process of decolonization through strengthening ecosystem health, reconnecting Indigenous and non-Indigenous peoples with their ecosystems, building new relationships, and redistributing capital towards these shared goals. Thus, although the idea of placing monetary value on nature is one derived from a colonial and Western economic view of nature, this model aims to broadly integrate Indigenous perspectives into the creation, implementation, and impact evaluation processes that can in turn contribute to the broader process of decolonizing the financing of conservation, while promoting reconciliation and improved sustainability outcomes. 
PART 1 FOUNDATIONS

"Building strong relationships of reciprocity with the land results in the crumbling of settler capitalism because it fundamentally shifts the relationships people experience and what they believe about who they are, how they are in relation to and with land, and what they believe to be true."

Erin Freeland Ballantyne ${ }^{65}$

\section{The Legacy of the European Enlightenment on Human Relationships with Nature}

How has society arrived at a point of environmental degradation that threatens the health of our biosphere and all life within? To understand this, one must consider the Western philosophies which underpin many contemporary societal structures and systems. The anthropocentric, or human-centric, Western perspective is largely engrained in the collective consciousness influencing human values, which in turn shape the ways in which humans interact with nature. ${ }^{66}$ Over the course of the European Enlightenment period, also referred to as the "Age of Reason", that occurred from the late 1600 s to early 1800 s, European politics, philosophy, science, and communications were radically reoriented. ${ }^{67}$ Enlightenment ideology, despite its merits in advancing Western philosophy, literature, art, and science, is also a culprit of decoupling humans from other forms of nature. A focus on empiricism, rationalism, and humanism was characteristic of the period of European Enlightenment. During this time, philosophers shifted their primary concern from looking at nature, to understanding the human process of looking at nature. ${ }^{68}$ This shift separates the humans, as the observers, from the rest of nature, as the observed.

During the European Renaissance and the following Enlightenment period, the philosophical movement of humanism was pivotal. Humanism placed emphasis on the human being. The value of the individual and the role of a human being as the source of reason were foundational thoughts influencing society and culture. Inspired by thought and literature from antiquity, the humanism movement of the Enlightenment strived for the intellectual autonomy and independence of human beings. ${ }^{69} \mathrm{~A}$ human-centric focus on individualism cognitively separates humans from the rest of nature which serves to justify the exploitation of the natural world for social gain, such as through the pursuits of industrialization and urbanization, which come at the expense of non-human forms of nature.

Product of the philosophical separation of human and non-human forms of nature, a contemporary Western worldview holds a set of assumptions regarding nature that justify its exploitation for economic progress. These assumptions include the ideas that: nature is composed of inert, physical elements; nature can and should be controlled and transformed by humans seeking private economic gain; and we must progress, notably in the form of economic development. ${ }^{70} \mathrm{It}$ is important to note these beliefs regarding nature are presented in this report, not because the authors believe they are explicitly correct or incorrect, but because it is important to understand the philosophical foundations and core beliefs of Western 
PART 1 FOUNDATIONS

society which have contributed to the perilous position of the biosphere and the life within it.

The Industrial Revolution exemplifies the unsustainable practices that emerge from the decoupling of humans from the ecosystems in which they are embedded. Philosophies stemming from the Industrial Revolution emphasize the pursuit of self-interest as a regulating force that will allow the market to operate freely. ${ }^{71}$ The presumed material abundance that industrialization would provide made it a vehicle used by societies to amass wealth. However, the ecological crisis displays that the Industrial Revolution was not an escape from the physical limits of the ecosystems in which economies are embedded, but a temporary replete from scarcity driven by finite fossil fuel stocks. ${ }^{72}$ While demand is slowly shifting towards more socially and environmentally conscious products and decision-making, the mass consumerism and productivism that came in the early $20^{\text {th }}$ century persists. Economic theory's emphasis on short-term economic growth independent of finite resources demonstrates the unsustainability of a decoupled relationship between humans and nature.

"We are approaching our planetary limits in carrying capacity in part because our modern worldview provides a set of beliefs that encourages us to use and abuse nature."

Deborah Du Nann Winter ${ }^{73}$ connections between nature, biodiversity, and ecosystem services in realizing human health and well-being benefits. ${ }^{74}$ In addition to its social benefits, connectedness with nature is also important due to its role as a motivator for environmentally responsible behaviour. ${ }^{75}$ Thus, increasing levels of human connectedness with nature has positive implications for both social and ecological well-being. Targeting youth contact and connection to nature is especially important since exposure to nature in one's youth is identified as a pre-condition for care of nature and pro-environmental behaviour later in life. ${ }^{76}$ Product of urbanization, children are increasingly growing up in urban environments with less opportunities for exposure to nature. Healing the relationships between humans and nature is integral to the social and ecological health and well-being now and for future generations.

\section{Embracing Indigenous Worldviews and their Relational Approaches to} Nature

"The future of our planet lies in Indigenous ways of living on Earth... As a global community, we have lost our way; we forgot what it means to have a relationship with the land."

Reconnecting humans with nature is an integral component of responding to the socio-ecological crises due to the

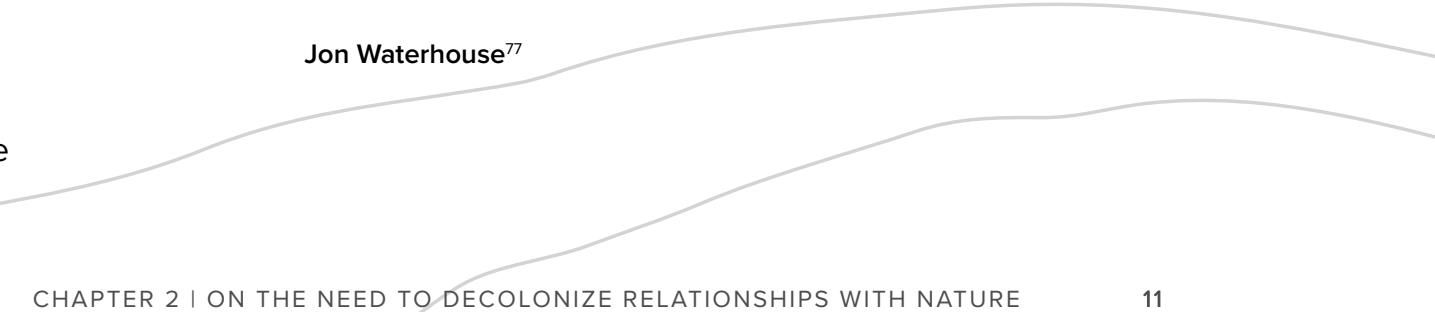




\section{Anishinaabe Prophecy of the Seven Fires}

The Anishinaabe peoples have the prophecy of Seven Fires. Seven prophets came with guiding words to the Anishinaabe regarding their future. The prophet of the First Fire told the Anishinaabe peoples to travel west to find the island that was shaped like a turtle, a symbol of purification. The prophet of the Second Fire told the Anishinaabe people that they would lose their way and be guided back on the true path. The prophet of the Third Fire reassured the Anishinaabe peoples they would be led to the land that had been prepared for them. The prophet of the Fourth Fire came in two forms bringing news of interaction with 'light-skinned peoples' (the settlers). First, they were brought news that the light-skinned peoples would bring brotherhood, shared knowledge, and mutual greatness. The second prophet of the Fourth Fire came to demonstrate the two-facedness of the light-skinned peoples and warned of greed and deception. The prophet of the Fifth Fire warned the Anishinaabe peoples that the lightskinned people were conflicted and struggling with their spirits. They were warned of a promise of salvation that would lead to great loss for future generations. The prophet of the Sixth Fire showed the Anishinaabe peoples the promise of salvation was false and brought destruction to those that strayed from their traditional teachings. The prophet of the Seventh Fire warned of a time when the Earth would grow sick and die, threatening all life. There would be some who, turning back to their traditional teachings would become strong again. Now, the world is at a crossroad. If we choose the right path, the Seventh Fire will ignite an Eight Fire of unity and peace. If the wrong path is chosen, and we remain in our current dominant mindsets of destruction, great suffering and death will ensue. ${ }^{78}$
Indigenous views of nature stem from an ecocentric understanding of the natural harmonic balance of all nature and the role of humans living within this rhythm and natural balance as a part of nature, as opposed to being separate from it. The cohesive balance of nature does not only exist across life forms, but also possesses a temporal element. One of the core values of the Haudenosaunee peoples is the Principle of Seven Generations, ${ }^{79}$ which involves taking into consideration and planning ahead for the seven future generations when considering the impacts associated with making present decisions.
This cultural value is an example of Indigenous philosophy which considers the connected relationships to others in the past, present, and future, as integral to sustainability. Relationships are multidirectional forces; just as one's existence is the continuation of life force from past ancestors, one possesses present responsibility of pushing the life force into the future in a positive and sustainable direction. The notion of sustainability and stewardship is engrained in Indigenous views of nature and the ways in which Indigenous peoples engage with their broader relations, including the natural environment. 


\section{The Success of Indigenous Land Management}

Indigenous-managed lands include some of the world's most biodiverse areas $^{80}$ and have been found to hold as high or higher rates of vertebrate biodiversity than compared to government-designated conservation land. ${ }^{81}$ Indigenous territories hold $80 \%$ of the planet's remaining biodiversity ${ }^{82}$ despite comprising only $22 \%$ of the world's land surface. Most Indigenous Peoples in Canada have long histories of sustainable coexistence within their territories. ${ }^{83,84}$ As a result, the recognition of the effectiveness of Indigenous-managed lands in sustaining ecosystem health has been growing around the world. ${ }^{85}$

In addition to successes in conserving biodiversity, Indigenous land management has also been found to increase community well- being scores. ${ }^{86}$ This displays the interconnectedness of ecological and social systems and the importance of co-existence in the health of human and non-human forms of nature.

Culture plays a key role in the relationships between human and non-human forms of nature and the successes of Indigenous conservation highlight the importance of reconnecting people and ecosystems and bringing Indigenous knowledge and land autonomy to the forefront.
An Indigenous worldview of nature regards the relationship between forms of nature as lateral. Although Indigenous communities around the world vary in dimensions of culture and philosophy, many share the perspective that humans, plants, and animals possess no ontological differences. ${ }^{87}$ This philosophy is also supported by the notion of "land as kin" and the Anishinaabe core principle that everything is related. Another interconnected principle is that of spirit - a life force or energy that lives in and links all things, including all forms of life in the past, present, and future. One's relationship with nature holds implications for sustainable interactions with nature. A kinship relationship with nature implies a moral obligation leading to an emotional affinity to nature and conservation ethics. ${ }^{88}$

Indigenous worldviews and experiences of nature contrast with the views of nature dominant in the Western world, which view the relationship between forms of nature as more hierarchical, ${ }^{89}$ with humans at the top. From these diverging worldviews of nature, one can understand how this would inform different values of and interactions with nature. A Western perspective, which holds humans above other animals and plants in a hierarchical form, may be able to justify the exploitation of other forms of nature for human gain. Such exploitation would not be supported by an Indigenous worldview of nature which equates humans with other life forms (See Figure 6). 


\section{EGO}

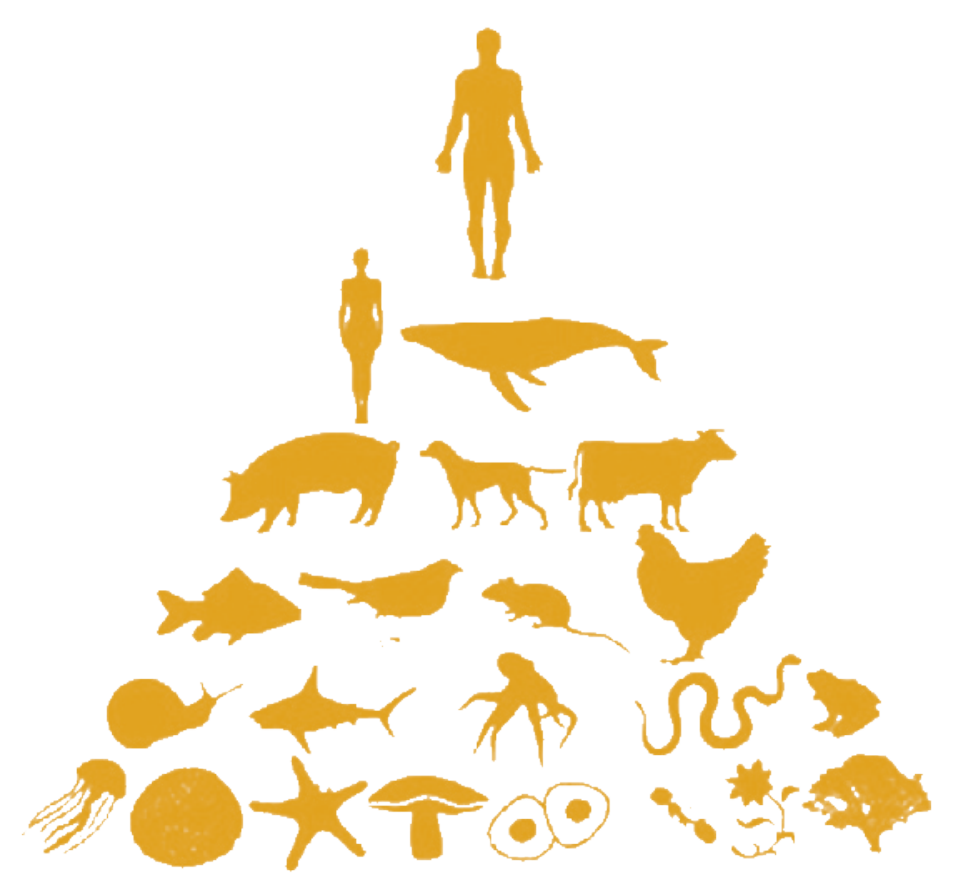

$\mathrm{ECO}$

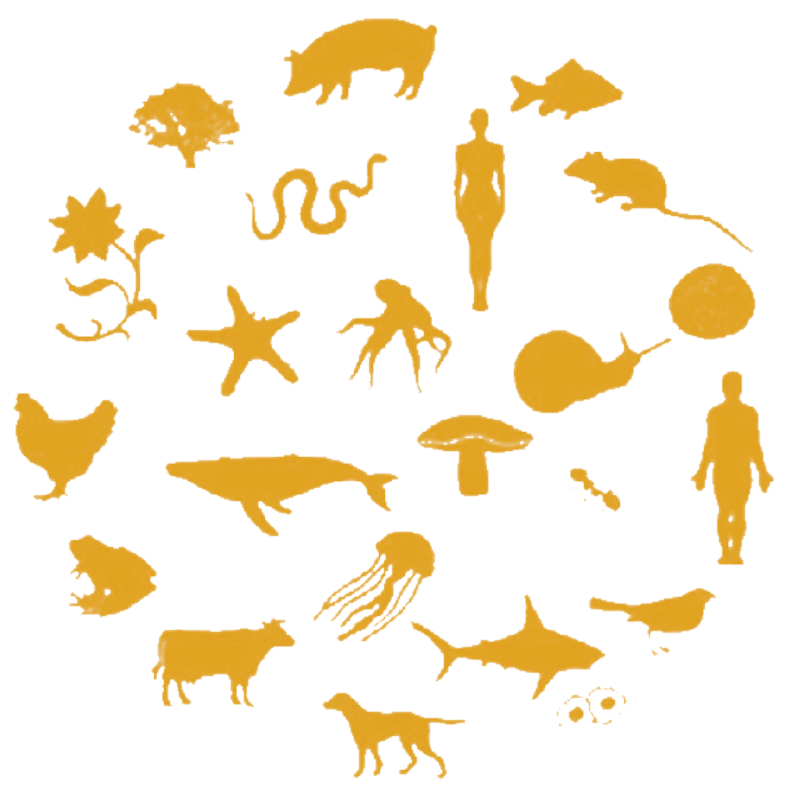

Figure 6: 'Ego-Eco' Diagram: Humankind is Embedded in the Ecosystem, not apart from it nor above it ${ }^{90}$ 


\section{PART 1 FOUNDATIONS}

Cree Elders teach the importance of relationality to supporting all life forms. Two concepts of this relationality include Wicihitowin and Wahkohtowin ${ }^{3}$. Wicihitowin refers to a life-giving energy that comes when people face each other as relatives, build trust, and engage in respectful ways. Wahkohtowin refers to kinship relationships and teaches one to extend one's relational networks to include non-humans. As humans, we are reminded that we are embedded in and surrounded by a series of life-sustaining relationships with and within the natural world. These concepts promote ethical relationality ${ }^{91}$ which is an understanding of the connectivity of living things, the significance of the relationships one has with others, how our histories position us in relation to others, and how our futures are interwoven. As humans, we are called to remember our roles in relation to our non-human relatives that live among us and to think and act in ways which respect those relationships. Ethical relationality is not about sameness between forms of nature, but a responsibility to recognize one's responsibilities to all one's relations. ${ }^{92}$

"Human beings are not above nature or above the rest of the world. Human beings are incomplete without the rest of the world. Every species needs to give to every other species in order to make up a universe."

Vine Deloria et al. (1999) ${ }^{93}$

This understanding of cooperative relationships between humans and non-humans is important to support the harmony

3 The authors want to acknowledge that in the Cree language, these words have more complex significance than can be translated into the English language due to the active verb-based nature of the Cree language.

\section{Embracing a Wide Diversity of \\ Human-Nature Relational Models}

The value placed on nature and ecosystems varies depending on who is valuing and why they are valuing. Nature valuation approaches are largely influenced by and based on assumptions associated with the specific lenses through which human-nature relations are perceived..$^{95}$ In order to appreciate and understand the importance of pluralistic valuations of nature, it is important to reflect, collectively and as an individual, on one's worldview and hu-

\section{man-nature relational lens.}

Each individual brings their own lens to observing their internal and external world. One's life experiences, worldviews, moral philosophies, and beliefs shape the ways in which one perceives and engages with one's internal and external environments. These different cognitive frameworks, that exist all around the world, lead to a wide diversity of ways of knowing, seeing, and being. 
Embracing a Wide Diversity of Human-Nature Relational Models

CONTINUED
"Putting a monetary value on the environment...that is challenging for us because we see nature as a relation or a family member. You would not put a monetary value on your sister or your mother."

Emma Young, Chippewas of the Thames First Nation

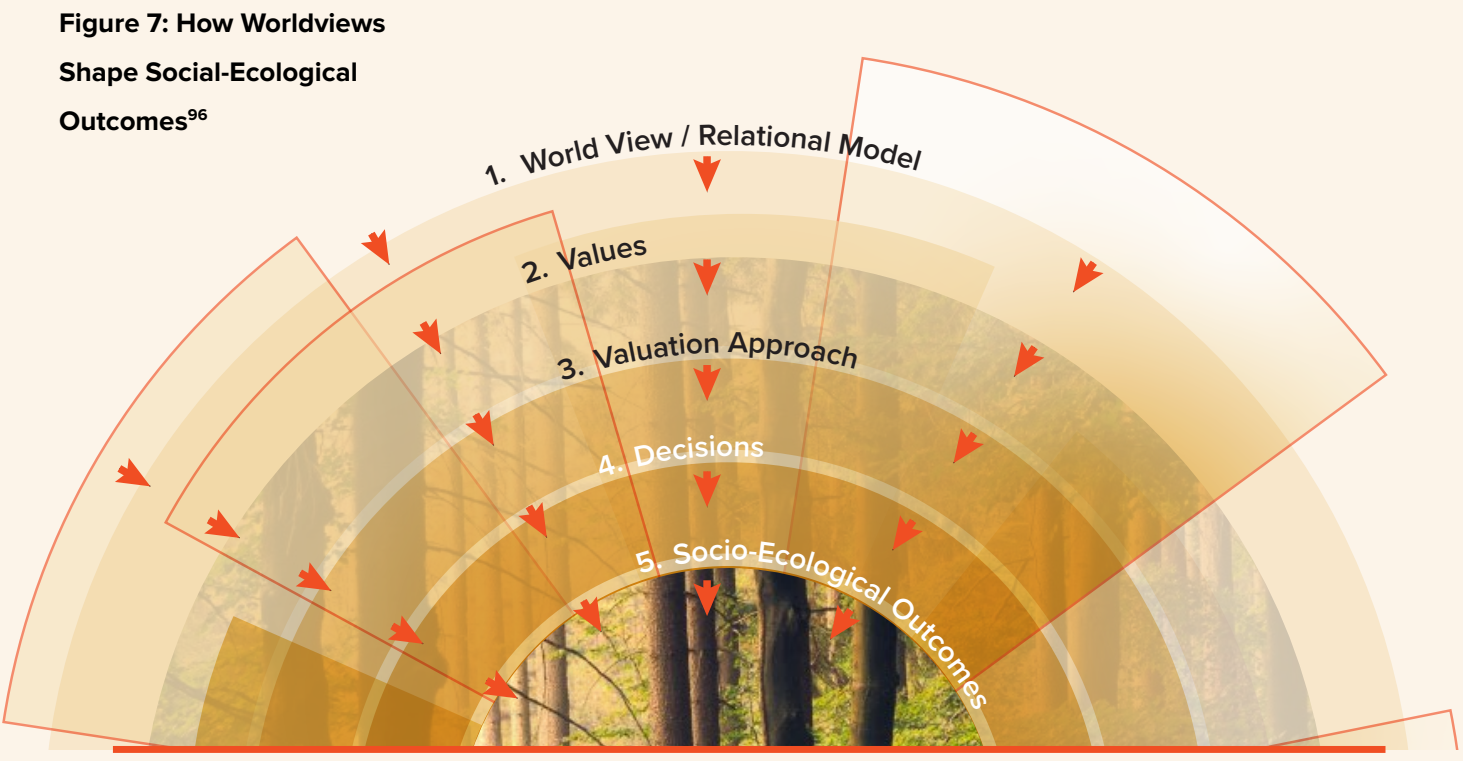

Figure 7: How Worldviews

cial-Ecological

It can be intuitively understood that the more one values nature, the more likely one is to respect, engage with, and care for nature. However, what humans and organizations value, and how that value is interpreted, is not uniform and can change over the course of time.

For some, nature is a place they turn to find solace and escape from their busy lives; for others, a place to engage in recreational activities; an energizing reconnection to source; a stock of free resources; a beautiful sight; a sacred gift; something to pay gratitude towards for supporting their life another day; a dangerous wilderness waiting to be tamed; a deep connection to past ancestors that have walked the land before and future generations to come. For others still, the concept of 'nature' external to oneself does not exist as they are so deeply connected to their internal and external environments that a distinction between human self and nature cannot be conceived. For many, sentiments from several of the aforementioned statements hold true. ${ }^{98}$

Through reflecting on, sitting with, and committing to understand the stories, life experiences, and beliefs that influence the multiplicity of human-nature relational models on our Earth, it becomes clear that these relational models rest at the core of many socio-environmental conflicts today and throughout history. shaping valuation processes. Many Indigenous peoples, for example, reject the notion of placing a monetary value on nature. ${ }^{97}$ 


\section{On the Need to Decolonize our Relationships with Nature}

» Western philosophy since the European Enlightenment has created a misguided belief in the supremacy of human beings over other life forms.

1) A more holistic relationship with nature is necessary to create the cultural shifts toward sustainability.

» Indigenous philosophies, which understand the roles of humans and nature within an interconnected and reciprocal relational context, and have culturally embedded principles of regeneration, are key to transforming contemporary systems which depend on extraction and the division between humans and non-human forms of nature.
» The design of the Deshkan Ziibi Conservation Impact Bond aims to take an approach to valuing nature that is inclusive of Indigenous and Western worldviews (TwoEyed Seeing approaches) to create a system of relational accountability.

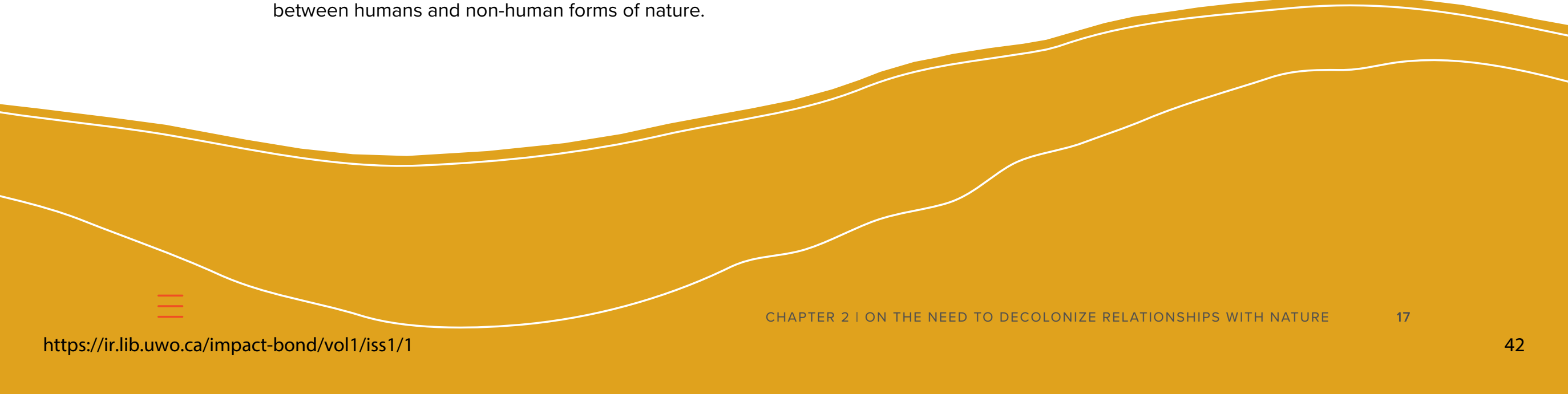




\section{Canada's Commitments to the Ecological Crises and Indigenous Peoples}

\author{
Climate and Biodiversity: \\ International Frameworks and \\ National Commitments in Canada
}

Canada is home to the second largest amount of the world's remaining wilderness, ${ }^{99} 20 \%$ of the world's freshwater, the world's longest coastline, the second largest tract of intact forests, and is among the top remaining countries in the world with both relatively high biodiversity intactness and high carbon density. ${ }^{100,} 101$ Therefore, Canada has both an incredible responsibility and opportunity to be a world leader in conserving landscapes for climate and biodiversity. ${ }^{102}$

Canada committed to acting on climate change and biodiversity loss in 1992 when the country signed on to the United Nations Framework Convention on Climate Change (UNFC$\mathrm{CC}$ ) and the Convention on Biological Diversity (CBD) at the Rio Earth Summit. ${ }^{103,104}$
In 2010, the Conference of the Parties for the CBD adopted a Strategic Plan for Biodiversity. This plan included 20 biodiversity targets, known as Aichi Biodiversity Targets, to be achieved by 2020 . The framework requires action from all 196 countries and stakeholders to safeguard biodiversity and the benefits it provides to people..$^{105}$ The vision is that "by 2050 , biodiversity will be valued, conserved, restored, and wisely used, maintaining ecosystem services, sustaining a healthy planet, and delivering benefits essential for all people."106 Conservation finance plays a role in all 20 Aichi Biodiversity Targets; however, it is explicitly referred to in Target 20: mobilization of financial resources for effectively implementing the Strategic Plan for Biodiversity.

In response to the Aichi Biodiversity Targets, Canada adopted the "2020 Biodiversity Goals and Targets for Canada" in $2015,{ }^{107}$ which includes four goals and nineteen targets. These goals and targets cover topics such as species at risk, connecting Canadians to nature, and protecting landscape. Canada's Target 1, which involves protecting at least 17\% 


\section{PART 1 FOUNDATIONS}

of terrestrial, and $10 \%$ of marine and coastal areas in Canada by 2020,108 inspired the formation of the Indigenous Circle of Experts (ICE) and commitments by provincial, territorial, and federal governments to work with Indigenous peoples in the spirit and practice of reconciliation. ${ }^{109}$ In September 2020, the federal government signed on to WWF's Leader Pledge for Nature and the High Ambition Coalition for Nature and People joining more than 65 countries in committing to safeguard species and habitat to better protect our planet.10 Around the same time, the federal government increased its commitments to protect $25 \%$ of its lands and oceans by 2025 and $30 \%$ by 2030 .11 $^{11}$

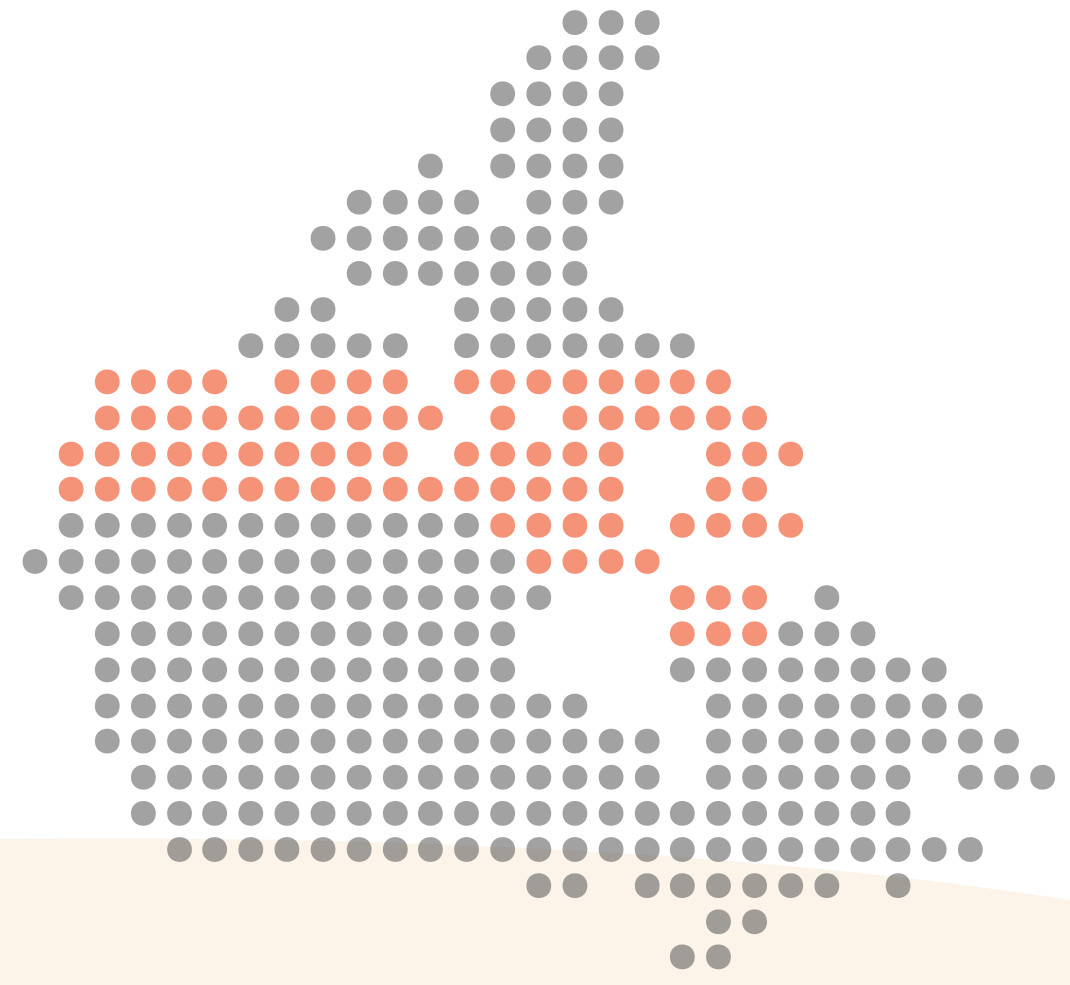

High Ambition Coalition for Nature and People 30x30 Target ${ }^{112}$

The High Ambition Coalition for Nature and People is an intergovernmental group that is cochaired by France and Costa Rica. The group's objective is to support the adoption of the target to protect $30 \%$ of the planet's land and $30 \%$ of its oceans by $2030(30 \times 30)$ in the future global framework of the Convention on Biological Diversity, which is to be adopted at the next Conference of the Parties (COP 15). The upcoming COP 15 is taking place in two parts with the first part taking place virtually in October 2021 and the second part taking place in Kunming, China in April and May 2022.13

The $30 \times 30$ target is science-based and reflects the recommendations of the Intergovernmental Science-Policy Platform on Biodiversity and Ecosystem Services (IPBES) and the International Union for Conservation of Nature (IUCN). These institutions have identified that protected areas are essential and effective solutions for the preservation of species and ecosystems and that the scope of protection needs to increase to at least $30 \%$ by 2030 . 
In 2015, the Conference of the Parties for the UNFCCC reached the Paris Agreement during which Canada and 194 other countries committed to the long-term target of keeping average global temperature rise below $1.5^{\circ} \mathrm{C}$ and well below $2^{\circ} \mathrm{C} .114$ Under the Paris Agreement, Canada had committed to a $30 \%$ reduction in greenhouse gas emissions within the next decade. At the Virtual Climate Summit in April 2021, Prime Minister Justin Trudeau announced that Canada had increased its target and would reduce greenhouse gas emissions by $40-45 \%$ of 2005 levels within the next decade. ${ }^{115}$ As part of the international effort to avert climate catastrophe, The Government of Canada has also committed to achieving net-zero emissions by $2050 .{ }^{116}$

Since 2015, Canada has invested approximately $\$ 60$ billion toward climate action and clean growth. ${ }^{117}$ In 2021 , the Government of Canada's Budget 2021 made several new commitments to combat the twin crises of climate change and biodiversity loss. A total of $\$ 17.6$ billion was allocated towards a green recovery from the COVID-19 pandemic including fighting climate change, reducing pollution, protecting nature, and creating jobs. ${ }^{118}$ This included $\$ 3.3$ billion allocated to support Canada achieving its target of protecting $25 \%$ of its lands and waters by 2025 and included support for Indigenous Protected and Conserved Areas (IPCAs). ${ }^{119}$

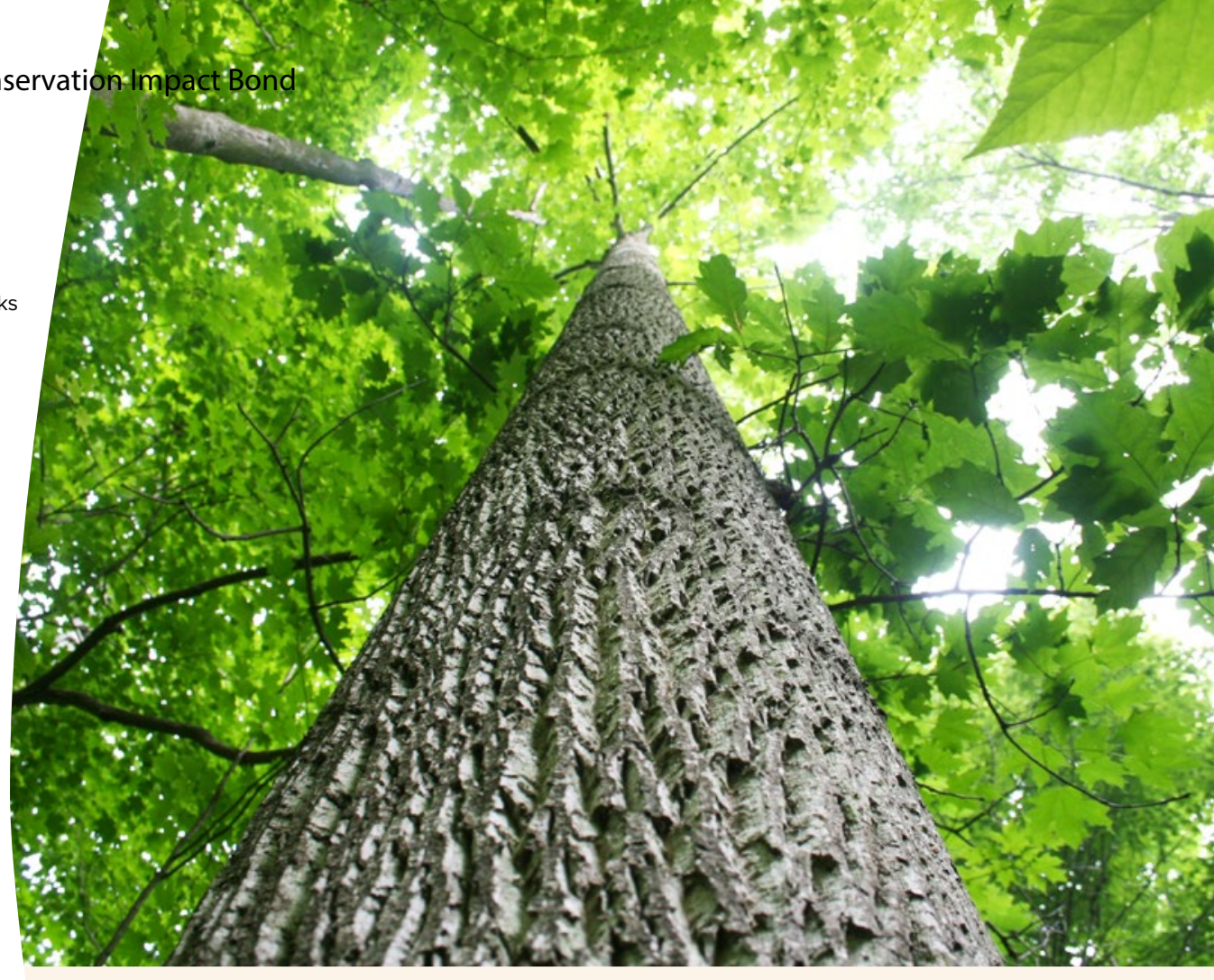

\section{Nature-Based Solutions and Indigenous Participation}

Nature-based solutions are defined as "actions to protect, sustainably manage, and restore natural or modified ecosystems, that address societal challenges effectively and adaptively, simultaneously providing human well-being and biodiversity benefits."'120 Recent estimates suggest that nature-based solutions can provide $30-40 \%$ of the cost-effective climate mitigation required between now and 2030 to ensure global warming is stabilised below $2^{\circ} \mathrm{C} .^{121}$ Many of the nature-based solution locations that are prioritised globally, including high carbon density forests and peatlands, are in the traditional territories of Indigenous Nations, such as Canada's Boreal Forest biome. ${ }^{122,123}$ Therefore, it is critical that nature-based solution projects are designed and implemented with Indigenous participation and consent to be successful. ${ }^{124}$ 


\section{Commitment to the Process of Truth and Reconciliation}

\section{Land Governance in Canada}

The nation now called Canada was established on the traditional territories of Indigenous peoples who were stewards of this land since time immemorial. The Lenape, Haudenosaunee, Anishinaabe, and other Woodland Nations gave the name 'Turtle Island' to the continent also known as 'North America', ${ }^{125}$ derived from renditions of the traditional creation story. Although different Indigenous cultures have various versions of the creation story, for many, the turtle is a significant character and an icon of life. ${ }^{126}$

When European peoples arrived on Turtle Island under the Doctrine of Discovery, they deemed North America as eligible for imperial claims of colonial sovereignty over the lands. Despite the pre-existing establishment of Indigenous cultures, societies, and inhabitants of the land, the Europeans did not consider this civilization to their standards; they viewed the Indigenous peoples as merely occupying the land rather than holding ownership over it. ${ }^{127}$
Treaties were used by the government as a method of forming relationships and alliances with Indigenous peoples, ${ }^{128}$ often regarding land use and ownership. However, treaties were often signed without mutual understanding on the contractual terms on the parts of both parties involved. An Indigenous perspective of nature does not allow for the concept of ownership over land; however, settlers held the perception that the land could be exploited for wealth gains. Upon signing treaties, many Indigenous peoples believed they would still be granted the right to coexist with the settlers on the land. Additionally, Indigenous information transmission methods of oral histories, which were seen as binding by Indigenous treaty-signers, were not equated with written records by settler societies resulting in the essence of many agreements becoming distorted in translation.

Current land governance systems in Canada continue to grant power primarily to the federal and provincial governments. Approximately
$89 \%$ of land in Canada ${ }^{129}$ and about $87 \%$ of land in Ontario, is Crown Land. ${ }^{130}$ This also includes reserve lands for which the legal title is not held by First Nations communities, but instead held in trust by the federal government. The remainder is privately owned land, and a portion is unceded territory of First Nations, meaning it was never signed over to the government through treaties. It is also important to note that in

Canada, over half of the Indigenous population lives off-reserve in surrounding urban areas. In Ontario, $63 \%$ of Indigenous peoples are living off-reserve. ${ }^{131}$

Better inclusion of Indigenous peoples in land governance and decision-making power over the land is important to the preservation of ecosystem health, community well-being, and to honor the broader process of reconciliation by supporting self-determination. 


\section{PART 1 FOUNDATIONS}

Reconciliation is the process of acknowledging historic injustices to Indigenous peoples and aiming to repair the relationships between Indigenous and non-Indigenous peoples damaged by years of mistrust and exploitation. The process of reconciliation involves learning about the past and present relationships between Indigenous peoples and the settler-colonial society, understanding the ongoing impacts of colonization, challenging dominant social structures and thought processes, and working towards the reconciliatory healing and rebuilding of relationships. ${ }^{132}$

As reconciliation aims at healing and relationship-building, it is important to acknowledge this is a broader process among Indigenous peoples and non-Indigenous peoples at a national level, a community level, interpersonal, and intrapersonal level.

In recent years, Canada has made a public commitment to the ongoing process of reconciliation. In 2016, Canada announced their support for the United Nations Declaration on the Rights of Indigenous Peoples (UNDRIP), which sought to create a universal standard for the rights of Indigenous peoples. ${ }^{133}$ On June 21, 2021, Bill C-15 received Royal Assent from the Senate of Canada, signifying the formal jurisdictional ratification of UNDRIP and consolidating the need for free, prior, and informed consent of Indigenous populations in natural resource development projects occurring in Canada. ${ }^{134}$ This act of committing to UNDRIP recognizes the wealth of knowledge Indigenous peoples have in environmental conservation, and the responsibility of Canada to engage in a process to rectify injustices to the standards of living, dignity, and well-being of Indigenous peoples.
Despite this declaration of support, there is still much progress required in reconciling the historic injustices to Indigenous peoples in Canada, including acknowledgement of the past and ongoing mechanisms of colonization and the intergenerational trauma incurred by Indigenous peoples through treaties, residential school, militarized diseases, laws and acts of Parliament, and other forms of disenfranchisement.

In 2008, the Government of Canada offered an official apology for the treatment of children in residential schools. ${ }^{135}$ However, this apology was merely a first step. In 2015, the Truth and Reconciliation Commission released a final report which was formed based on six years of primary research across Canada. The commission aimed to hear the Truths of Indigenous peoples' experiences with residential schools and included 94 Calls to Action for the Canadian government to work towards a process of reconciliation. ${ }^{136}$ In 2018, the Canadian government announced the development of a Recognition and Implementation of Indigenous Rights Framework that will include policy and legislation supporting self-determination of Indigenous peoples as part of a commitment to reconciliation and renewed relationships with First Nations, Inuit, and Métis. ${ }^{137}$ These are merely steppingstones to the broader and ongoing process of repairing the relationships between Indigenous Nations and the nation of Canada.

Since colonization was largely about removing Indigenous peoples from the land, a key part of decolonization involves restoring relationships to the land. ${ }^{138}$ Various mechanisms have been used in the dispossession of Indigenous peoples from the land. Treaties between settlers and Indigenous 


\section{PART 1 FOUNDATIONS}

leaders are regarded as an agreement in the exchange of ownership of the land; however, they did not adequately acknowledge the diverging values and worldviews of nature of the Indigenous peoples and settlers when entering into such agreements. Additionally, the idea of an ownership exchange does not honour the essence of a kinship relationship to nature where the land is not something that can be owned nor traded for monetary compensation. Thus, though treaties are often viewed as a contractual and legally binding agreement between settlers and Indigenous peoples, these negotiations were often done in bad faith and do not recognize the relational value of the land. This is an example of how land played a central role in colonization; not only was there a physical dispossession of land involved, but the process of treaty agreements also served to dispossess Indigenous peoples of their cultural ties and values of the land.
The value of land is not merely based on the wealth of resources which can be extracted from the land to support humans as a hierarchical worldview of nature would justify, but through an Indigenous perspective, one can see the value of land as teacher, land as kin, and land as a place of ceremony. Removing an Indigenous person from their homelands, for example, through the residential school system, is removing a person from a key source of community, culture, and ceremony. Thus, a key element of Canada's role in the process of reconciliation involves reconciling people and ecosystems. The Truth and Reconciliation Commission of Canada also recognizes the embedded role of land in the process of reconciliation:

\section{"If human beings resolve problems between them-selves but continue to destroy the natural world, then reconciliation remains incomplete. This is a perspective that we as Commissioners have repeatedly heard: that reconciliation will never occur unless we are also reconciled with the earth."}

Truth and Reconciliation Commission of Canada; pg. 123 139 
Recognizing the importance of autonomous Indigenous land management is a promising next step in honoring the significance of land health in a process of reconciliation. Indigenous Protected and Conserved Areas (IPCAs) in Canada is a term which describes lands and waters where Indigenous governments hold the primary role in conservation through Indigenous governance and knowledge systems. Provincial, federal, and territorial governments are called to take a holistic and integrative approach to stewardship that honor and create space for Indigenous knowledge systems and local protocols, practices, and ceremony. ${ }^{140}$

"By supporting the Indigenous-led conservation movement, we aim to help bring about the bold, transformative change to heal the relationships between humans and our planet, including relationships amongst human and non-human beings. We strive to model this change by centering Indigenous leadership, mutual respect, reciprocity, shared relationships, and a deep concern for our current condition. We hold a deep conviction that bringing about reconciliation in the conservation world will result in the transformation necessary to heal the planet."

Conservation through Reconciliation Partnership ${ }^{14}$

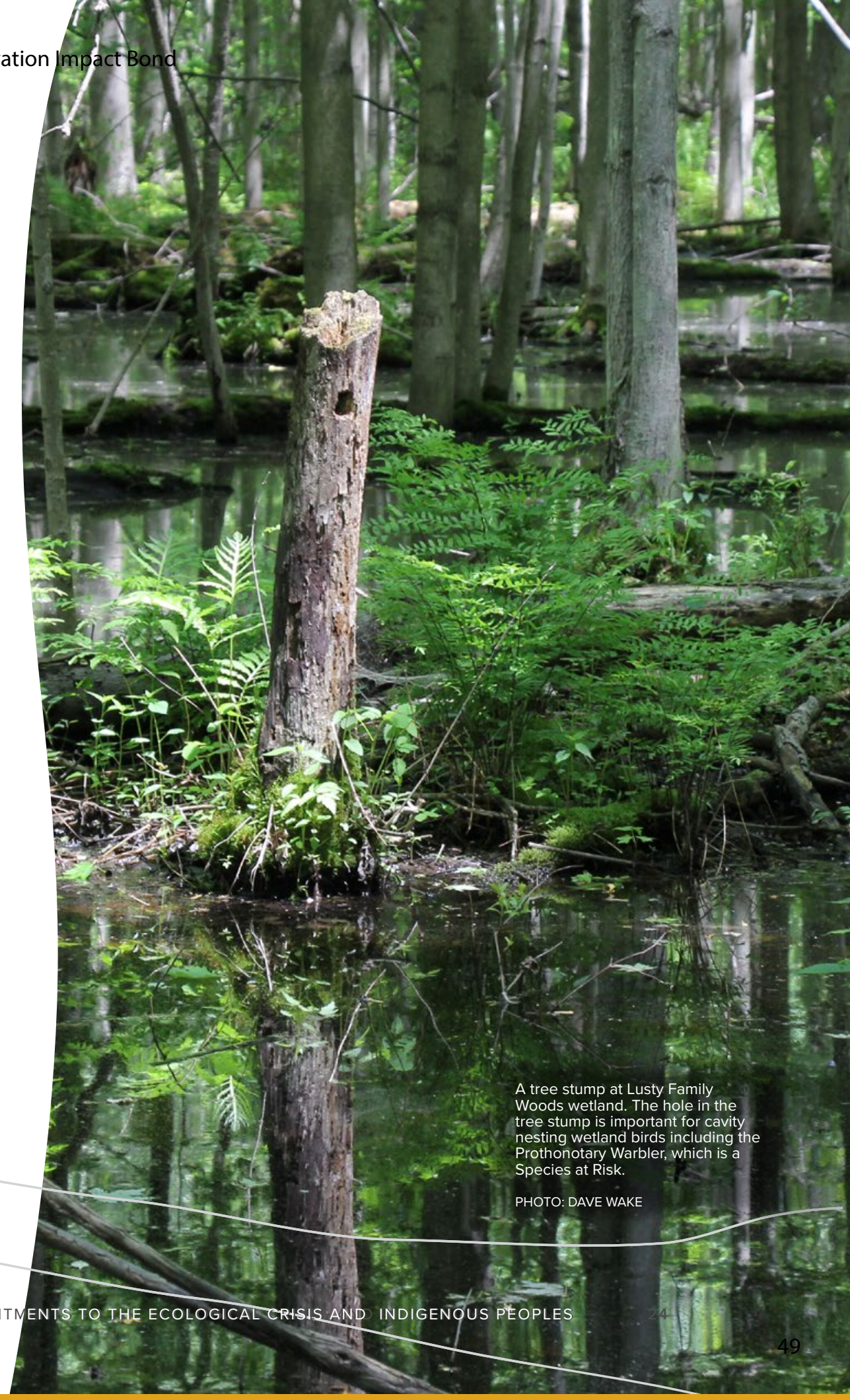




\section{Haida Law of Gina 'Waadluxan Gud Ad Kwaagiida and Indigenous Rights in Conservation Finance ${ }^{142}$}

One example of how Indigenous partnership in conservation finance has provided funding for protecting ecosystems and is a meaningful step in the process of reconciliation is the Council of the Haida Nation and the Gwaii Trust.

The Haida law gina 'waadluxan gud ad kwaagiida, is a law of interconnectedness and an understanding that everything relates to everything else. Thus, proper management considers the human, natural, and metaphysical worlds.

In honour of this principle, the Haida Nation established the Council of the Haida Nation whose mandate involves the protection of the lands, waters, and culture for future generations. Part of this project was the designation of 'Haida Protected Areas', which were identified as significant places of culture, environment, and history for the Haida Nation. These protected areas included land across the Haida Gwaii, an unceded archipelago of islands, located off the West Coast of Canada.

Later, the Council of the Haida Nation and the Government of Canada entered into cooperative management agreements based on the mutual agreement regarding the need to protect the region's natural, cultural, and marine treasures. The Gwaii Haanas Agreements recognize the differing views of land sovereignty, title, and ownership among the Haida Nation and the federal government, yet still allow for cooperative management towards a common goal of ecosystem protection.
Beyond this exemplary model of co-management, the Gwaii Haanas model is also successful due to its financial component, the Gwaii Trust. The objective of the Gwaii Trust is to support the island's community through culture, environment, and a self-sufficient economy. Haida leadership is involved in the governance of the trust in accordance with the UNDRIP ${ }^{143}$ standards. The Gwaii Trust invests in a wide variety of community projects reflecting their beliefs of the interconnectedness of Indigenous cultural traditions and values, economic stability, and environmental conservation. 


\section{Canada's Commitment to the Ecological Crisis and Indigenous Peoples}

1) Canada has committed to protect $25 \%$ of its lands and waters by 2025 and $30 \%$ by 2030 .

» Since 2015, Canada has invested approximately $\$ 60$ billion toward climate action and clean growth, however national results have been negligible on matters of reducing climate changing greenhouse gases and enhancing biodiversity.
》II 2016, Canada announced their support for the United Nations Declaration on the Rights of Indigenous Peoples (UNDRIP), formally ratifying the agreement in 2021.

1) This act of formally committing to the UNDRIP recognizes the wealth of knowledge Indigenous peoples in Canada have in environmental conservation and the responsibility of Canada in engaging in a process of rectifying injustices to the standards of living, dignity, and well-being of Indigenous peoples and work towards reconciliation.

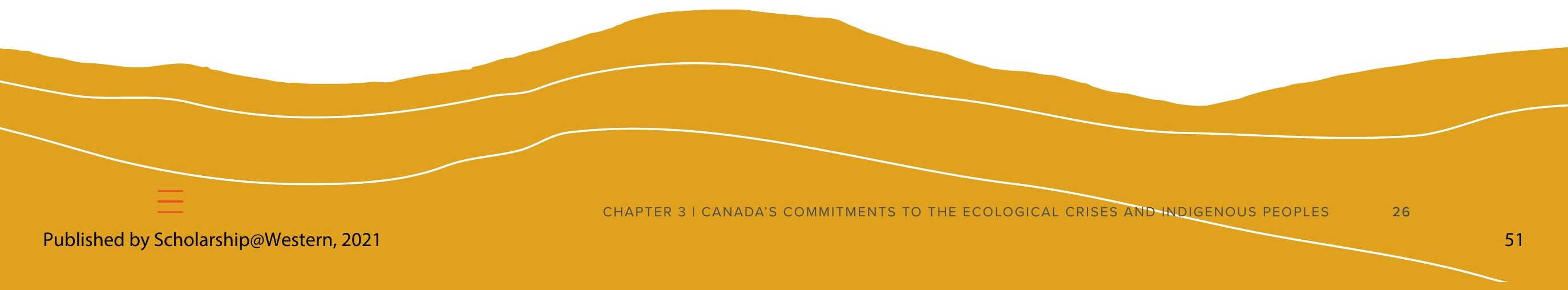




\section{The Conservation}

\section{Finance Funding Gap}

\section{Defining Conservation Finance}

The Conservation Finance Alliance defines conservation finance as "mechanisms and strategies that generate, manage, and deploy financial resources and align incentives to achieve nature conservation outcomes." ${ }^{144}$ An objective of implementing conservation finance solutions is to produce a self-sustaining financial system that functions to achieve sustainable management of nature and align diverse interests. ${ }^{1.5}$

The definition of conservation finance includes four key terms: ${ }^{146}$
1. Generating revenues for nature conservation.

2. Managing capital through operational efficiencies and avoided costs.

3. Deploying capital by allocating funds towards achieving conservation outcomes. This includes accounting for efficiency and effectiveness of spending through tracking outputs and long-term outcomes.

4. Aligning incentives by effectively implementing mechanisms to change behaviour towards achieving greater conservation outcomes.
Throughout our research, we came across terms such as "conservation finance," "biodiversity finance," "restoration finance," "climate finance," "sustainable finance," and "nature-based solutions finance." Since conservation, biodiversity, restoration, climate, and sustainability are interconnected and components of each collectively contribute to the implementation of nature-based solutions to the climate and biodiversity crises, this report will touch on elements of each of these domains. 


\section{PART 1 FOUNDATIONS}

Due to natural capital and ecosystem services (e.g., clean air, clean water, productive soil, food crop pollination, etc.) being largely unpriced and undervalued in capitalist modes of production, the lucrativeness of resource exploitation drives the dominant economy and hastens environmentally degrading and destructive activities. ${ }^{147}$ As such, investing in the conservation and protection of nature has historically been the domain of public actors, such as provincial and federal governments in Canada. ${ }^{148}$ Conservation campaigns that are focused on protecting ecosystems and species at risk have largely relied on publicly funded resources and in some cases private donor contributions whether from individuals, corporations, or organizations. ${ }^{149}$ Unfortunately, these funding models, despite best efforts, have been unable to halt or begin to reverse the trend of biosphere degradation as exemplified by the heightening of the biodiversity and climate crises.

Public investment in nature is a critical component for sustaining financial support for conservation; however, there is a growing call to encourage private investment in nature since public funding alone cannot fulfill the scale of investment required in the short-term. Additionally, the private sector continues to play a major driving force behind biosphere degradation, so shifting corporate perceptions on how nature is valued and creating conservation funding tools that align incentives aims to reverse this trend. Although the long-term aim is to appropriately value nature and ecosystem services in economic models, in the short to medium-term there is an urgent need to scale up investments in biodiversity conservation, utilizing a diversity of financial resources..$^{150}$

\begin{abstract}
"Unless we fundamentally change the movement of money to become nature-positive, rather than nature-negative, as it is on balance today, we will continue to finance ourselves into extinction."
\end{abstract}

John Tobin-de la Puente \& Andrew W. Mitchell151

In recent years, there has been growing interest and activity around the creation of novel approaches to financing nature conservation. ${ }^{152}$ As a result, public, philanthropic, and private sources of conservation financing are no longer being seen as mutually exclusive options; instead, a more collaborative approach that combines the strengths and synergies of these sectors into blended finance strategies are becoming more common. 153

In 2012, the global flow of finance to biodiversity conservation was estimated to be CAD $\$ 64$ billion..$^{154}$ In 2020 , the annual global flow of finance for conservation increased and was estimated to be CAD $\$ 153-176$ billion, ${ }^{155}$ with $80-85 \%$ of funding being derived from the public sector. ${ }^{156}$ While the recent trend towards increased funding for conservation is promising, to meet climate change, biodiversity, and land degradation targets, the estimated annual conservating financing gap is CAD \$741-1,021 billion. 157,4 For Canada, the estimated annual funding gap is CAD \$18.6-24.8 billion through to 2030.158 Both the public and private sectors have key roles to play in closing the global biodiversity financing gap over the next decade. ${ }^{159,160}$

4 Note all estimates were converted from USD to CAD using an exchange rate of CAD $\$ 1.24$ to USD \$1. 
PART 1 FOUNDATIONS

Additionally, calls for more rigorous metrics to assess the non-financial returns of investments through environmental, social, and governance (ESG) considerations have increased substantially in both the public and private sectors, ${ }^{161}$ which has contributed to a larger movement towards recognising and holding organizations accountable to the impacts of capital flows within society. Initiatives such as the Task Force for Climate-related Financial Disclosures (TCFD) ${ }^{162}$ and the
Task Force on Nature-related Financial Disclosures (TNFD) ${ }^{163}$ seek to align global finance with long-term sustainability objectives such as the Paris Climate Agreement, ${ }^{164}$ Aichi Biodiversity Targets, ${ }^{165}$ and the Sustainable Development Goals. ${ }^{166}$ Their work aims to support firms in understanding the scale of their exposure to biodiversity and climate-related risks and provide reporting and monitoring frameworks. ${ }^{167}$

Bluebells on the Bluebell Walk at

Newport Forest.

PHOTO: DAVID WAKE

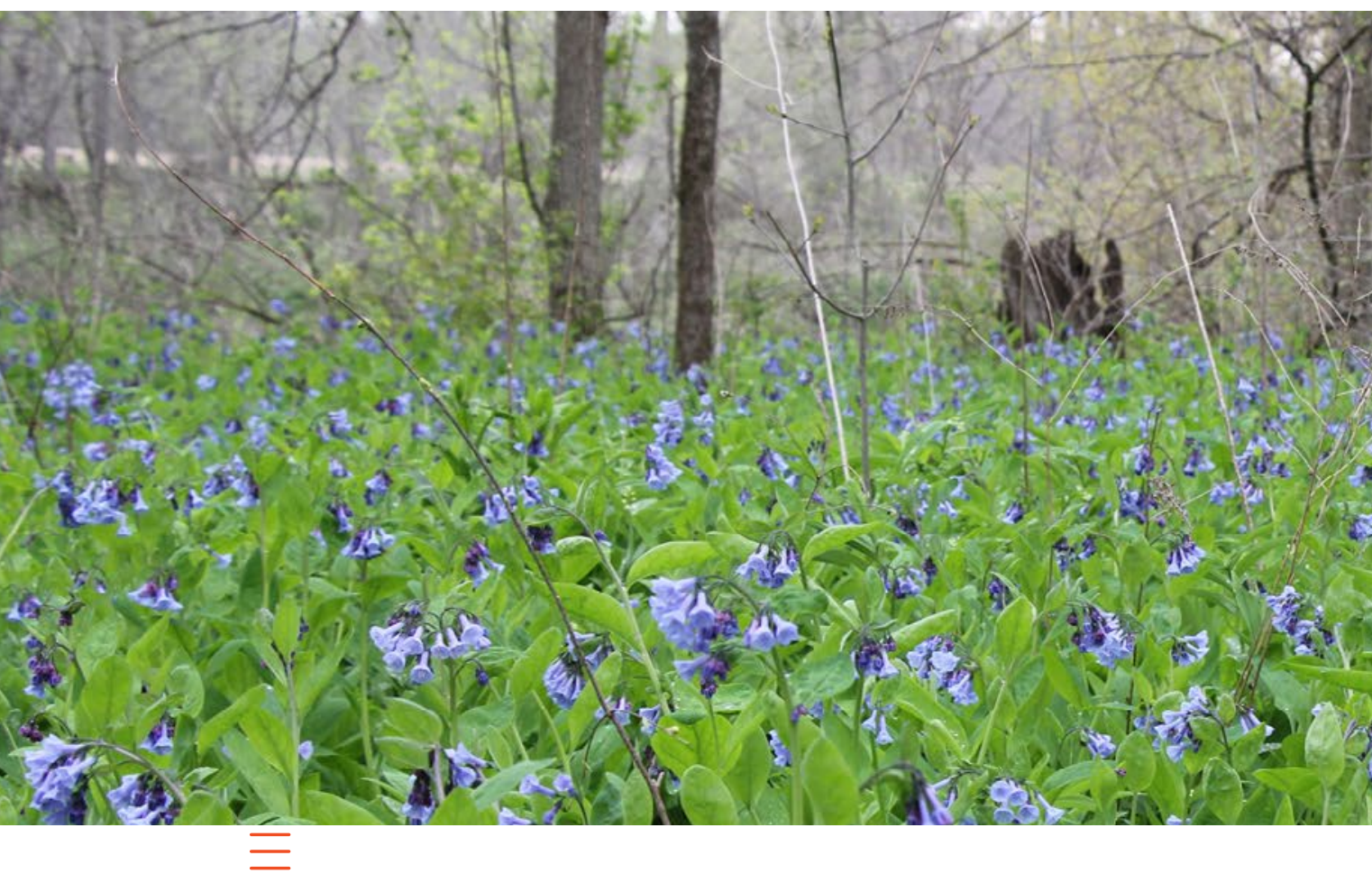

https://ir.lib.uwo.ca/impact-bond/vol1/iss1/1 


\section{The Conservation Finance Funding Gap}

» The economy is currently dominated by environmentally degrading activities.

» Investing in nature has historically been the domain of public actors.

\) There is an urgent need to scale up investments in nature in the short to medium-term and innovative financial solutions are needed to mobilize private pools of capital.
» The estimated global annual biodiversity conservation funding gap is CAD \$741-1,021 billion.

1) Canada's estimated annual conservation funding gap is CAD \$18.6-24.8 billion through to 2030 . 


\section{Conservation Finance Mechanisms and Strategies}

Conservation finance is defined as "mechanisms and strategies that generate, manage, and deploy financial resources and align incentives to achieve nature conservation outcomes." ${ }^{168}$ Subsequently, a conservation finance solution can be defined as "an integrated approach to solve a specific problem or challenge by the context-specific use of finance and economic instruments." ${ }^{169}$ Conservation finance solutions aim to produce a financial system that is self-sustaining, aligns diverse interests, and sustainably manages nature. ${ }^{170}$

\section{Mechanisms of Conservation}

Finance

There are seven categories of conservation finance mechanisms. ${ }^{171}$ These mechanisms provide a structure for analysis, planning, and implementation of conservation finance solutions. The categories below consist of mechanisms that range from contemporary to innovative. Many of these categories are overlapping and non-exclusive; for example, the Deshkan Ziibi Conservation Impact Bond (DZCIB) aims to combine the last three categories (i.e., risk management, return-based investments, financial efficiency) into a holistic conservation finance solution.

1 Public Financial Management

2 Grants and Other Transfers

3 Economic and Policy Instruments

4 Business and Markets

5 Risk Management

6 Return-Based Investments

7 Financial Efficiency 
TABLE 1: MECHANISMS OF CONSERVATION FINANCE ${ }^{172}$

\section{Public Financial Management}

Public financial management is focused on how the public

sector prioritizes, plans, and executes its national finances.

\begin{tabular}{lll}
\hline PROS & CoNS & EXAMPLES \\
\hline $\begin{array}{l}\text { National government budgetary allocations } \\
\text { are the largest stable source of finance for } \\
\text { nature globally and in most countries. }\end{array}$ & $\begin{array}{l}\text { Assuring adequate allocations to } \\
\text { conservation in national budgets can be } \\
\text { challenging given competing demands on } \\
\text { these budgets. }\end{array}$ & $\begin{array}{l}\text { Public fiscal planning (e.g., } \\
\text { mainstreaming conservation), } \\
\text { budgeting, and disbursement }\end{array}$ \\
& & Fiscal transfers \\
& & Government grants \\
Reforming harmful subsidies & Designating revenue for nature
\end{tabular}

\section{Grants and Other Transfers}

Grants and other transfers are finance mechanisms

that enable financial flows from sources of finance to

recipients or beneficiaries seeking funding for sustainable

development and conservation objectives.

\begin{tabular}{|c|c|c|}
\hline PROS & CONS & EXAMPLES \\
\hline $\begin{array}{l}\text { Unlike other investments, this finance } \\
\text { is provided with either no expectation } \\
\text { of financial return to the finance source } \\
\text { or below-market concessional rates of } \\
\text { financing. }\end{array}$ & $\begin{array}{l}\text { Achievement of desired long-term } \\
\text { outcomes can be challenging to ensure. } \\
\text { Restricted by charitability of financiers. }\end{array}$ & $\begin{array}{l}\text { » Official Development Assistance } \\
\text { P Private and Corporate Philanthropy } \\
\text { " Remittances } \\
» \text { Conservation Trust Funds }\end{array}$ \\
\hline
\end{tabular}


PART 1 FOUNDATIONS

\section{Economic and Policy Instruments}

Economic instruments include fiscal and other economic incentives and disincentives to incorporate environmental costs and benefits into the budgets of households and enterprises. ${ }^{173}$ These instruments

seek to increase prices of environmentally harmful products and services and decrease costs and prices of positive environmental goods and services.

\begin{tabular}{|c|c|c|}
\hline PROS & CONS & EXAMPLES \\
\hline $\begin{array}{l}\text { Provides a continuing incentive for } \\
\text { organizations and individuals to respond } \\
\text { to market forces and meet environmental } \\
\text { management objectives at the least cost. }\end{array}$ & $\begin{array}{l}\text { Effects on environmental quality are not } \\
\text { predictable because organizations can } \\
\text { independently decide how to respond } \\
\text { to incentives. Usually, sophisticated } \\
\text { institutions are required to implement and } \\
\text { enforce. }\end{array}$ & 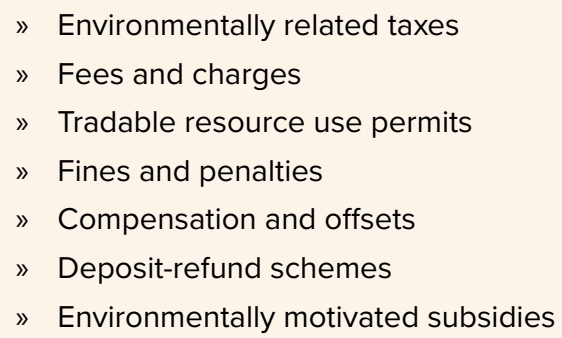 \\
\hline
\end{tabular}

\section{Business and Markets}

Business and market approaches focus on actions that can be taken by and for the private sector that are generally aimed at decreasing the cost of conservation, aligning private and public incentives, and improving business models and operations in ways that support the sustainable management of nature. They differ from "return-based investments" (see category 6 ) in that they are investments and actions taken by operating companies or governments that target business operations and not focused on investments in companies. Business and market mechanisms can overlap with "economic instruments," however this category focuses on the perspective of operating businesses and not investors or governments.

\begin{tabular}{lll}
\hline PROS CONS & EXAMPLES
\end{tabular}

Companies can undertake a wide range of actions to improve sustainability and decrease the negative impact of the production of goods and services. There is growing consumer demand for ecologically conscious companies.
As this instrument only focuses on the actions of the operating businesses, the scope of the conservation project is limited. Other stakeholders, such as investors and conservationists, likely do not get involved in the process, reducing its impact potential. Also, there have been cases of "greenwashing," where companies exaggerate their efforts with little evidence of actual environmental or conservation activities completed.
» Supply chain resilience

"Conservation businesses

» Corporate social responsibility and sustainability

"Voluntary offsets 


\section{Risk Management}

Risk management mechanisms and strategies seek to either use various risk management mechanisms to improve the conservation of natural ecosystems or leverage the risk abatement properties of well-managed ecosystems. The combination of risk management instruments and/or return-based investment instruments can produce what is termed "blended finance," which is considered a financial risk management strategy that facilitates private sector investment in nature.

\begin{tabular}{|c|c|c|}
\hline PROS & CONS & EXAMPLES \\
\hline $\begin{array}{l}\text { Combining mechanisms that are designed for } \\
\text { managing financial risks with investments can } \\
\text { mobilize new sources of capital and facilitate } \\
\text { transactions that would not have been } \\
\text { previously possible. }\end{array}$ & $\begin{array}{l}\text { Managing risks is a challenging task for } \\
\text { individuals, localities, and businesses. } \\
\text { Strong coordination between public and } \\
\text { private sector stakeholders is required to } \\
\text { facilitate risk management instruments. }\end{array}$ & $\begin{array}{l}\text { » Insurance products } \\
\text { » Financial guarantees } \\
\text { » Pay-for-success } \\
\text { » Blended finance }\end{array}$ \\
\hline
\end{tabular}

\section{Return-Based Investments}

Return-based investments for nature include a range of finance

strategies and mechanisms that seek both positive environmental

impacts as well as financial returns for a business owner or investor.

\begin{tabular}{lll}
\hline PROS & cons & EXAMPLES \\
\hline $\begin{array}{l}\text { These strategies support the mobilization of } \\
\text { private pools of capital. Many investors use a } \\
\text { combination of debt and equity instruments } \\
\text { to achieve their investment goals. }\end{array}$ & $\begin{array}{l}\text { Many return-based investments are } \\
\text { still focused on financial returns above } \\
\text { conservation outcomes. A systemic } \\
\text { change will have to occur to attract } \\
\text { more investment firms to consider more } \\
\text { sustainable investment strategies. }\end{array}$ & $\begin{array}{l}\text { Microfinance } \\
\text { Peer-to-peer investing and } \\
\text { crowdfunding }\end{array}$ \\
& & Angel investing, incubators, and \\
venture capital & Private equity & Debt: leasing, bank loans, notes, and \\
trade finance & Capital markets & Sustainable investment strategies
\end{tabular}




\section{PART 1 FOUNDATIONS}

\section{Financial Efficiency}

Financial efficiency includes a series of mechanisms that produce

enhanced conservation results relative to cost. Financial efficiency strategies can be implemented in combination with almost all other mechanisms described in this table.

\begin{tabular}{|c|c|c|}
\hline PROS & CONS & EXAMPLES \\
\hline $\begin{array}{l}\text { Offers a series of mechanisms that can be } \\
\text { applied in many organizations, projects, and } \\
\text { programs. Many of these mechanisms can } \\
\text { be applied internally increasing their ease of } \\
\text { implementation. }\end{array}$ & $\begin{array}{l}\text { The scale of impact of financial efficiency } \\
\text { strategies can be limited as most focus } \\
\text { on crosscutting internal mechanisms to } \\
\text { enhance conservation results. Public- } \\
\text { private partnerships are the exception; } \\
\text { however, a number of these partnerships } \\
\text { are formed with non-profit organizations } \\
\text { whose resources are often limited and } \\
\text { reliant on public sector funding. }\end{array}$ & $\begin{array}{l}\text { Management effectiveness } \\
\text { Public private partnerships } \\
\text { Integrated accounting } \\
\text { Mainstreaming biodiversity in } \\
\text { development }\end{array}$ \\
\hline
\end{tabular}




\section{Conservation Finance Models}

CONTEMPORARY CONSERVATION FUNDING

Contemporary conservation funding, in the form of grants and philanthropy, involves capital flowing linearly from the sources of finance to recipients (See Figure 8). These financing strategies have historically been the primary sources of funding for conservation.

\section{CONTEMPORARY CONSERVATION}

FUNDING MODELS

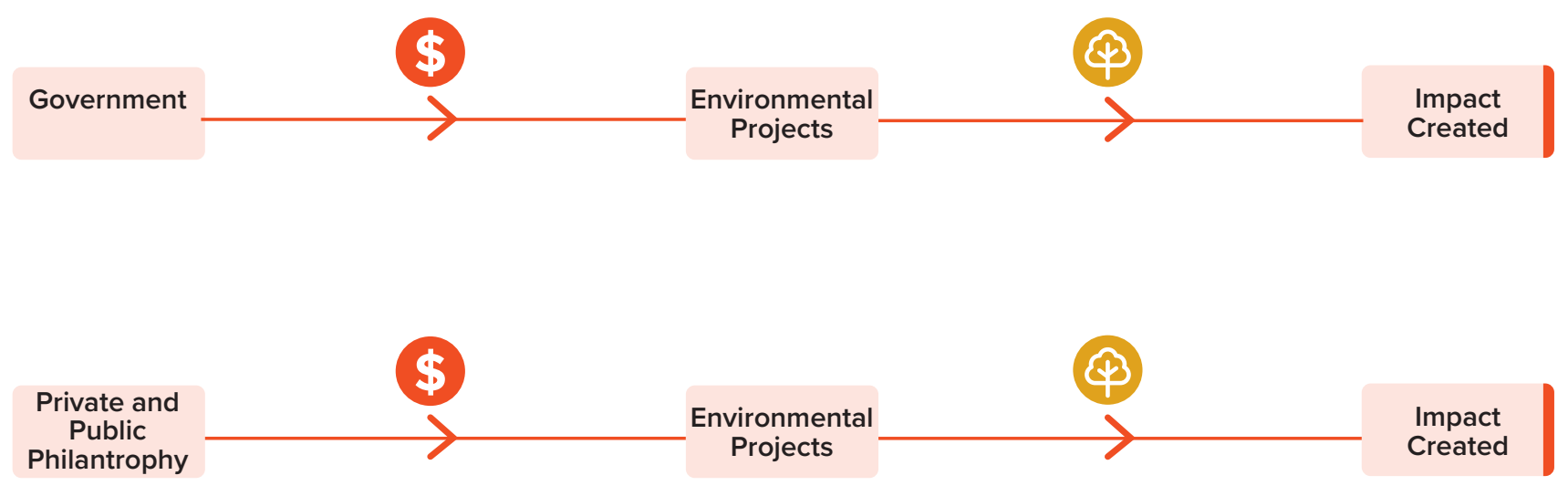

Recent decades have seen innovative developments of conservation financing strategies that diverge form contemporary conservation funding models. Before introducing the conservation financing model used in the case of the Deshkan Ziibi Conservation Impact Bond, this section will provide context into other innovative models for funding conservation along with some examples.

Figure 8: Contemporary Conservation Funding Models 


\section{PART 1 FOUNDATIONS}

GREEN BONDS

Green bonds are debt instruments that are traded in the capital markets and can be categorised under the returns-based investments conservation finance mechanism (see Table 1).

The green bond model involves issuers (including corporate, municipal, state, or federal entities) raising investor capital and allocating the proceeds to environmental projects. The issuers commit to allocating $100 \%$ of proceeds to finance projects with specific environmental benefits. ${ }^{174}$ After the term of the bond, the investors receive their principal investment and a return (See Figure 9) based on the cash flows generated from the environmental projects.
First established in 2007, green bonds are a relatively new strategy for environmental financing. Despite their novelty, the market for green bonds has been rapidly growing; ${ }^{175}$ in 2013, the global market for green bonds was CAD $\$ 13.6$ billion and in 2017, the market had grown to CAD $\$ 192.2$ billion. ${ }^{176}$

Despite the growing market, examples of green bonds financing land conservation are limited. A significant barrier to the use of green bonds for land conservation is the difficulty of generating cash flows. ${ }^{177}$

GREEN BOND MODEL

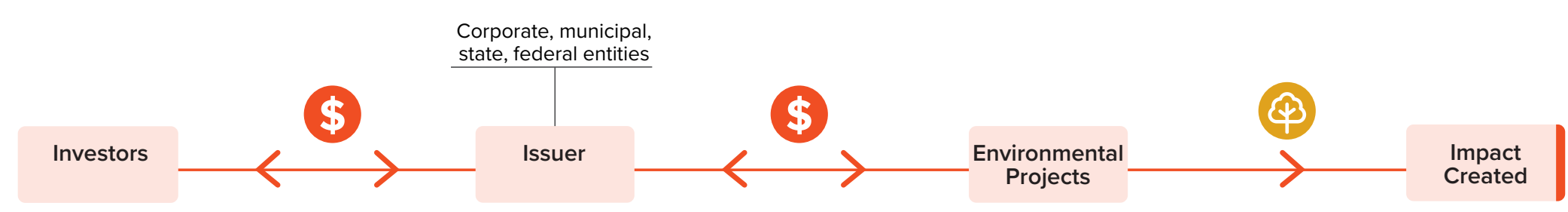

Figure 9: Green Bond Model 


\section{PART 1 FOUNDATIONS}

ENVIRONMENTAL IMPACT BONDS

Environmental Impact Bonds (EIBs) are blended finance payfor-success instruments. These instruments involve private companies or NGOs taking on the risk of implementing projects that seek to achieve quantifiable public benefits. EIBs operate under an established agreement with donors or government who, once the agreed upon environmental outcomes are achieved, will pay for the project costs and an additional profit margin. ${ }^{178}$ The pay-for-success model allows governments or donors to simultaneously decrease their investment risk while promoting innovation, efficiency, and effectiveness through the project implementation. This model allows private finance to flow into public projects and be rewarded if the program is successful. ${ }^{179}$

The first pay-for-success financial instrument was a Social Impact Bond (SIB). The structure of a SIB is very similar to an EIB but instead of pursuing environmental outcomes, it is focused on social outcomes (See Figure 10).

\section{PAY-FOR-SUCCESS/IMPACT} BOND MODEL

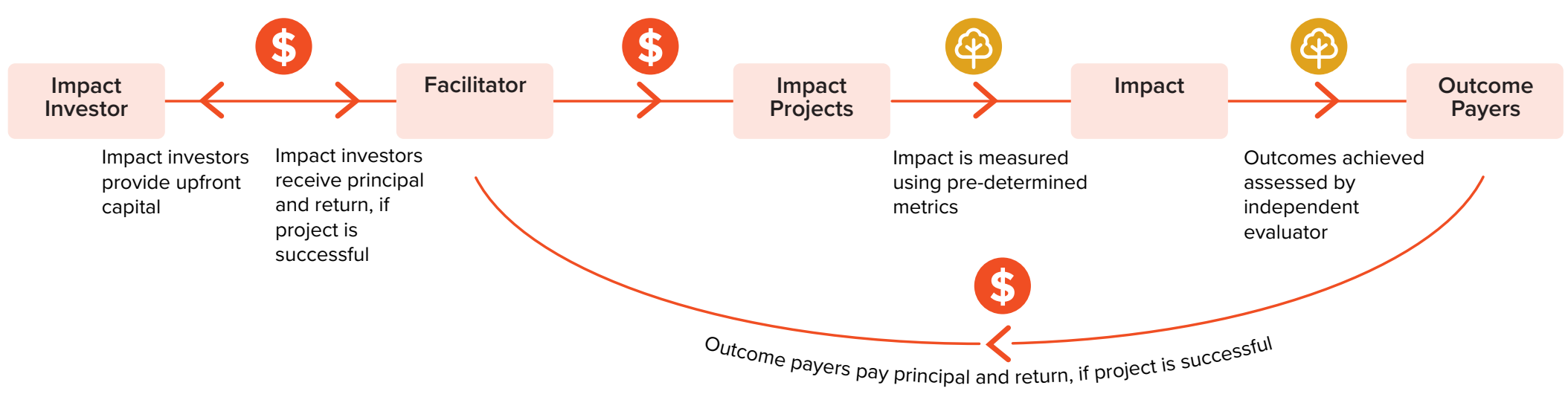

Figure 10: Pay-for-Success/Impact Bond Model 


\section{PART 1 FOUNDATIONS}

While the pay-for-success model has several advantages it also has received criticism. One criticism of pay-for-success models is that private investors may not be interested in achieving "real impact" and instead want to reduce their risk, leading them to set outcome targets that are easily achievable so they can quickly earn their return and exit. Another criticism is that projects can be too narrow in their evaluation and miss the complex nature of the issues that they are trying to solve. It has been argued that in order to genuinely pursue desirable societal outcomes, projects need to be locally adapted and community driven.

For example, the United State's first social impact bond was the Rikers bond which aimed to reduce youth recidivism at New York City's Rikers Island prison. On the pathway to achieving this desirable outcome, the bond applied only one strategy, introducing a specific therapy. Although the set goal of the bond was clear, it was limited to a single pathway to achieve that goal. ${ }^{180}$ Ultimately, the Rikers bond failed to achieve its desired social outcomes and both financial and philanthropic returns were lost. ${ }^{181}$ This bond's failure has been suspected to be a result of limited local innovation in developing the project's strategy and minimal adaptation as the project unfolded.

Despite some of the early-stage impact bond instruments facing challenges and scrutiny, a number of innovative models are continuing to be developed building on the lessons learned from prior projects. Some other examples include community-driven outcomes contracts and environmental impact bonds which follow.

\section{Raven Indigenous Capital Partners and the Argument for Community Driven Outcomes Contracts ${ }^{182,183}$}

Raven Indigenous Capital Partners (Raven) is an Indigenous-led financial intermediary based in Canada that works to empower Indigenous entrepreneurs with the capital and expertise they need to succeed. Their purpose is to facilitate the flow of capital through impact investing and to support the ongoing revitalization of the Indigenous economy in Canada. As an Indigenous intermediary, Raven honours the Seven Sacred Teachings (love, respect, bravery, honesty, wisdom, humility, and truth) and operates from the perspective of an Indigenous worldview.

Raven develops and implements community-driven outcomes contracts (CDOC), a social finance instrument based on the social impact bond (SIB) model. Although the SIB and CDOC models are similar, an important distinction is who determines the sought-after outcomes. SIB outcomes can be at risk of being determined by stakeholders who are external to the communities in which projects are being implemented. To avoid this risk CDOCs shifted their model to ensure community partners rest at the core of the financial strategy and co-develop outcomes based on what is deemed most important to community members.

Raven is currently developing and launching a pilot Diabetes Reduction Bond/Community Driven Outcomes Contract to finance diabetes prevention interventions. This CDOC will cover a five-year intervention period during which private capital will be deployed and the government will pay for successful outcomes. The CDOC will focus on reducing and/or preventing Type 2 diabetes in six Indigenous communities through implementing interventions that have been co-created and community-driven and are in alignment with community cultures and priorities. 


\section{Water Environmental Impact Bond ${ }^{184,185}$}

In 2016, DC Water, Quantified Ventures and investors, Goldman Sachs, and Calvert Foundation announced the United State's first Environmental Impact Bond (EIB). This bond aims to fund the construction of green infrastructure to manage stormwater runoff and improve DC's water quality. The proceeds of the EIB will be used to reduce the incidence and volume of combined sewer overflows that pollute DC's watershed by constructing green infrastructure that will absorb and slow surges of stormwater during periods of heavy rainfall.

Annually, two billion gallons of combined sewer overflows had been flowing directly into the Chesapeake Bay watershed adversely affecting the water quality and ecosystems in the region. As climate change is increasing the frequency and severity of intense rainfall events, combined sewer overflow reduction has become an increasingly urgent environmental challenge.

By using this financing technique, DC Water covers the costs of constructing the green infrastructure, but the performance risks are shared between DC Water and the EIB investors. The main evaluated metric is percentage reduction in stormwater runoff. Payments on the EIB vary based on specified percentage reduction in stormwater runoff outcomes.

\section{The Forest Resilience Bond ${ }^{186,187}$}

Blue Forest's Forest Resilience Bond seeks to overcome the funding gap for forest restoration by mobilizing private capital to support public land management and realize the value of reduced risk of catastrophic wildfire and enhanced landscape resilience. Working with partner organizations, Blue Forest provides sustainable financing with the goal of increasing the pace and scale of forest restoration activities in California, the Pacific Northwest, and across western United States.

In the Forest Resilience Bond model, once capital is deployed, beneficiaries of the ecological restoration work pay investors over time for a diversity of benefits including reduced wildfire risk, avoided carbon dioxide emissions, protected water quality, increased water quantity, and job creation.

The first pilot project of the Forest Resilience Bond, the Yuba Project, was launched in 2018 and provides USD $\$ 4$ million ${ }^{5}$ in private capital from four investors to finance ecological restoration across 5,886 hectares (14,545 acres) of land in Sierra County, California.

Approximately CAD $\$ 4.96$ million using an exchange rate of CAD $\$ 1.24$ to USD \$1

\section{The Rhino Impact Investment Project ${ }^{188,189,190}$}

The Rhino Impact Investment Project is developing the world's first pay-for-success financial instrument for species conservation. This project aims to mobilize new capital for conservation work and drive impact-focused and cost-efficient growth in the black rhino population. The project is a United for Wildlife initiative, a partnership of seven of the world's leading wildlife charities.

The black rhino population is listed by the International Union for Conservation of Nature as a critically endangered species. Over the last 50 years, the black rhino population has fallen from 65,000 to 5,500 in the wild due to intensified poaching and habitat degradation.

The five-year, USD $\$ 45$ million $^{6}$ security will be sold by the World Bank beginning in 2021 Returns for investors will be determined based on the black rhino's rate of population growth in two South African reserves. If successful, the program could be expanded to protect black rhino populations in Kenya, as well as expanded to other endangered wildlife species.

6 Approximately CAD $\$ 55.8$ million using an exchange rate of CAD $\$ 1.24$ to USD $\$ 1$ 
PART 1 FOUNDATIONS

ENVIRONMENTAL FUNDS

Environmental funds are categorised as grants and other transfers in the conservation finance mechanisms table (See Table 1). Environmental funds enable financial flows from sources of finance to recipients seeking funding for conservation objectives, providing financing for a range of environmental projects including protected areas, sustainable livelihoods, and restoration. ${ }^{191}$

\section{The Land Degradation Neutrality Fund ${ }^{192}$}

The Land Degradation Neutrality (LDN) fund was initiated by the United Nations Convention to Combat Desertification and aims to support the mobilization of blended financial resources to achieve the United Nation Sustainable Development Goal (SDG) target of a land degradation-neutral world by 2030 .

The LDN fund is an impact investment fund that pools resources from private, public, and philanthropic sectors to support sustainable land management and land restoration projects. The LDN fund was created through a public-private partnership between the Governments of France, Luxembourg, Norway; the Rockefeller Foundation; and the investment management firm, Mirova. By leveraging long-term non-grant financing, the LDN will invest in financially viable private projects for land rehabilitation and sustainable land management including sustainable agriculture, sustainable forestry, and agroforestry. Projects that are considered eligible for financing must generate environmental, socio-economic, and financial returns.

In 2021, Global Affairs Canada announced a contribution of up to $\$ 55$ million to the LDN Fund as part of Canada's $\$ 2.65$ billion climate finance commitment. ${ }^{193}$

\section{HSBC Pollination Climate Asset Management Funds ${ }^{194}$}

In 2020, HSBC Global Asset Management and Pollination partnered to create the world's largest dedicated natural capital asset management company leveraging HSBC's sustainable finance experience with Pollination's global expertise in natural capital. HSBC Pollination Climate Asset Management aims to establish a series of natural capital funds to invest in a diverse range of activities that preserve, protect, and enhance nature over the long-term. The funds seek to support the growing demand for nature-based solutions to climate change that also diversify investment risk and offer attractive, longterm returns.

Global natural capital investment themes include regenerative and sustainable agriculture; sustainable forestry; oceans, including sustainable fisheries, coastal restoration, and blue carbon; biodiversity and wildlife protection and restoration; natural capital and real assets that generate carbon credits.

CHAPTER 5 | CONSERVATION FINANCE MEC
Planting seed rows for a native plant seed orchard at Blain Farm. PHOTO: COLIN JOHNSON

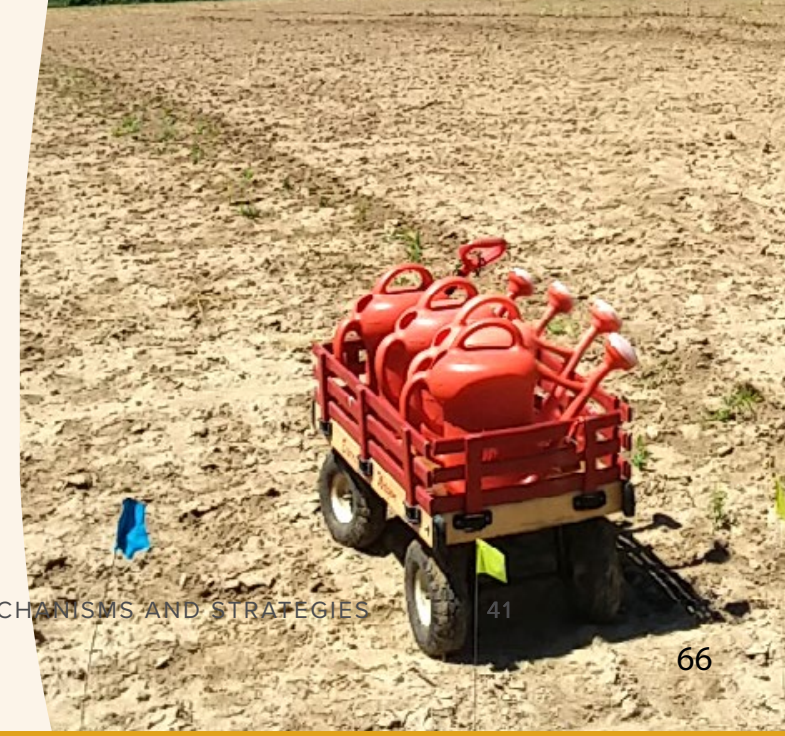




\section{KEY TAKEAWAYS \\ Conservation Finance Mechanisms and Strategies}

» A conservation finance solution can be defined as an integrated approach to solve a specific problem or challenge by the context-specific use of finance and economic instruments.

1) There are seven categories of conservation finance mechanisms that are overlapping and non-exclusive. These range from contemporary mechanisms (e.g., financial efficiency and public financial management) to innovative (e.g., return-based investments, risk management/ blended finance)
Examples of innovative financial instruments for conservation include green bonds, environmental impact bonds, land degradation neutrality funds, and natural capital asset management funds. 
PART 2

CAROLINIAN CANADA CONSERVATION

\section{IMPACT BOND}

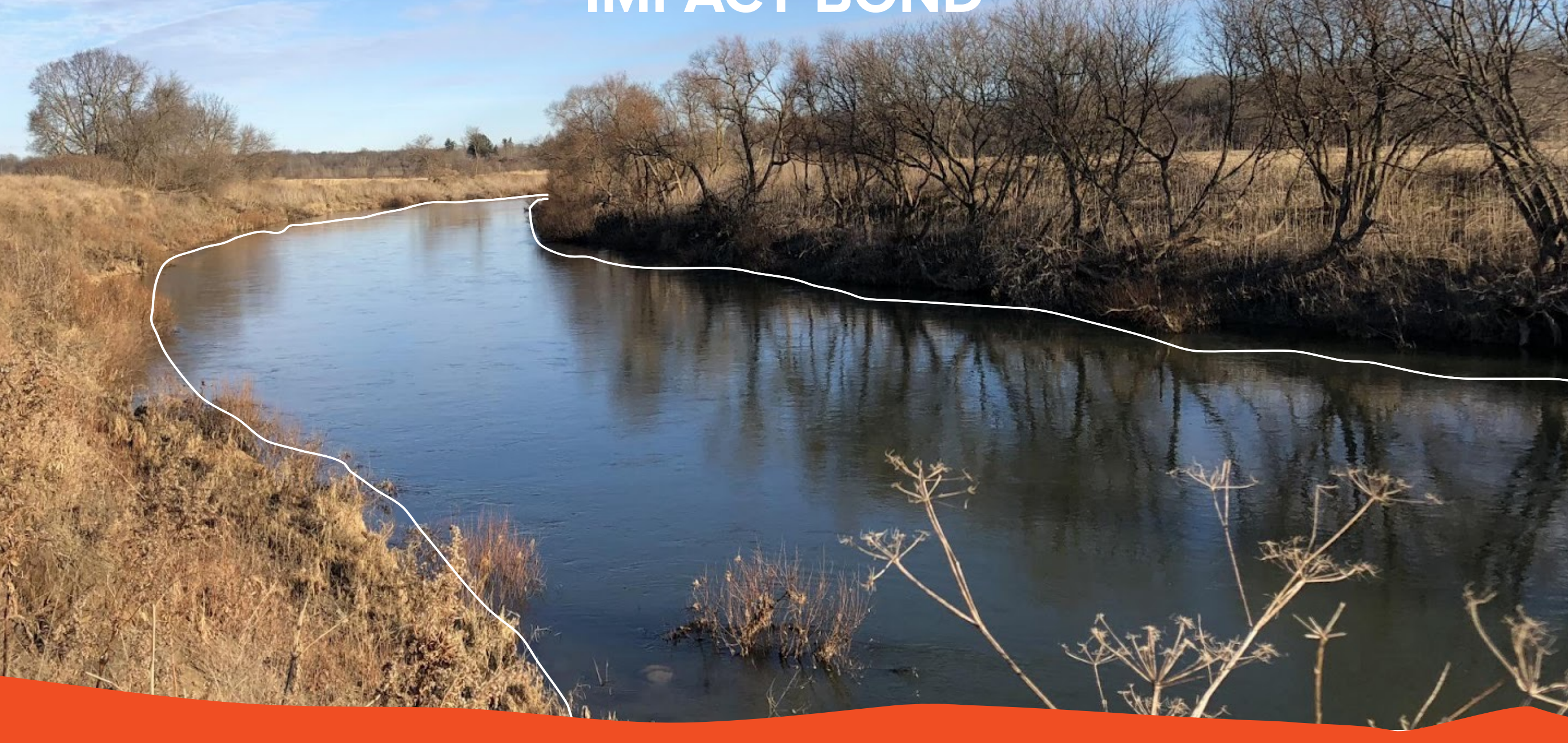

$$
\equiv
$$

https://ir.lib.uwo.ca/impact-bond/vol1/iss1/1 


\section{The Carolinian Zone and Carolinian Canada Coalition}

\section{The Carolinian Zone}

The Carolinian Zone, or Lake Erie Lowland, extends from Windsor to Toronto and is Canada's most southern ecoregion positioned at the northern limit of the Eastern deciduous forest region (See Figure 11). ${ }^{195}$

The Carolinian Zone is the traditional territory of the Anishinaabe, the Haudenosaunee, the Lunaapeew, the Wendat, and the Attawandaron (See Figure 12) who have lived, learned, stewarded, and thrived on this land for many generations. Today, many First Nations still call the Carolinian Zone home and have long historic treaties and ties to this land including the Aamjiwnaang First Nation, Bkejwanong (Walpole Island First Nation), Caldwell First Nation, Chippewas of Kettle and Stony Point First Nation, Deshkan Ziibiing (Chippewas of the Thames First Nation), Eelünaapéewi Lahkéewiit (Delaware Nation at Moraviantown), the Mississauga of the Credit First Nation, Munsee Delaware Nation, Oneida Nation of the Thames, and Six Nations of the Grand River. ${ }^{197,198}$

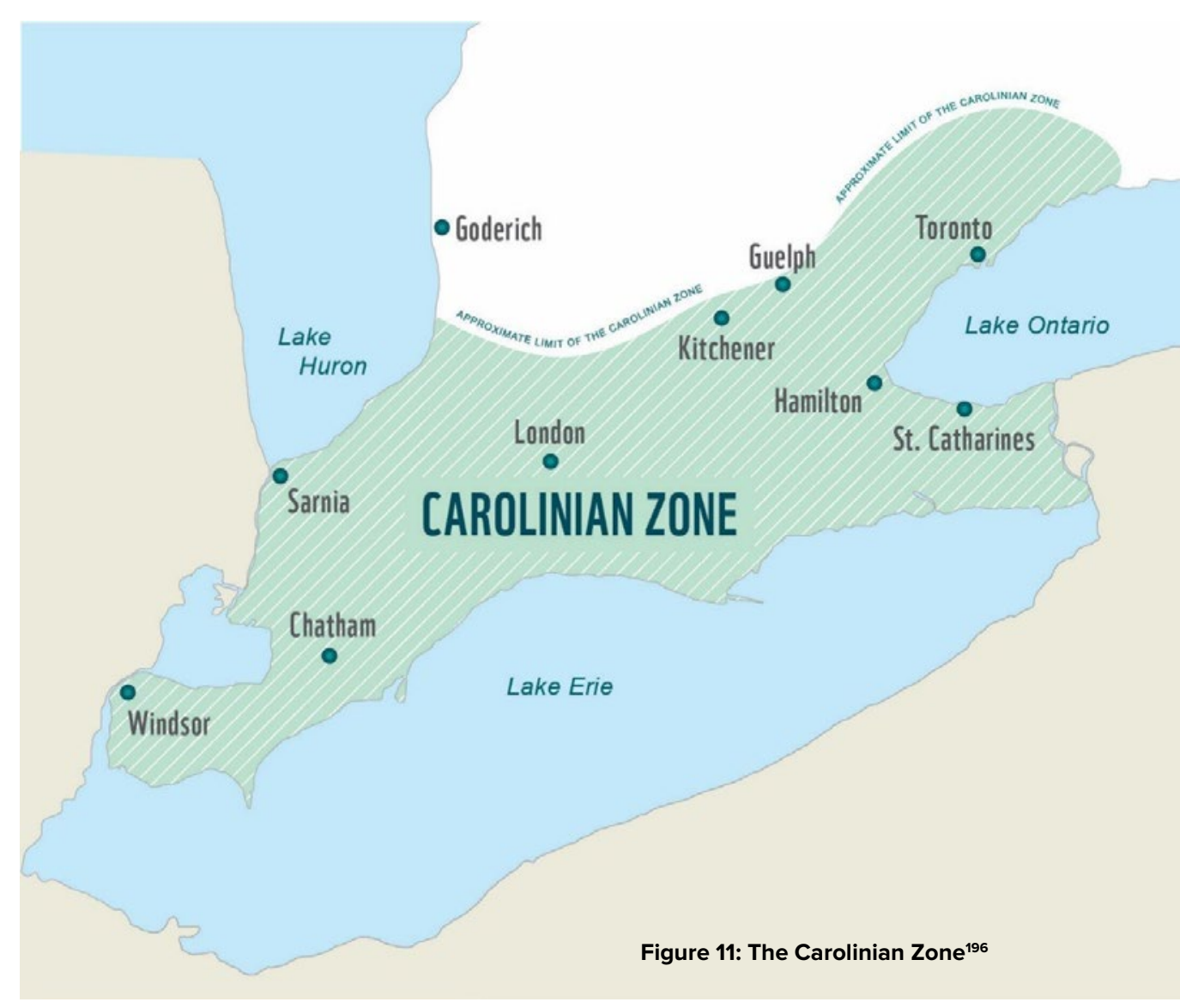


PART 2 CAROLINIAN CANADA CONSERVATION IMPACT BOND

Situated among the Great Lakes, the Carolinian Zone's mild climate supports a greater number of plant and animal species than any other region in the country. ${ }^{200}$ Recognised as a biodiversity hotspot and referred to as a "National Natural Treasure," 201 this region is home to approximately 2,200 species of herbaceous plants, 400 species of birds, and some of the country's most productive farmland. ${ }^{202}$
Unfortunately, these diverse inhabitants and their habitat are under threat. Although the region represents merely $0.25 \%$ of Canada's land mass, the Carolinian Zone supports 25\% of the country's human population with several of Ontario's largest cities located here including: Toronto, Hamilton, Niagara Falls, London, and Windsor. ${ }^{203}$ Approximately $95 \%$ of the land in the Carolinian Zone is privately owned, ${ }^{204}$ and $73 \%$ is farmland. ${ }^{205}$

Figure 12: Indigenous Territories of the Carolinian Zone ${ }^{199}$

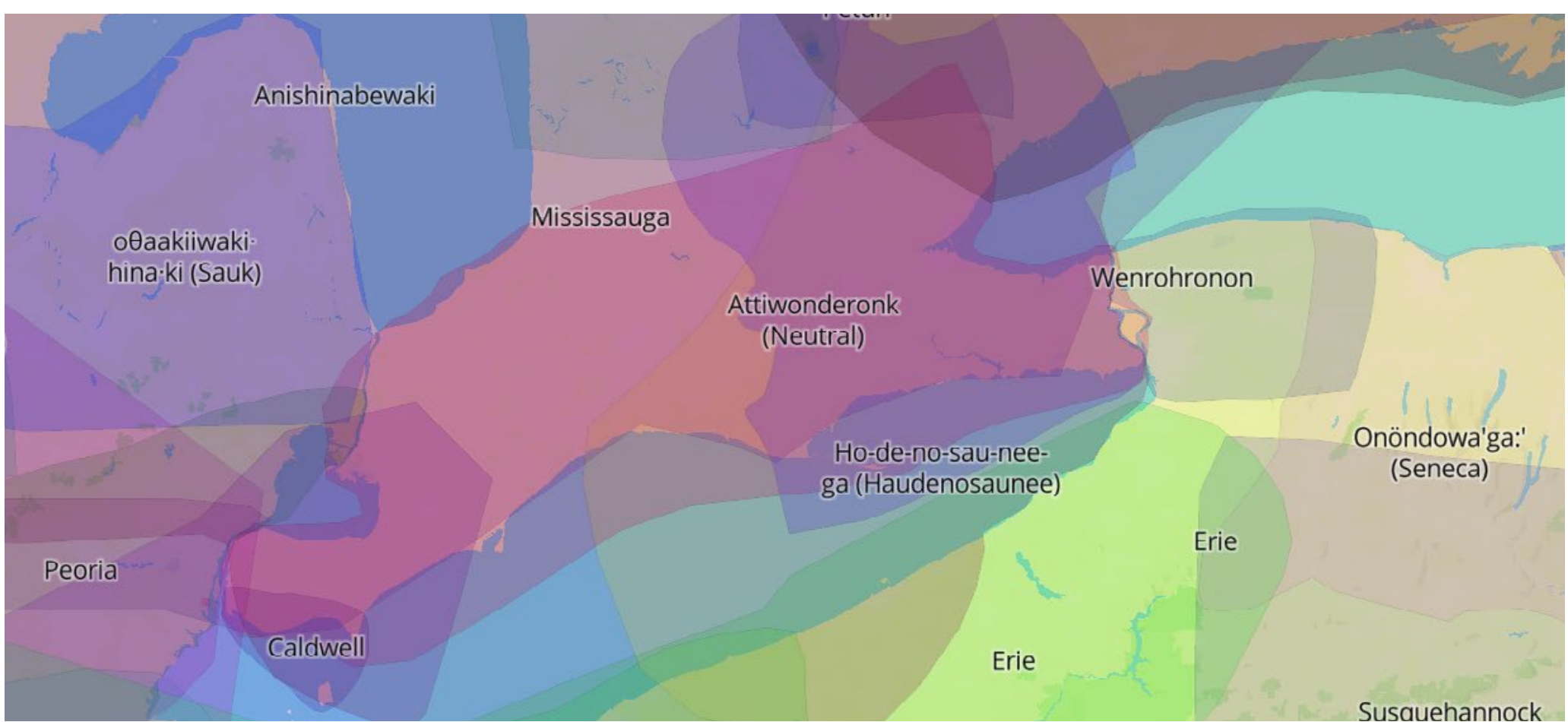


Over the last two centuries, around $85 \%$ of the ecoregion has been converted to cropland, pasture, and urban uses. Consequently, forest cover has been reduced from $80 \%$ to $11 \%$, and wetland cover has been reduced from $28 \%$ to $5 \% .{ }^{206,207} \mathrm{Hab}$ itat loss has been a main factor of biodiversity decline; this region is now home to more than $50 \%$ of the federally listed species at risk in Canada and has been identified as the most imperiled region in Ontario. ${ }^{208,209,210}$ This ecoregion is a complex and multi-use landscape sustaining diverse flora and fauna, millions of people, and highly productive agricultural land. The threat of biodiversity loss in the Carolinian Zone warrants a solution that recognizes the diversity of land uses and the complexity of the landscape, and responds accordingly.

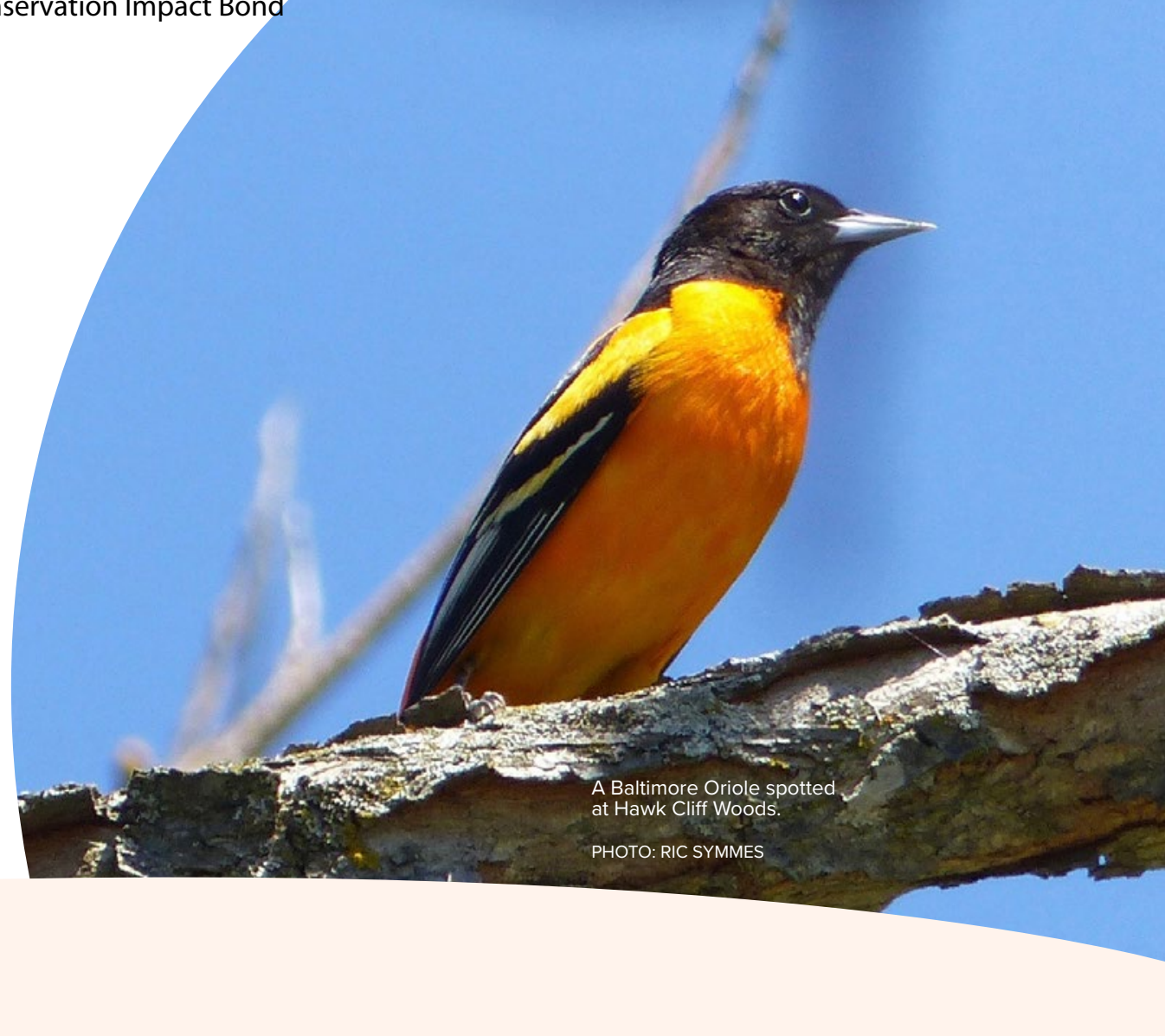

\section{The Carolinian Canada Coalition and the Healthy Landscape Strategy ${ }^{21,212}$}

THE CAROLINIAN CANADA COALITION In 1984, the Carolinian Canada Coalition (Carolinian Canada) was formed by scientists and local organizations in response to the high level of threats being faced by the region's natural ecosystems. ${ }^{213}$ Carolinian Canada was created with the mission to reverse the trend of habitat loss and accelerate healthy landscapes in the Carolinian Zone by advancing a collaborative conservation strategy with diverse groups who care about the unique nature of the region. ${ }^{214}$
From 1984-1994, Carolinian Canada Coalition funded research, stewardship projects, and land acquisitions to conserve 38 critical unprotected natural areas across the region. ${ }^{215,} 216$ These projects resulted in conservation groups acquiring 809 hectares (2,000 acres) of land, private landowners agreeing to conserve an additional 6,070 hectares (15,000 acres), new scientific research, and the progression of public education on the importance of healthy landscapes. ${ }^{217}$
In 2000, the Carolinian Canada Coalition partnered with the Ontario Ministry of Natural Resources' Natural Heritage Information Centre and launched the "Big Picture" project to design a long-term natural heritage vision for Canada's most southern ecoregion (See Figure 13). ${ }^{218}$ Informed by advancing scientific understanding, the "Big Picture" project served to shift the conservation paradigm in the region from the creation of "islands of green" 219 toward a larger system of connected natural areas, referred to as a "natural heritage system." ${ }^{220,221,222,223}$ 
PART 2 CAROLINIAN CANADA CONSERVATION IMPACT BOND

The Carolinian Canada Coalition and the Healthy Landscape

CONTINUED
The "Big Picture" project resulted in the identification of a natural heritage system of core natural areas and connecting corridors in the Carolinian Zone that, if pursued, would result in landscape benefits including healthier ecosystems, enhanced biodiversity, cleaner water and air, and healthier communities.224 Today, the "Big Picture" is a critical component of Carolinian Canada's Healthy Landscape Strategy and continues to inform and complement natural heritage planning by municipal, provincial, and federal governments, conservation authorities, local groups, and landowners.

In 2006, Carolinian Canada became incorporated and registered as a charity in $2008 .{ }^{225} \mathrm{At}$ that time, a five-year strategic plan was developed through consultation with members and partners. The strategic plan has been updated every five years since then with the most recent plan being launched in 2018. The Strategic Plan 2018-2023 "Growing a Green Future, together" has three main objectives: enable leaders for thriving green communities; grow connections to scale up healthy habitat action; and track impact for a healthy zone, together. ${ }^{226}$ This plan also includes an expanded network of activities to focus on supporting Indigenous leadership, the native plant economy, and conservation finance.

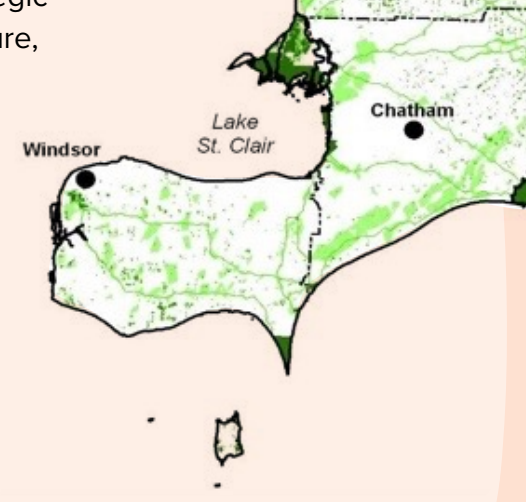

\section{THE BIG PICTURE}

Natural Cores and Connections in Canada's Carolinian Life Zone

Natural Core Areas

Other Significant Natural Areas

Potential Habitat Corridors

Potential Strategic Habitat Enhancement Areas

- Carolinian Life Zone

Counties 
The Carolinian Canada Coalition and the Healthy

Landscape

CONTINUED

\section{HEALTHY LANDSCAPE STRATEGY}

Carolinian Canada's Healthy Landscape Strategy aims to grow Canada's Biggest Wildlife Garden connecting Toronto to Windsor with healthy habitat. ${ }^{227}$ Native plants are building blocks to developing healthy habitats. Growing native plants on everyday landscapes inhabited by Canadians such as parks, agricultural fields, lawns, and urban areas is key to their strategy. Doug Tallamy, ecologist and author of "Bringing Nature Home: How Native Plants Sustain Wildlife in our Gardens", has played a key role in inspiring Carolinian Canada's strategy as his research has demonstrated the ways in which native plants support greater insect populations, biodiversity, and landscape health than non-native plants. ${ }^{228}$ Additionally, Environment Canada's report, "How Much Habitat is Enough?"229 informs Carolinian Canada's strategy as it describes the minimum amounts of habitat needed to help support populations of wildlife in Canada. ${ }^{230}$ Guidelines for land use planning and restoration and conservation practitioners include: $30-50 \%$ minimum forest cover, $75 \%$ of the length of a stream naturally vegetated, and less than $10 \%$ impervious cover in a watershed. ${ }^{23}$
As the demand for native plants increases, part of Carolinian Canada's strategy is to ensure a viable seed strategy for native plants within the region. This strategy prioritizes Indigenous leadership in the stewardship and cultivation of native plants. Native plants hold cultural and relational significance to many Indigenous peoples who view native plants as relatives and friends, not commodities. Thus, a respectful seed strategy for ethical source-identified native plants goes hand-in-hand with Carolinian Canada's Healthy Landscape Strategy.

The Healthy Landscape Strategy includes four key activities, linking restoration and conservation priorities based on the latest local and global science. ${ }^{232}$ The on-the-ground habitat restoration work involves one or more of the following activities, adapted to local needs:

\section{Milkweed seeds.}

PHOTO:

DARIA KOSCINSKI

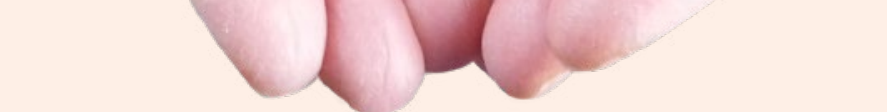

1. Save local nature: increase commitment to saving habitat with long-term agreements.

2. Steward healthy landscapes with best ecosystem practices: increase habitat quality.

3. Seed, grow, create, or restore high-quality habitat and green infrastructure using native plants sourced locally, ecologically, and ethically: increase habitat quantity and connections.

4. Lead healthy resilient communities connected to nature through strong equitable collaboration, positive engagement, First Nations leadership, and an ethical, local native plant industry. Support a climate-smart, green economy for thriving local communities through cross-sector collaboration. 


\section{The Carolinian Canada Zone and Carolinian Canada Coalition}

» The Carolinian Zone is a complex and multi-use landscape sustaining diverse flora and fauna, highly productive agricultural land, and $25 \%$ of Canada's human population including many Indigenous Nations.

» The Carolinian Zone has been experiencing significant habitat loss and ecosystem degradation over the last two centuries.
» Carolinian Canada's Healthy Landscape Strategy seeks to reverse the trend of habitat loss and accelerate healthy landscapes through a portfolio of habitat projects guided by four main activities: save, stewards, seed, and lead. 


\section{The Carolinian Canada} Conservation Impact Bond Model and the Deshkan Ziibi Pilot Project

\section{The Carolinian Canada Conservation Impact Bond Model}

The CIB model is a pay-for-success conservation finance mechanism driven by collaboration to reverse the trend of habitat loss by accelerating healthy landscapes, advancing Indigenous Reconciliation, and empowering the human-nature relationship in the Carolinian Zone. It is a place-based effort that leverages cross-sector and cross-cultural collaboration to support a holistic ecosystem approach that is aligned with local community goals. The CIB aims to operate in the spirit and practice of reconciliation aligning with efforts to heal Turtle Island and all our relations.
The development of the CIB began with relationship building and goal setting with partners from five key interest groups (See Figure 14). The CIB program was initiated in 2019 when twenty local partners, representing each of the key partner groups, came together in ethical space, hosted by the Chippewas of the Thames First Nation, to develop initial project strategies and goals. This collaboration was aligned with global frameworks such as the Open Standards for the Practice of Conservation, ${ }^{233}$ and the Healthy Country Planning Approach, ${ }^{234}$ which emphasizes the importance of Indigenous leadership. From these initial discussions, the Deshkan Ziibi Conservation Impact Bond (DZCIB) pilot project was created and a local and diverse Leadership Team was established to further co-develop the CIB model, and implement the model's first pilot project, the DZCIB. 
PART 2 CAROLINIAN CANADA CONSERVATION IMPACT BOND

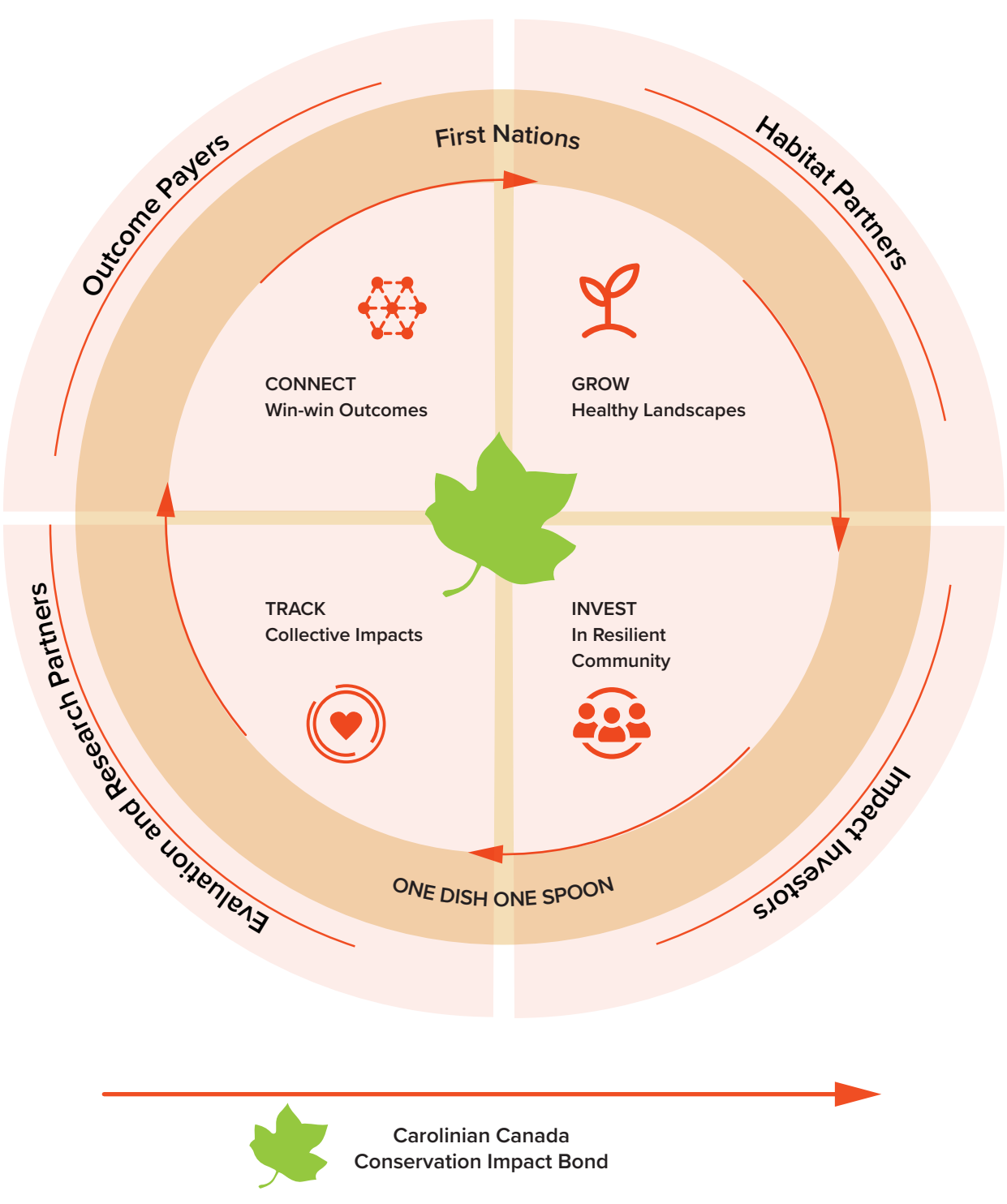

\section{Coming Together in \\ Ethical Space}

Ethical space involves groups from disparate worldviews engaging with each other. The theoretical space between worldviews and cultures is ethical space, which allows for dialogue and development between diverse perspectives. ${ }^{235}$ The purpose of ethical space is to create a safe setting where knowledge systems can interact while the integrity of each diverse system is respected and validated; it does not hold one perspective as more legitimate. Ethical space involves flexibility of those involved to adjust, rethink, and change through the process of engaging. ${ }^{236}$

The CIB model aims to operate in ethical space, by bringing together Indigenous and Western knowledge systems to create healthy landscapes, healing Turtle Island and all its relations.

Figure 14: Carolinian Canada Conservation Impact Bond Partner Groups 
PART 2 CAROLINIAN CANADA CONSERVATION IMPACT BOND

The Carolinian Conservation Impact Bond Model (See Figure 15) involves Carolinian Canada as the program facilitator, coordinating a portfolio of habitat projects with partner organizations and landowners to achieve quantifiable public benefits. The CIB involves partnering with local Indigenous communities to come together in ethical space and co-develop habitat projects and goals, recognizing the importance of Indigenous-led conservation. Initial capital investments in the CIB model are fronted by impact investors who fund the cost of the habitat work and receive back their principal plus a

THE CAROLINIAN CANADA CONSERVATION

IMPACT BOND MODEL

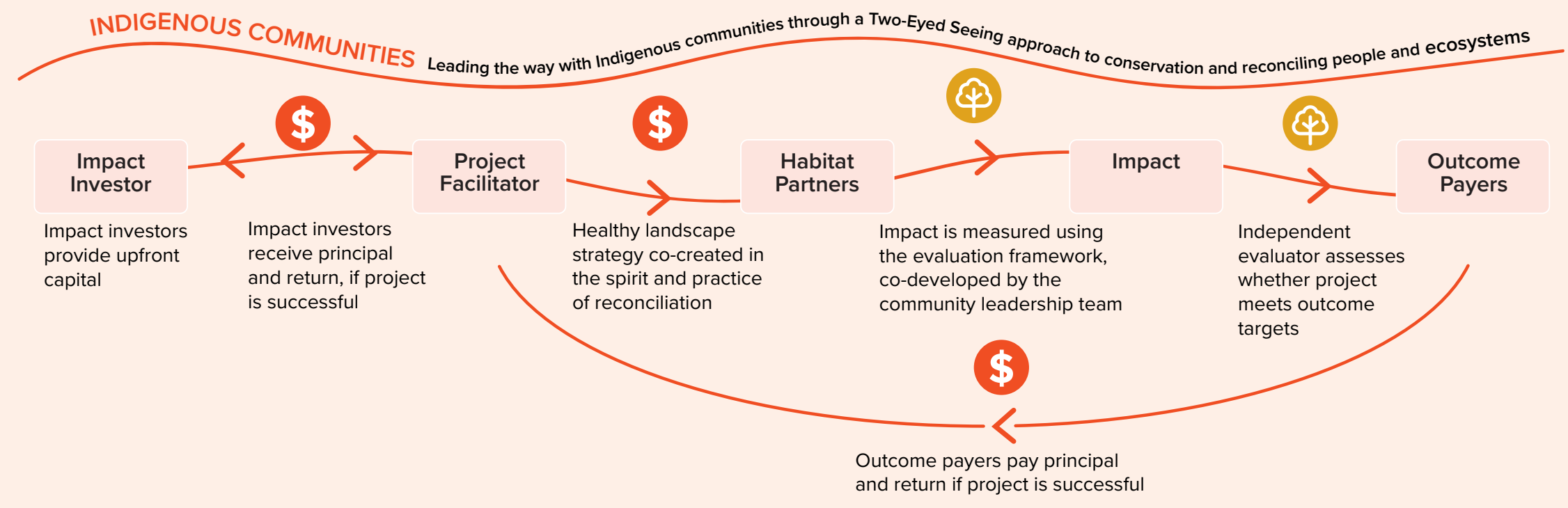

Figure 15: Carolinian Canada Conservation Impact Bond Model 
PART 2 CAROLINIAN CANADA CONSERVATION IMPACT BOND

return on investment if the agreed upon outcomes are achieved. Habitat partners perform the on-the-ground habitat improvement work based on best practices from Indigenous Traditional Ecological Knowledge and Western conservation science. Collectively, these habitat projects form a Healthy Landscape Portfolio. Third-party impact evaluators assess the impact of the CIB and determine whether the habitat projects collectively achieved desired outcomes, thus indicating whether or not investors are entitled to a return. If the project is deemed successful (i.e., the agreed upon outcomes are achieved), the outcome payers provide payment back to the impact investors, plus a return. If the outcomes are not achieved, payment is not required from the outcome payers. By making return on investment contingent on impact, partners within the model can ensure the funding is tied to local goals for a healthy landscape.

Phase one of the Carolinian Canada Conservation Impact Bond project is the Deshkan Ziibi Conservation Impact Bond (DZCIB) pilot, launched in March 2020. Phase two of the CIB is the Long Point Walsingham Conservation Impact Bond (LCIB) pilot project, set to launch in early 2022. Carolinian Canada's goal for these pilot projects is to solidify a scalable CIB model and use this model to build relationships for improving a total of 400 hectares $(1,000$ acres) of land in the Carolinian Zone by 2023 . The aim of the CIB model is to become a self-sustaining financial model supported by a community of people willing to work together in a process of advancing healthy landscapes and healing relations for the long-term.

As this report intends to support the scalability and replicability of the $\mathrm{CIB}$ model, the following sections will dive deeper into the design, development, and implementation of the DZCIB to date, with a focus on the design phase. The purpose of this section of the report is to tell the story of the DZCIB project and share this collaborative and innovative approach with others who may find the model beneficial to implement in their own settings. Since the DZCIB is a pilot project, revisions to the initial bond design based on lessons learned during implementation are expected. These lessons will be key to successfully scaling the CIB model in the future.

\section{The Deshkan Ziibi Conservation Impact Bond Pilot Project}

The CIB model has been further developed and refined concurrently with the design and implementation of the DZCIB. The DZCIB is a five-year pilot project that seeks to accelerate healthy landscapes, nature-based solutions, advance Indigenous reconciliation, and empower the human-nature relationship in southern Ontario. Included in the DZCIB pilot are 60 hectares (150 acres) of land in the Carolinian Zone. The DZCIB pilot project is a prototype of the CIB model and is structured as a legally binding loan with the impact investor. Outcome payer grants are legally bound to the achievement of specific outcomes, including benefits for pollinators, species at risk, and Canadians. Outcome payer payments are triggered by an impact report submitted by Carolinian Canada. In future iterations of the CIB model, payment will be triggered by a third-party audit of project successes and bound to specific outcome thresholds. The prototype structure of the DZCIB allows for the opportunity to pilot the $\mathrm{CIB}$ structure with lower risk for investors and to develop viable pay-for-success metrics and evaluation structures for future implementations. 
PART 2 CAROLINIAN CANADA CONSERVATION IMPACT BOND

\section{PARTNERS OF THE DESHKAN ZIIBI}

CONSERVATION IMPACT BOND
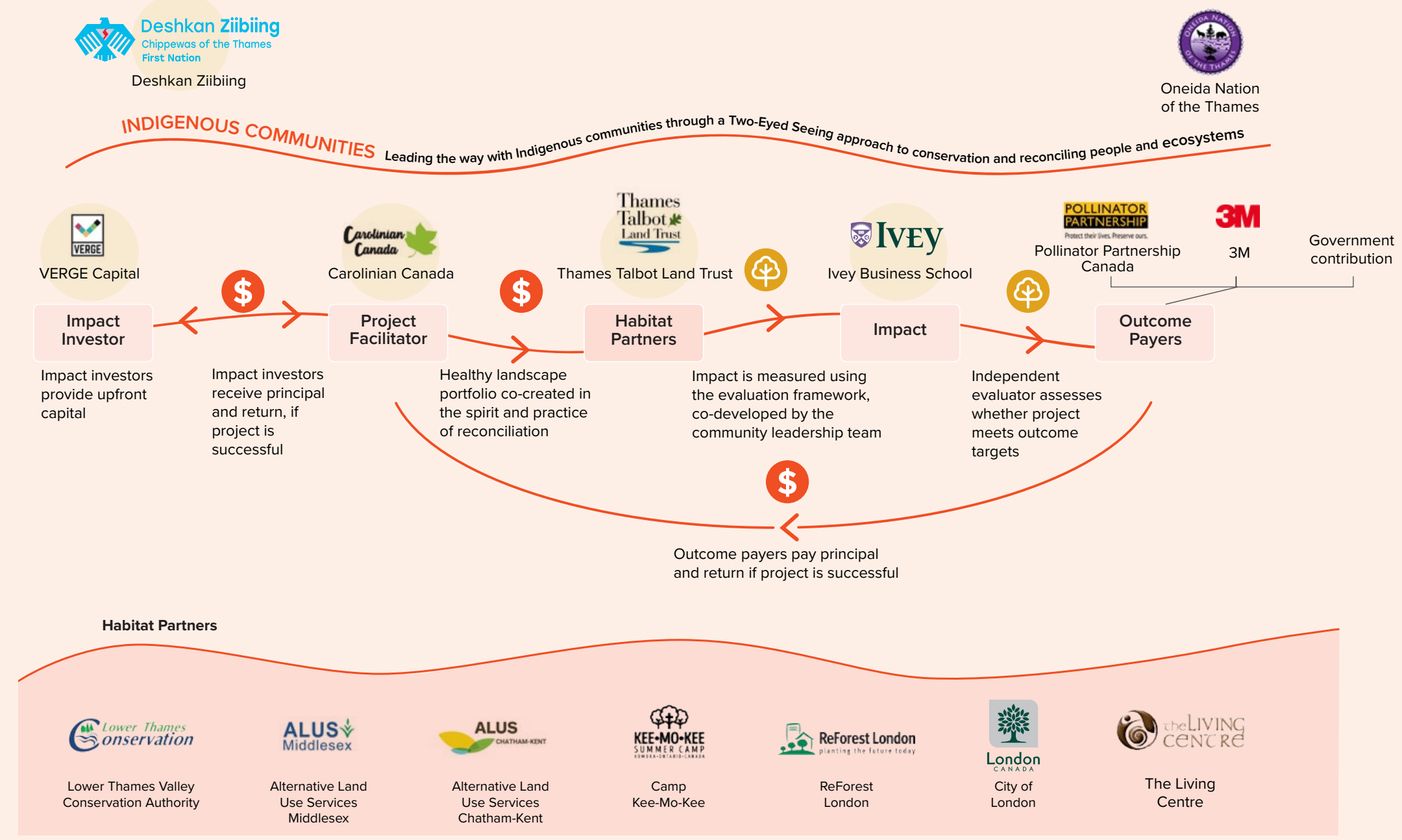

\section{LEADERSHIP TEAM}

MEMBERS

\section{Figure 16: Partners of the Deshkan Ziibi Conservation Impact Bond}


PART 2 CAROLINIAN CANADA CONSERVATION IMPACT BOND

\section{PARTNERS OF THE DZCIB}

DESHKAN ZIIBI CONSERVATION IMPACT BOND LEADERSHIP TEAM The Deshkan Ziibi Conservation Impact Bond Leadership Team (Leadership Team) consists of representatives from Carolinian Canada, VERGE Capital, Thames Talbot Land Trust, Deshkan Ziibiing (Chippewas of the Thames First Nation), and the Ivey Business School at Western University. The goal of the Leadership Team was to design the DZCIB to be locally adapted with community partners and experts from a variety of disciplines. This included defining impact goals for the bond, deciding on pay-for-success metrics upon which to evaluate impact, and participating in ongoing dialogue about the design of the DZCIB and related activities. The cross-sectoral and cross-cultural composition of the Leadership Team ensured representation of a variety of perspectives to reflect the variation of motivations, goals, and worldviews of broader partners of the CIB. The inclusion of Indigenous and non-Indigenous peoples on the Leadership Team was integral to the goal of taking a Two-Eyed Seeing approach to the design, implementation, and evaluation of the DZCIB.

The Leadership Team meets monthly. The initial meetings were held in-person at different partners' locations (e.g., Chippewas of the Thames First Nation, Ivey Business School, and VERGE Capital) and were subsequently moved online during the COVID-19 pandemic. In addition to the monthly meetings, external events and workshops for additional dialogue and learning were held on an ad-hoc basis.

\section{THE LANDSCAPE AND ITS INHABITANTS}

One of the goals of the DZCIB is to honour and recognize the agency of the land and its inhabitants - plants, animals, fungi, and humans alike. Through the implementation and evaluation of the DZCIB, listening to and sharing the stories of the Carolinian Zone going beyond human actors is crucial. The Leadership Team and project partners aim to provide space for and bring voice to the plant, animal, and other non-human actors who are often suppressed through Western value systems. These efforts also support one of the bond's goals of shifting from an anthropocentric to ecocentric lens.

PROGRAM FACILITATOR

Carolinian Canada is the program facilitator for the DZCIB. Their leadership is a key driving force behind the CIB model and DZCIB pilot. Carolinian Canada manages legal agreements and finances, coordinates a healthy landscape portfolio that convenes and mobilizes projects with habitat partners, meets with the Leadership Team, drives key decisions, and integrates the management of the CIB into their not-for-profit business model.

\section{INDIGENOUS COMMUNITIES}

Partnering with local Indigenous communities is integral to the CIB mission of healing Turtle Island and all our relations and advancing Indigenous Reconciliation. Indigenous peoples, and broader Indigenous communities, may lead, participate, and benefit in any or all roles within the CIB model. The DZ$\mathrm{CIB}$ involved engagement with local First Nations including Chippewas of the Thames First Nation, Oneida Nation of the 
PART 2 CAROLINIAN CANADA CONSERVATION IMPACT BOND

Thames, and Delaware Nation of Moraviantown. The DZCIB and CIB model were co-developed from cross-cultural conversations across partners with disparate worldviews. Those involved came to these engagements with open hearts and minds and with the acknowledgement that the Western science conservation paradigm has much to learn from Indigenous ecological knowledge, values, and respect for all of Creation. The inclusion of First Nations in the CIB model goes beyond consultation to active engagement in ethical space. These partnerships acknowledge Indigenous rights and land sovereignty, Indigenous contributions to land stewardship and conservation, and the cultural and relational significance of the land. The collaborative premise of the CIB is based on the idea that we can only achieve healthy landscapes, communities, and economies by working together across all sectors and cultures.

IMPACT INVESTORS

The initial capital investment for the DZCIB of CAD $\$ 130,000$ was provided by VERGE Capital. VERGE Capital is a social finance program of Pillar Non-profit Network that connects social enterprises with investors in their community. The DZCIB pilot project is a prototype bond, which means that financial agreements are not structured to be strictly tied to outcomes as they are in the CIB model. Instead, the DZCIB is structured as a legally binding loan through the VERGE Breakthrough Fund, which includes a 5\% interest rate and three-year repayment schedule. The outcome payer funding is legally bound to the achievement of specific outcomes, but thresholds and outcome reporting has a bit more leniency as the viability of the pay-for-success model is being tested and adapted through the prototype.

\section{HABITAT PARTNERS}

Habitat partners include a diverse range of groups and landowners conducting or hosting on-the-ground conservation work. The CIB model is designed to leverage existing programs by providing support through funding, connecting opportunities, and tracking impact. The CIB involves a breadth of different habitat projects, operating in both rural and urban spaces, with similar standards for habitat improvements. The habitat projects collectively comprise a Healthy Landscape Portfolio and are guided by the four main activities of Carolinian Canada's Healthy Landscape Strategy (save, steward, seed, and lead) which are adapted to meet local needs.

The habitat projects funded by the DZCIB were nominated by local partners invited through Carolinian Canada's network of habitat partners and landowners working towards ecosystem recovery. Habitat projects were chosen and evaluated based on impact metrics and project goals that were determined collaboratively by the DZCIB Leadership Team through early development stages, workshops, and continued dialogue.

Each project is unique to the partner involved and thus habitat partner agreements are made individually with each habitat partner. These agreements outline the goals of the project, based on Carolinian Canada's Healthy Landscape Portfolio, and specify the funds from the CIB that will be allocated to the project. As part of their habitat agreements, habitat partners are expected to provide a minimum of a one-to-one in-kind funding match to the CIB funding received. Habitat partner progress is tracked through tools such as the In the Zone Habitat Tracker, annual project reports, and ad hoc updates. 
Collectively, The Healthy Landscape Portfolio supports diverse land management goals including Indigenous, municipal, business, recreational, and ecotourism. A number of diverse habitat partners are involved in the DZCIB including: Chippewas of the Thames First Nation, Oneida Nation of the Thames, Thames Talbot Land Trust, Lower Thames Valley Conservation Authority, Alternative Land Use Services Canada, ReForest London, Camp Kee-Mo-Kee, the Living Center, and the City of London.

\section{The In the Zone Habitat Tracker ${ }^{237}$}

Since most of the land in the region is privately owned, ${ }^{238}$ landowners in the Carolinian Zone play an instrumental role in habitat sustainability. Carolinian Canada uses a community-based approach to equitably include all people who want to contribute to supporting healthy landscapes and the goals of the CIB. Habitat partners, landowners, volunteers, and community members are welcome to participate by logging their habitat projects using the In The Zone Habitat Tracker. This multi-partner platform, facilitated by Carolinian
Canada and WWF-Canada, connects and assists diverse landowners and communities to grow, steward, and measure healthy landscapes using "Big Picture" measures of landscape health and resilience, as well as localized impact metrics. This initiative combines ecology, technology, and behavioural science to empower thousands of landowners to steward their properties for healthy habitat and demonstrate how their efforts contribute to the holistic ecological health of the Carolinian Zone.

\section{OUTCOME PAYERS}

Outcome payers are community leaders that are committed to healthy landscapes because they value nature, ecosystem services, natural capital, green infrastructure, a functioning biosphere, and/or other valuable features provided by nature.
Any group or individual actor from the private or public sector can be an outcome payer including corporations, governments, foundations, non-profits, or a blend of any of the above. Outcome payers are responsible for covering the costs of the conservation projects, plus a premium, contingent on the achievement of project outcomes. Since outcome payers only pay once desired outcomes are achieved and other actors within the model are held accountable to agreed upon outcomes, they reduce their risk associated with achieving successful outcomes compared to the direct funding of conservation projects.

The outcome payers for the DZCIB include a blend of private and public sector organizations, a multinational corporation (3M Canada), government, and a non-profit (Pollinator Partnership). A three-year government grant for approximately CAD $\$ 150,000$ provided anchor funding to co-develop and initiate the CIB model and Healthy Landscape Portfolio. Pollinator Partnership contributed CAD \$4,500 and 3M Canada committed to CAD $\$ 150,000$ of philanthropic funding over three years, sourced from their corporate social responsibility division. Since the DZCIB pilot project is a prototype of the CIB structure, this funding was provided in the form of grants with payment legally bound to the achievement of specific outcomes, including benefits for pollinators, species at risk, and Canadians. For this pilot project, outcome payment is triggered by a Carolinian Canada report. In future iterations of the CIB model, outcome payment will be triggered by a third-party audit of project successes and bound to specific outcomes and thresholds. 


\section{Special Note on Outcome Payers}

There are a variety of motivations, realizable benefits, and goals which drive participation from outcome payers. Groups or individuals from the private or public sector may be interested in:

" Supporting conservation in the spirit and practice of reconciliation

》 Reaching net zero targets and offsetting greenhouse gas emissions from their operations by purchasing carbon credits from habitat projects

» Reducing nitrogen and phosphorus in water sources by improving farmer agricultural practices and enhancing vegetation along waterways

» Reducing risks of flooding and wildfires through protection of wetlands and forests
» Reducing the costs of supplying mandated services by protecting green infrastructure instead of building grey infrastructure

» Accelerating on-ground action for healthy landscapes and targeting their resources efficiently (e.g., through a coordinated network of established on-ground expert and community groups rural to urban)

» Supporting strategic community co-benefits on the landscape (e.g., nature-smart climate solutions, green jobs, parks, recreation, mental and physical health)

》 Switching to green purchases that boost local green business (e.g., native plant infrastructure)

» Connecting with funding matches to maximize their impact
Soliciting outcome payers is a crucial component of the CIB model. The CIB model includes a number of advantages to outcome payers that are likely to garner their interest in the structure of this financial instrument. First, financial and philanthropic risk to achieving successful projects is low because outcome payers do not have to pay until outcomes are achieved. Second, outcome payers can tie their funding to "real impact" since funding is directly linked to quantifiable impact metrics. Third, the flexibility of the CIB model allows outcome payers to have a role in selecting the outcomes they hope to achieve depending on their individual goals. While each outcome payer may value a certain aspect of "nature's contributions to people" (e.g., insurance companies and a reduced risk of flooding, transportation companies and net zero targets, health care and improved mental and physical well-being), the CIB acts as a mechanism to pool resources for shared goals on the landscape. 
PART 2 CAROLINIAN CANADA CONSERVATION IMPACT BOND

\section{EVALUATION AND RESEARCH PARTNERS}

Since the DZCIB pilot serves as a prototype bond, it did not involve independent evaluators to audit and determine outcome payment and investor return. During the DZCIB pilot, the Leadership Team has been developing the evaluation framework and audit trail for the CIB model to facilitate future implementations. The goal is for future CIB projects to be independently evaluated using the developed evaluation framework and to have investor return and outcome payer payments legally bound to outcome agreements.

It is also important to note that the DZCIB was not certified against third-party carbon, greenhouse gas, or biodiversity standards. As the CIB model develops, third-party standards and independent evaluations will be critical to communicating the credibility of the projects and protecting the buyer, sellers, and intermediaries.

An academic research team, led by Professor Diane-Laure Arjaliès from the Ivey Business School at Western University, engaged with the DZCIB project as part of the Leadership Team. Their work supported the design of the CIB model and implementation of the DZCIB pilot, including the financial structure and evaluation framework. The research team will stay on-board to help develop, scale, and study future phases of the CIB model in Canada. Notably, the team will be conducting an independent research assessment of the project that will be peer-reviewed. The research team was responsible for the preparation of this report and incorporated the feedback received from the rest of the DZCIB Leadership Team through the editing process.

The research team, along with other student projects, informed the development of the CIB model researching topics such as: Earth system science, conservation finance, Western and Indigenous worldviews, ecosystem service valuation, capitalism, colonialism, Indigenous history, decolonization, reconciliation, and indigenization. The CIB model is designed to integrate research and learning to continually improve understanding, efficiency, connections, and scaling of the model for best outcomes. As the model is scaled, other researchers will be invited to participate as diverse opportunities arise that warrant further exploration. 


\section{The Carolinian Canada Conservation Impact Bond Model and Deshkan Ziibi Pilot Project}

» The CIB model is a financial instrument aiming to address the conservation funding gap by engaging a diverse set of local partners mobilizing towards the common goal of accelerating healthy landscapes and reconciling people and ecosystems.

» The model involves an upfront investment and outcome payers which provide a return conditional on the achievement of impact metrics which were determined collaboratively with local partners.
» The DZCIB pilot project is a prototype of the CIB model that takes place on the traditional territories of the Deshkan Ziibiing in the Carolinian Zone. 


\section{Assessing the Impact of the Deshkan Ziibi Conservation Impact Bond}

\section{The Deshkan Ziibi Conservation Impact Bond: A Systems Approach}

With a birthplace in biology, the General Systems Theory proposes a transdisciplinary approach capable of understanding systems and their connections. ${ }^{239,240}$ Systems thinking has been used in numerous areas of knowledge, with particular attention to biological, ecological studies, and social studies.

Systems thinking unfolds a new understanding of complexity and avoids pitfalls of dualism and reductionism for understanding social systems. ${ }^{241} \mathrm{~A}$ system can be defined as a set of dynamically related elements with a defined purpose. ${ }^{242,243}$

Defined as a systems approach, the focus of systems to management sciences arose from the need for a holistic view to deal with complexity in organizational decisions. The systems approach was developed out of the need for complex explanations required by science. ${ }^{244}$ The goal was to embrace complexity by creating a science of "wholeness," representing a fundamental shift in providing a comprehensive weltanschauung (shared worldview), emphasizing relationships, and grounding technical rationality in a broader social, environmental, and cultural context.

A systems approach requires exploring the dynamics and interrelationships of different aspects of society, ${ }^{245}$ providing multiple perspectives, and helping to set priorities and solve challenges. With the new paradigm of sustainable development, organizations now must deal with significant social challenges that go beyond their organizational boundaries and require holism and systems thinking. Society needs to unfold complexity and address problems by understanding their interconnections, providing solutions to wicked problems and grand societal challenges.

The DZCIB represents a systemic initiative based on a multi-stakeholder co-creation project. In its essence, the project is embedded in systems thinking. It creates a powerful network of interactions to address a complex problem. Using a systems approach and an innovative framework, the DZCIB creates synergy and a shared worldview to the ecological crises we face today.

Noting that systems change approaches are rooted in the epistemologies of Western science, through which knowing is analytical compared to experiential as with Indigenous 
epistemologies, it is important to recognize the need to decolonize systems thinking to acknowledge cultural and spiritual perspectives in awareness-based systems change. ${ }^{246}$ Urban living has allowed us to further ourselves from natural systems. Reconnecting to Mother Earth is essential to understanding the systemic thinking that acknowledges the systems of life on Earth. ${ }^{247}$
In the process of decolonizing systems thinking, one must consider knowledge through one's senses, spiritual elements, interconnectedness of all forms of nature, and intertemporal ties to the past, present, and future. Relational Systems Thinking is an approach that seeks to work in a space between Indigenous and Western epistemologies which involves awareness-based systems centered around the idea of mutual benefit between humans, non-human beings, unborn generations, and Mother Earth as a whole. ${ }^{248}$ It involves a 'revitalization of human spiritual integrity', and connecting humans 'to themselves, to each other, to a sense of place, to a physical and spiritual involved', and understanding the system involved in these relational connections. ${ }^{249}$

\section{Using a Theory of Change Framework to Assess Impact}

The Theory of Change model (See Figure 17) aims to provide a framework for understanding the process and pathway for change within a particular context. This dynamic model reflects the various inputs, activities, and outputs associated with a project which seek to influence desired outcomes and big-picture impact. It is focused on mapping out the 'missing middle' and discovering the interim steps that are necessary to achieve the changes desired. ${ }^{250}$ By mapping out the flows of activities and impact, a Theory of Change is a useful tool to aid in assessing impact.

Impact assessments have considerable variability, due to the difficulty to calculate future effects of activities, the complexity of social issues, and the input of human bias. ${ }^{251}$ It is impossible to measure all the direct impacts of $\mathrm{CIB}$ activities without the use of assumptions and proxies. The traditional approach used in finance and accounting will prioritize metrics that can be best incorporated into a financial statement, however this does not align with many conservation targets.

In the context of the $\mathrm{CIB}$, the Theory of Change is meant to describe the mechanisms through which the CIB activities trigger change. While it is presented in a linear model for ease of understanding, many of the categories are interrelated and feedback loops exist among activities, outcomes, and impact. This model can be used to guide cash flows and provide a direction for the overall trajectory of CIB activities.

For the DZCIB, the Theory of Change model was developed through a series of conversations with relevant community 
PART 2 CAROLINIAN CANADA CONSERVATION IMPACT BOND

partners and workshops with the Leadership Team. This section will describe the desired impact of the bond and work backwards through the Theory of Change to discuss the outcomes, metrics, and project activities which support arriving at the desired impact. At any point in the DZCIB's development, the Theory of Change reflects a synthesis of existing knowledge around best practices for the carrying out of goals. As the implementation of the DZCIB takes place, the model will be refined to best reflect the mechanisms of the DZCIB which drive impact.

\section{IMPACTS}

The DZCIB aims to reconcile people and ecosystems to accelerate healthy landscapes including nature-based solutions, advance Indigenous reconciliation, and enhance community well-being in southern Ontario. The DZCIB's desired impact was developed through collaborative dialogue among the Deshkan Ziibi Leadership Team and other community partners. To understand how the DZCIB can achieve and evaluate this impact, the Leadership Team worked backwards through the Theory of Change model.

\section{OUTCOMES}

The Leadership Team developed five short- and medium-term outcome categories that guide the pathways towards the desired impact: connecting healthy habitat, connecting opportunities, connecting knowledge / circling and learning, connecting our hearts and minds, and connecting our bodies. The five categories were chosen as outcomes which collectively address the project's desired impacts. The outcome categories are interrelated with the understanding that a particular activity of the DZCIB may contribute to multiple outcomes and success in one category may enhance success in another. These five outcome categories serve as the DZCIB's evaluation pillars and will be described further below.

\section{CONNECTING HEALTHY HABITATS}

This outcome category / evaluation pillar takes an ecological lens to advance healthy landscape goals. Associated goals of this pillar include increasing habitat quality, quantity, commitment, and leadership with native plants that supports a range of nature-based solutions (e.g., climate-adapted landscapes, protected areas, wildlife corridors, biodiversity, greenhouse gas sequestration, canopy cover, groundwater infiltration and storage, ecosystem resilience, and native seed security, air quality, soil productivity, and eco-trails). This pillar also seeks to advance the application of Two-Eyed Seeing in habitat work through interweaving Western science, Indigenous ecological knowledge, and the teachings of nature. ${ }^{252}$

\section{CONNECTING KNOWLEDGE / CIRCLING AND LEARNING}

This outcome category / evaluation pillar takes a sociocultural lens to advance the goals of connecting knowledge / circling and learning and increase the number of people engaged in high-quality learning about the land. Circling is understood in this context as a non-hierarchical and continuous process of learning. Associated goals of this pillar include increasing intergenerational learning, cross-cultural learning, eco-literacy, land-based learning, understanding of Indigenous history and wisdom, and revitalizing local Indigenous languages. 
Arjaliès: Deshkan Ziibi Conservation Impact Bond

Inputs

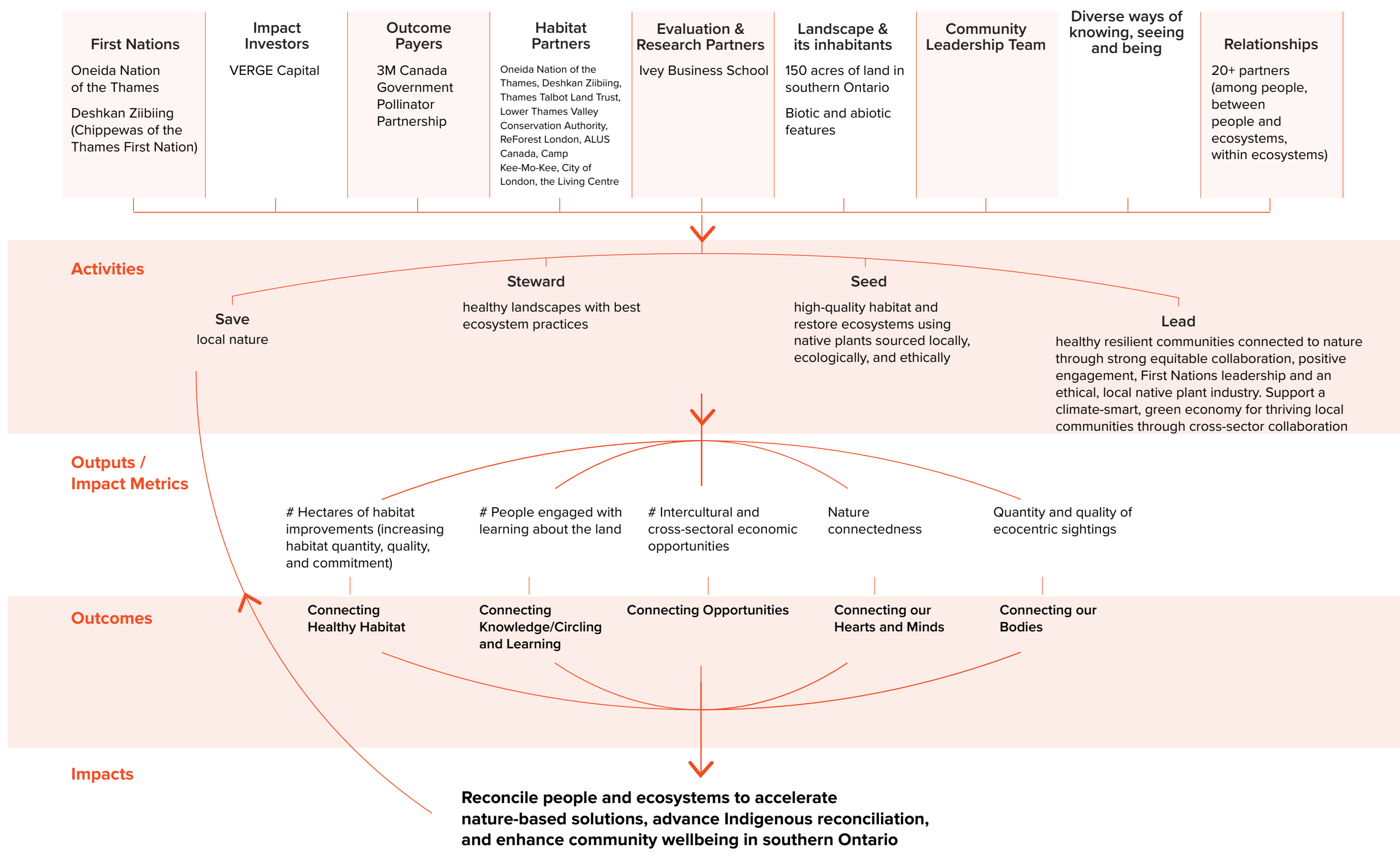

Figure 17: Deshkan Ziibi Conservation Impact Bond Theory of Change

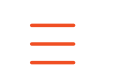


PART 2 CAROLINIAN CANADA CONSERVATION IMPACT BOND

\section{CONNECTING OPPORTUNITIES}

This outcome category / evaluation pillar takes a sociocultural lens to advance the goals for increased economic opportunities that improve landscape health. The aim of this pillar is to align economic incentives with desirable ecological outcomes for humans and non-humans who are living and working on the land. Associated goals of this pillar include intercultural and cross-sectoral economic opportunities, implementing ecosystem service valuations and supporting Indigenous, native plant, agriculture, ecotourism, and other regenerative economic opportunities.

CONNECTING OUR HEARTS AND MINDS

This outcome category / evaluation pillar takes an overlapping sociocultural and ecological lens to advance the goals of mentally, emotionally, and culturally connecting people with ecosystems. Associated goals include enhancing cultural health, community ceremonies and traditions, and relationships among people and between people and ecosystems. This pillar intends to support self-determination and create space for the people of this region to thrive based on their own values and vision.

CONNECTING OUR BODIES

This outcome category / evaluation pillar takes an overlapping sociocultural and ecological lens to advance the goals of physically connecting people with ecosystems. This category also seeks to report on the well-being of non-human relations on the land. For example, looking at whether the eagles are returning to the land, the presence of monarch butterflies, the number of birds nesting, etc. Associated goals include shifting people's lenses from anthropocentrism to ecocentrism, enhanced ecosystem relations, increasing food security, access to traditional medicines, and access to land. This pillar also intends to support self-determination and create space for the people of this region to arrive at what it means for them to thrive based on their own values and vision.

Together connecting our hearts and minds and connecting our bodies seek to report on all the relationships supported by the DZCIB. These include relationships among people, between people and ecosystems, and within ecosystems.

\section{"Restoring land without restoring relationship is an empty exercise. It is relationship that will endure and relationship that will sustain the restored land."}

Robin Wall Kimmerer ${ }^{253}$ 
PART 2 CAROLINIAN CANADA CONSERVATION IMPACT BOND

CONNECTING OUTCOMES TO IMPACT

\#2 Connecting Knowledge

\#1 Connecting Healthy Habitat

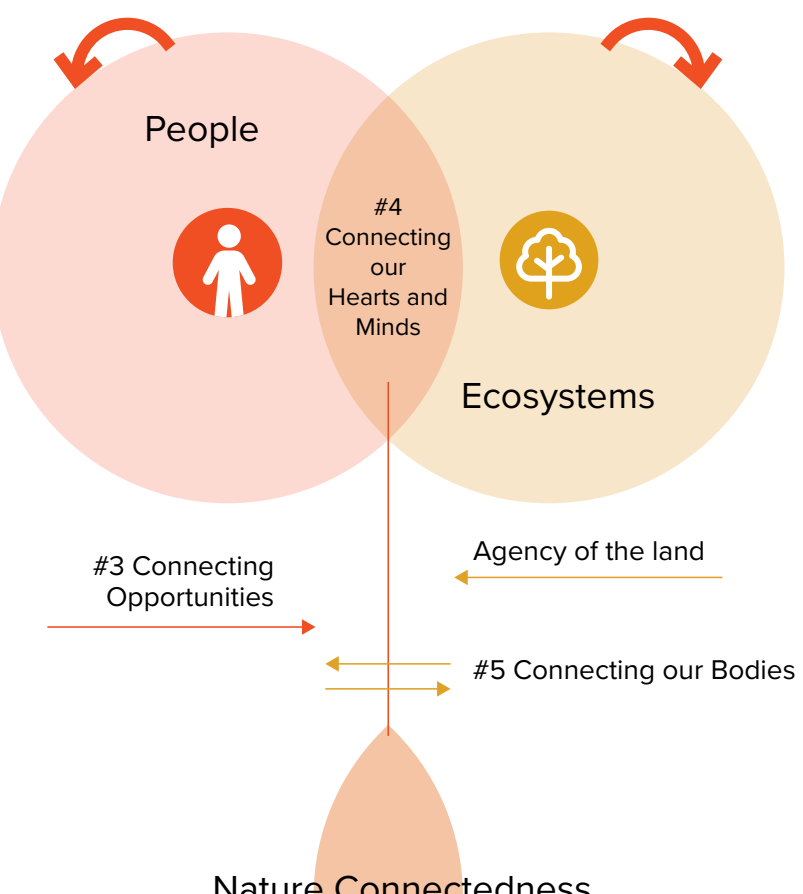

Nature Connectedness
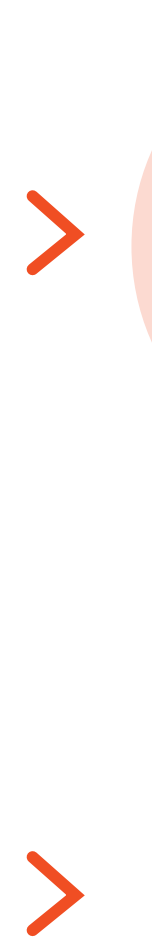

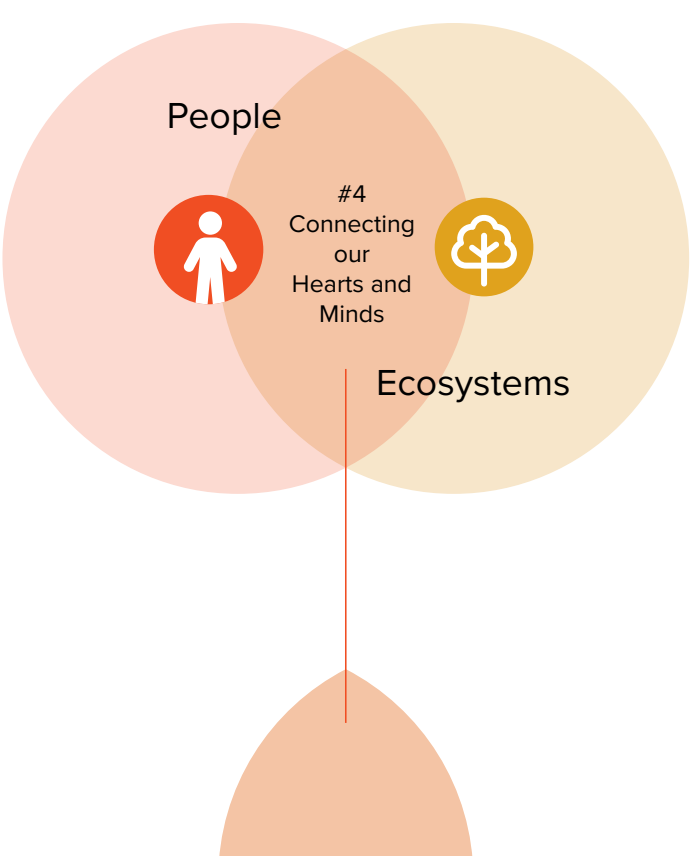

Nature Connectedness

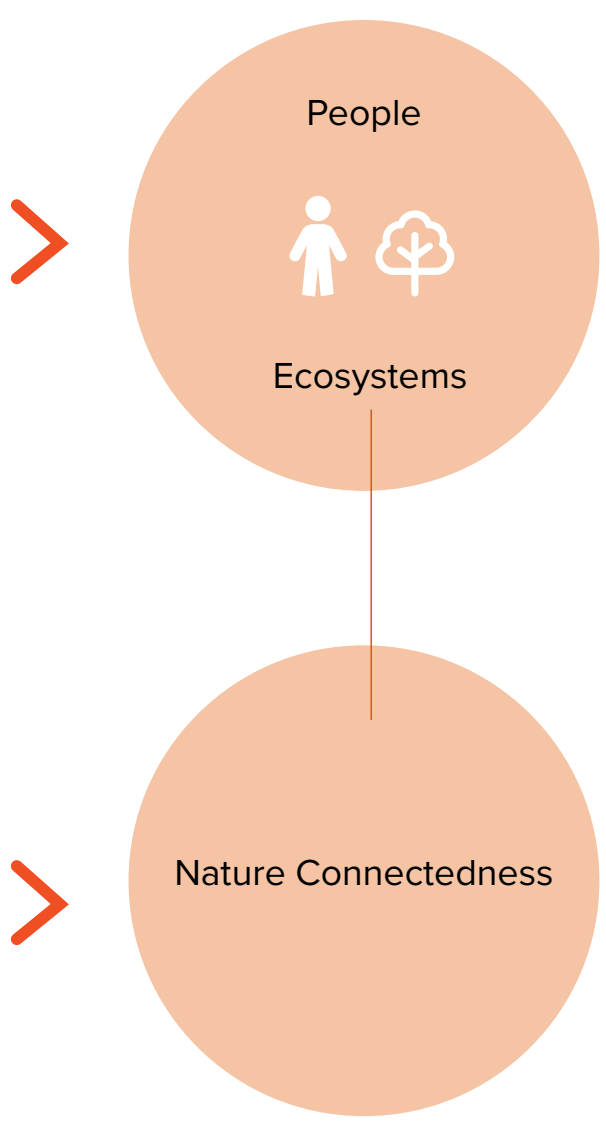

Figure 18: Connecting Outcomes to Impact: The Process of Reconciling People and Ecosystems 


\section{Connecting Outcomes to Impact}

Figure 18 aims to provide a visual representation of the connections between the outcome categories and the impacts that the DZCIB model is pursuing. The three images aim to capture the process of reconciling people and ecosystems and the role of the outcome categories in advancing this process.

The image on the left demonstrates the ways in which the five outcome categories interrelate and contribute to the process of reconciling people and ecosystems. The Connecting Healthy Habitat category supports a positive feedback loop of enhancing ecosystems and their resilience. Connecting knowledge / Circling and Learning supports a positive feedback loop for increasing human knowledge about the ecosystems in which they are embedded through people sharing lessons and wisdom across cultures and generations.
Connecting Opportunities contributes to bringing people closer to ecosystems by creating economic opportunities for people who steward the ecosystems in which they live and work. Connecting our Bodies contributes to bringing people closer to ecosystems and vice versa by shifting from an anthropocentric to ecocentric lens, observing non-human land relations, and increasing physical engagements with the ecosystem. Connecting our Hearts and Minds is represented by the growing overlap between people and ecosystems in the figure. It represents the strengthening of the cognitive, emotional, and cultural connections with ecosystems and enhanced relationships among people and between people and ecosystems through engagements with all categories. Lastly, this model recognizes and leaves space for the agency of ecosystems to respond to the efforts of enhancing relations. This recognizes the embeddedness of people in ecosystems and that components of this process are not in the direct control of people. For example, people can plant a seed and provide it with the water and nutrients that they believe it needs, however, the biotic and abiotic factors of the ecosystem must align to create a conducive environment for growth and the plant itself must do the growing.

For additional clarification, representing people and ecosystems as two separate circles in this figure does not intend to communicate that people are separate from the ecosystems in which they are embedded. Instead, these two separate circles aim to represent the spectrum of cognitive decoupling between people and ecosystems and the subsequent physical separation that often ensues.

\section{OUTPUTS / IMPACT METRICS}

In the process of developing the metrics on which to evaluate the success of the DZCIB in achieving its desired impact, the Leadership Team developed a list of metrics that fell into the five holistic outcome categories/evaluation pillars described above (See Table 2). These metrics were selected with the support of the Leadership Team's diverse areas of expertise including ecology, conservation science, finance, accounting, and Indigenous knowledge.
Since the DZCIB is a pilot project of the broader Carolinian Canada CIB, the metrics have gone through multiple iterations and remain dynamic with ongoing collaborative input from partners, both during the design and implementation phases. Future implementations of the CIB model can leverage the lessons learned from the DZCIB pilot to accelerate the metric selection and stabilization process, while remaining locally adapted to community goals. 
Arjaliès: Deshkan Ziibi Conservation Impact Bond

PART 2 CAROLINIAN CANADA CONSERVATION IMPACT BOND

TABLE 2: EVALUATION PILLARS AND IMPACT METRICS

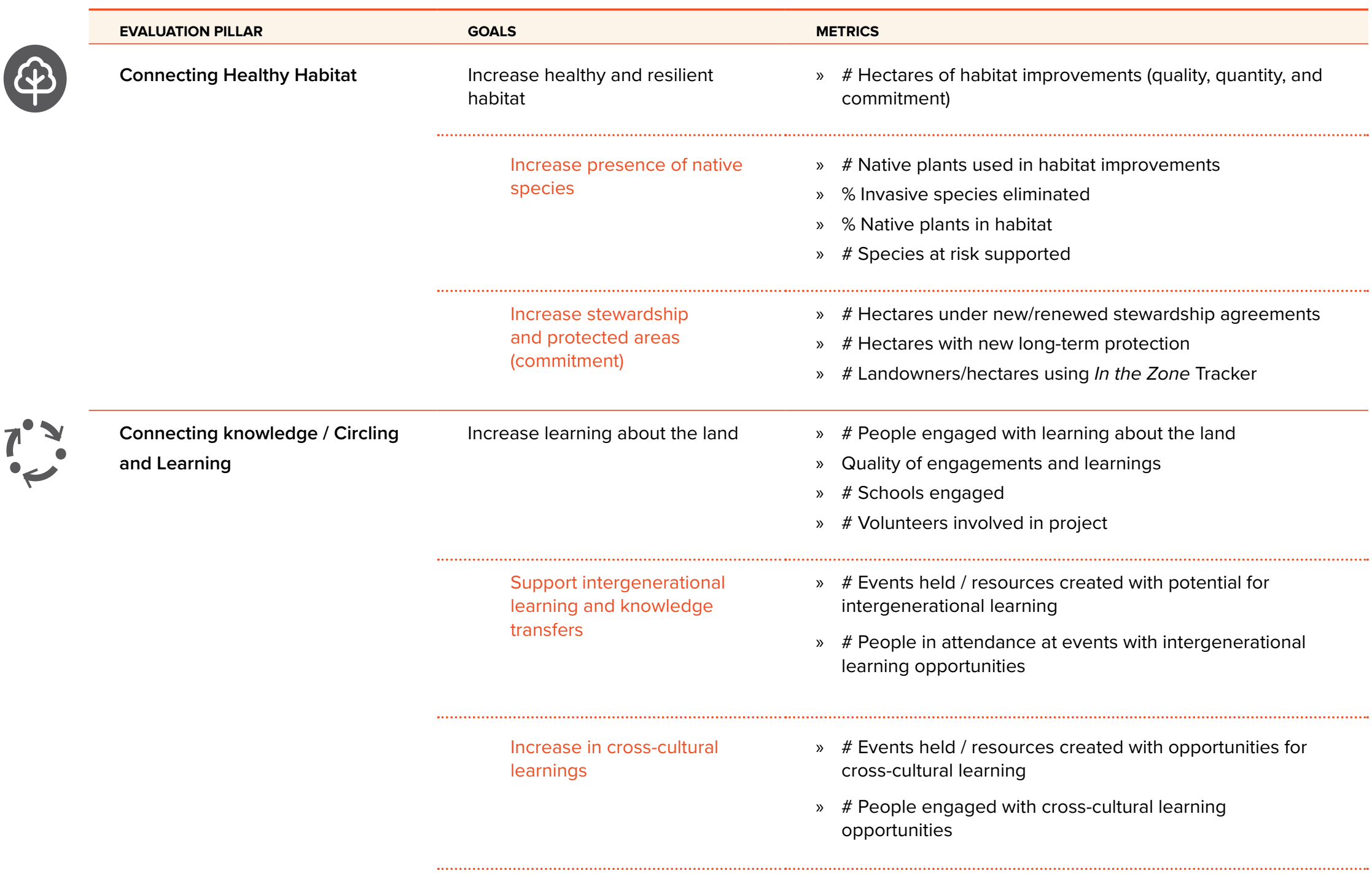


Deshkan Ziibi Conservation Impact Bond Project: On Conservation Finance, Decolonization, and Community-Based Participatory Research, Vol. 1 [2021], Iss. 1, Art. 1

PART 2 CAROLINIAN CANADA CONSERVATION IMPACT BOND

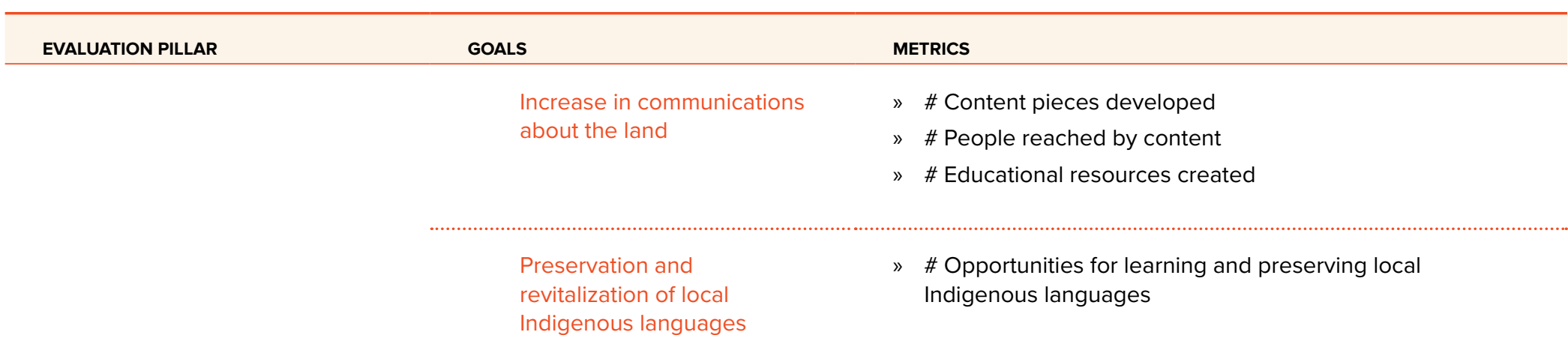

Connecting Opportunities

\section{Increase in economic}

opportunities for green and just

economy and healthy landscapes
» \# Opportunities for intercultural and cross-sectoral collaboration

» \# Jobs enhanced

» \# Training opportunities

» \# Businesses supported Quality of opportunities

» \# Alternative revenue innovations
Increase native seed security/ protect genetic resources

Increase in Indigenous opportunities in traditiona territories
» \# Hectares of native seed orchards planted (climateadaptive living seed banks)
" \# Indigenous-led projects

» \# Indigenous co-created projects

» \# Indigenous people employed or trained through the project

" \# Indigenous businesses supported

» \# Opportunities created in ethical space that consider jurisdiction, financial solutions, capacity development and cultural keystone species in the spirit and practice of reconciliation 
Arjaliès: Deshkan Ziibi Conservation Impact Bond

PART 2 CAROLINIAN CANADA CONSERVATION IMPACT BOND

Connecting

Opportunities

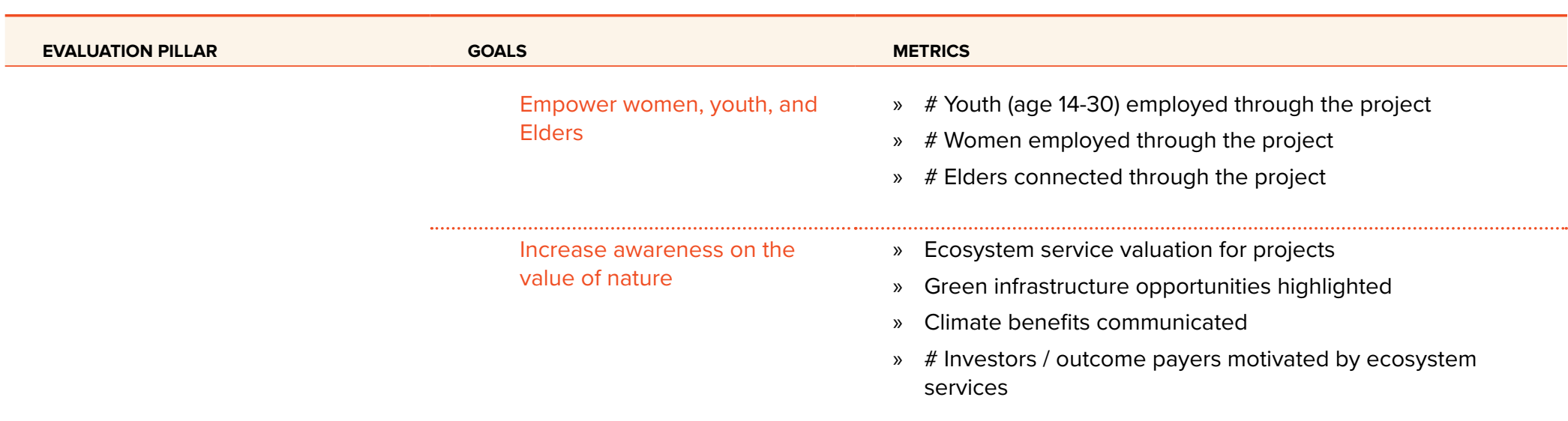

CONTINUED

Increase in tourism
opportunities
Increase in farming
opportunities

» \#/types of sectors benefiting from projects

»Project benefits for tourism

Connecting our Hearts and Minds opportunities
Enhancing human-nature relationships

Increased cultural health and quality of life
» Project benefits for farming

» Level of nature connectedness

»Cultural health indicators

» Level of happiness and other community-driven well-being indicators

» Relations assessment

Protection/increase of community traditions

» \# Community traditions and traditional stewardship practices

» \# People engaged in community traditions and traditional stewardship practices

» \# Culturally significant species enhanced 
Deshkan Ziibi Conservation Impact Bond Project: On Conservation Finance, Decolonization, and Community-Based Participatory Research, Vol. 1 [2021], Iss. 1, Art. 1

PART 2 CAROLINIAN CANADA CONSERVATION IMPACT BOND

\begin{tabular}{|c|c|c|}
\hline EVALUATION PILLAR & GOALS & METRICS \\
\hline \multirow[t]{5}{*}{ Connecting Our Bodies } & $\begin{array}{l}\text { Ecocentric well-being (enhancing } \\
\text { relationships among non-human } \\
\text { nature) }\end{array}$ & $\begin{array}{l}\text { \# Ecocentric sightings or changes observed } \\
\text { "Quality of ecocentric sightings } \\
\text { Observations of relationships among non-human nature } \\
» \quad \text { \# Communities/groups/people participating }\end{array}$ \\
\hline & $\begin{array}{l}\text { Increase food security and access } \\
\text { to traditional medicines }\end{array}$ & $\begin{array}{l}\text { " \# Communal gardens } \\
» \text { \# Food or pollinator gardens } \\
» \text { \# Medicine gardens } \\
» \text { \# People growing their own food }\end{array}$ \\
\hline & Increase shelter and housing & » \# New shelter opportunities \\
\hline & Increase access to land & $\begin{array}{l}\text { " \# Sites with access to land for traditional practices (hunting, } \\
\text { fishing, gathering, ceremony) }\end{array}$ \\
\hline & & » \# Sites with public access \\
\hline
\end{tabular}

\section{Using Impact Metrics to Assess Holistic Impact}

The goal of the metric development for the DZCIB involves assessing holistic impact which includes both quantitative and qualitative metrics, leaving space for lived experiences and individual stories, and leveraging both Indigenous and Western knowledge on conservation. By considering a breadth of experiences in, and values of, nature when developing a holistic set of impact metrics, the evaluation process of the DZCIB aims to honor plural valuation theories and implementation methods.
The impact evaluation is a critical component for attracting outcome payers and impact investors by being able to measure and communicate both the financial and non-financial returns facilitated by the bond. For some groups that are rooted in instrumental value, including businesses and investors, communicating impact through a monetary lens is helpful. This includes quantifying the value of ecosystem services such as carbon sequestration, stormwater management, biodiversity enhancement, improved air and water quality, and enhanced community well-being. For many, the value of healthy ecosystems exceeds quantification through a monetary lens. These metrics aim to communicate impact to a breadth of partners involved. 
The metric selection process for the DZCIB aims to incorporate Indigenous values by measuring impact beyond economic value of the exploitation of the land and, instead, honoring a breadth of experiences of the land. For example, the inclusion of metrics which track opportunities for traditional ceremonies taking place on the land honors the cultural value of land as central to land-based teachings, traditional activities, and ceremonial practices. The inclusion of ecocentric metrics is important to honor Indigenous values of nature and honor nature's agency and right to exist independent of the human benefit of nature.

The intertemporal considerations of the DZCIB are another element that benefits from the integration of Indigenous and Western value systems. Evaluating impact through the selection of metrics which measure holistic health benefits into the long-term honor Indigenous principles of relatedness and responsibility to relations in the past, present, and future. The impact evaluation of the DZCIB aims to reconcile long-term and short-term perspectives by taking a long-term view and bringing it to focus in the short- and medium- term.

The localized development and selection of metrics is an integral part of impact assessment within the DZCIB model. Consulting local communities and key local partners in developing the metrics for DZCIB honors local knowledge and connection between people and place. In scaling the CIB model to other areas, one must adapt metrics to local communities to honor the essence of what the DZCIB impact metrics aim to achieve. The goal of the impact metrics is to be flexible enough for local partners to adopt metrics that best meet the conditions of their local community environment, yet still are holistic and capture the essence of the DZCIB model by addressing the five categories of impact evaluation. In other contexts, different metrics may be selected as pay-for-success metrics based on the conditions of the local environment and the local partners involved in the development of the bond. However, the impact goals and five pillars of evaluation for holistic impact will remain consistent across the Carolinian Canada CIB model.

\section{SELECTED PAY-FOR-SUCCESS METRICS}

The pay-for-success metrics are the metrics that will be assessed and audited to determine how much outcome payers will pay for the outcomes created by the project and, subsequently, if investors will receive their principal plus a return. The above listed metrics were all brainstormed through group workshops and are important to assess the holistic impacts of projects. However, in order to develop the pay-for-success component of the CIB financial model, the number of metrics to be assessed for the financial instrument were reduced to five core metrics.

When financing around outcomes it can be tempting to develop evaluation processes that measure a wide variety of potential outcomes and impacts from the project. However, by trying to capture many diverse impacts and create a wide scope of evaluation, transaction costs increase. The goal for outcomes-based finance is to select pay-for-success metrics 
PART 2 CAROLINIAN CANADA CONSERVATION IMPACT BOND

that are as simple as possible while remaining true to the holistic strategies developed by the local Leadership Team. One way to do this is to select proxy metrics that are associated with a variety of co-benefits. Therefore, if the proxy metric is achieved, it can be reasonably assumed that desired outcomes were achieved, following the flow of impact in the Theory of Change.

For the DZCIB, one metric from each outcome category was selected as a benchmark metric against which project success, and thus, outcome payment and return on investment, will be determined. These pay-for-success metrics were selected by the Leadership Team in a consensus-style

\section{TABLE 3: SELECTED PAY FOR SUCCESS METRICS OF THE}

DESHKAN ZIIBI CONSERVATION IMPACT BOND decision-making format. In addition to the metric-selection dialogue that took place in a group setting, partners were individually interviewed to determine the feasibility and holistic reach of the five selected pay-for-success impact metrics.

These five pay-for-success metrics encompass land-based, group-based, and individual-based assessments of impact. The combination of metrics used in evaluating the success of the DZCIB seek to broaden and strengthen relationships among people and between people and ecosystems.

The following pay-for-success metrics were selected for each category:

\section{EVALUATION PILLAR}

Connecting Healthy Habitat

\section{METRICS}

\# Hectares of habitat improvements (increasing habitat quantity, quality, and commitment)

\section{JUSTIFICATION FOR SELECTION}

This metric was selected because it reports on the extent of native habitat quality and quantity improvements supported by the DZCIB. This metric also allows for a diversity of activities that contribute to enhancing habitat quality, quantity and commitment including protection (e.g., land securement, conservation easements, Indigenous Protected and

Conserved Areas, protected area assessments for Canada Target 1), stewardship (e.g., removing invasive species or other best ecosystem practices), restoration and planting of native plants (e.g., create wild habitat, cultural habitat, or highquality green infrastructure). Additionally, this metric serves as a proxy for co-benefits associated with ecosystem services (e.g., climate-adapted landscapes, including greenhouse gas sequestration, stormwater management, biodiversity enhancement, soil protection, and increased ecosystem resilience) 
Arjaliès: Deshkan Ziibi Conservation Impact Bond

PART 2 CAROLINIAN CANADA CONSERVATION IMPACT BOND

\begin{tabular}{|c|c|c|}
\hline EVALUATION PILLAR & METRICS & JUSTIFICATION FOR SELECTION \\
\hline $\begin{array}{l}\text { Connecting Knowledge / } \\
\text { Circling and Learning }\end{array}$ & $\begin{array}{l}\text { \# People engaged with learning } \\
\text { about the land }\end{array}$ & $\begin{array}{l}\text { This metric was selected because it reports on the quantity } \\
\text { of people engaged and quality of those engagements } \\
\text { facilitated by the DZCIB. The quality of learning aims to be } \\
\text { assessed through the content of the learning as well as the } \\
\text { reflections and testimonies provided by participants. Learning } \\
\text { events could be land-based, intergenerational, cross-cultural, } \\
\text { historical, and/or ecocentric. Examples of events could } \\
\text { include an Indigenous-led workshop on habitat restoration } \\
\text { in the spirit of reconciliation or an ecologist-led workshop on } \\
\text { native plant species. }\end{array}$ \\
\hline
\end{tabular}

Connecting Opportunities \# Intercultural and cross-sectoral economic opportunities
This metric was selected in recognition of the importance of economic opportunities which seek to connect groups across diverse sectors and cultures to facilitate knowledge sharing and develop opportunities for mutual growth in supporting a green and just economy. Examples of such opportunities could include green jobs created, businesses supported, collaborations among Indigenous groups, municipalities, farmers, etc.

\section{Connecting our Hearts and}

Minds
Nature connectedness

Nature connectedness refers to the extent to which people feel connected with nature. This connectedness can include affective, cognitive, and experiential dimensions. This metric was selected to acknowledge the importance of reconciling and strengthening the relationships between people and nature culturally, spiritually, and emotionally. It also allows for the project to report on impacts related to enhancing relationships among people and between people and ecosystems. 
EVALUATION PILLAR

\section{Connecting our Bodies}

METRICS

Quantity and quality of ecocentric sightings

\section{JUSTIFICATION FOR SELECTION}

This metric was selected because it captures impact through an ecocentric lens. It acknowledges the autonomy of nature and the meaningfulness of local ecological indicators in evaluating broader system health and ecological crises. This metric allows for the project to report on impacts related to enhancing relationships among non-humans within ecosystems. Examples include ecological health indicators including those based on Indigenous local knowledge, culturally significant species identification, and observation of non-human interactions and impact within ecosystems.

\section{Acknowledging the Agency of Nature through the use of Ecological Health Indicators}

The challenge of quantifying impact often leads to investors selecting 'hard' metrics as proxies upon which to measure impact. These 'hard' metrics are desirable for their quantitative

features making them more easily understood in the context of a balance sheet. Although the breadth and complexity of issues such as globa crises are difficult for humans to conceptualize, the use of ecological indicators can allow for an understanding of these global issues, and their consequences, on a local scale. The use of local ecological indicators as a sign of global ecological conditions is a practice embedded in the Traditional Ecological Knowledge of Indigenous peoples who have inhabited their local environments for thousands of years.
The connections of local indicators to global issues may be missing for some organizations for a variety of reasons. First, limited resources may lead to attention on only the strongest indicators, which influences what issues an organization may perceive to be most salient. Second, organizations may have a hard time logically linking indicators that are distributed over geographical space and/or time. Third, they may be challenged to adopt indicators if they do not fit into pre-existing mental maps prominent in the organization. Organizations that are able to overcome these challenges and connect local cues over time and space can understand the indications of a global underlying issue. ${ }^{254}$
The most meaningful indicators of environmental change are available on a site-to-site basis, subject to natural variation. Due to the devastating social, economic, and health implications for human and non-human populations of environmental degradation, understanding how to meaningfully understand the extent of global crises, in a local context, is important. One example of the use of local ecological indicators is the Denesoline of Lutsel K'e Dene First Nation.

The Denesoline of Lutsel K'e Dene First Nation in the Northwest Territories use traditional indicators, such as the body condition and composition of various fish species, native animal population levels, and land and water quality, ${ }^{255}$ 
to communicate changes in the health of the broader ecosystem. The Denesoline take an integrated approach to holistic ecosystem evaluation, which is indicative of the complex changes felt by their community. This approach has the potential to be integrated with resource management methods and can be used by governments, corporations, or any organization aiming to evaluate ecosystem quality. Ecological health indicators have been insufficiently incorporated

in Western decision-making processes, but hope is provided by a Two-Eyed Seeing approach, an integration of traditional Indigenous knowledge (e.g., awareness of ecological health indicators) with Western knowledge (e.g., conservation science), to evaluate and implement change. This can be envisioned as someone viewing the world through both of their eyes: using the strengths of each where appropriate and regarding both as equal. Thus, Two-Eyed Seeing aims to recognize the value of both Indigenous and Western worldviews, avoiding knowledge domination and assimilation. ${ }^{256}$
The metrics within the DZCIB that have been deemed most impactful are therefore not the 'hard' and easily financialized metrics, but rather those that strive to provide co-benefits, connect communities with one another, and connect individuals with the land. These connections will provide the added benefit of introducing radical change to the collective consciousness.

\section{Evaluating the Success of the} DZCIB

The five selected pay-for-success metrics will be audited by an independent evaluator who was not involved in developing the $\mathrm{CIB}$ model. The independent evaluator will assess the success of the overall $\mathrm{CIB}$ project on the basis of the five pay-for-success metrics. The role of the auditor is to determine the level of success of the project for the purpose of determining the return on investment that should be paid to the impact investors based on the achieved outcomes.
Not all habitat partners are required to incorporate all five payfor-success metrics into each project; each individual habitat partner agreement will outline the goals of that specific project. However, the accumulation of the habitat partner projects funded by the DZCIB should cover impact across the five evaluation pillars to ensure holistic success of the bond. In future implementations of this model, minimum and maximum thresholds will be set during initial agreements with impact investors and outcome payers to evaluate the performance of each outcome category and ensure holistic impact. For the DZCIB pilot, these thresholds have yet to be set; the data from the implementation of DZCIB will be used to set thresholds for future iterations of the CIB model. 


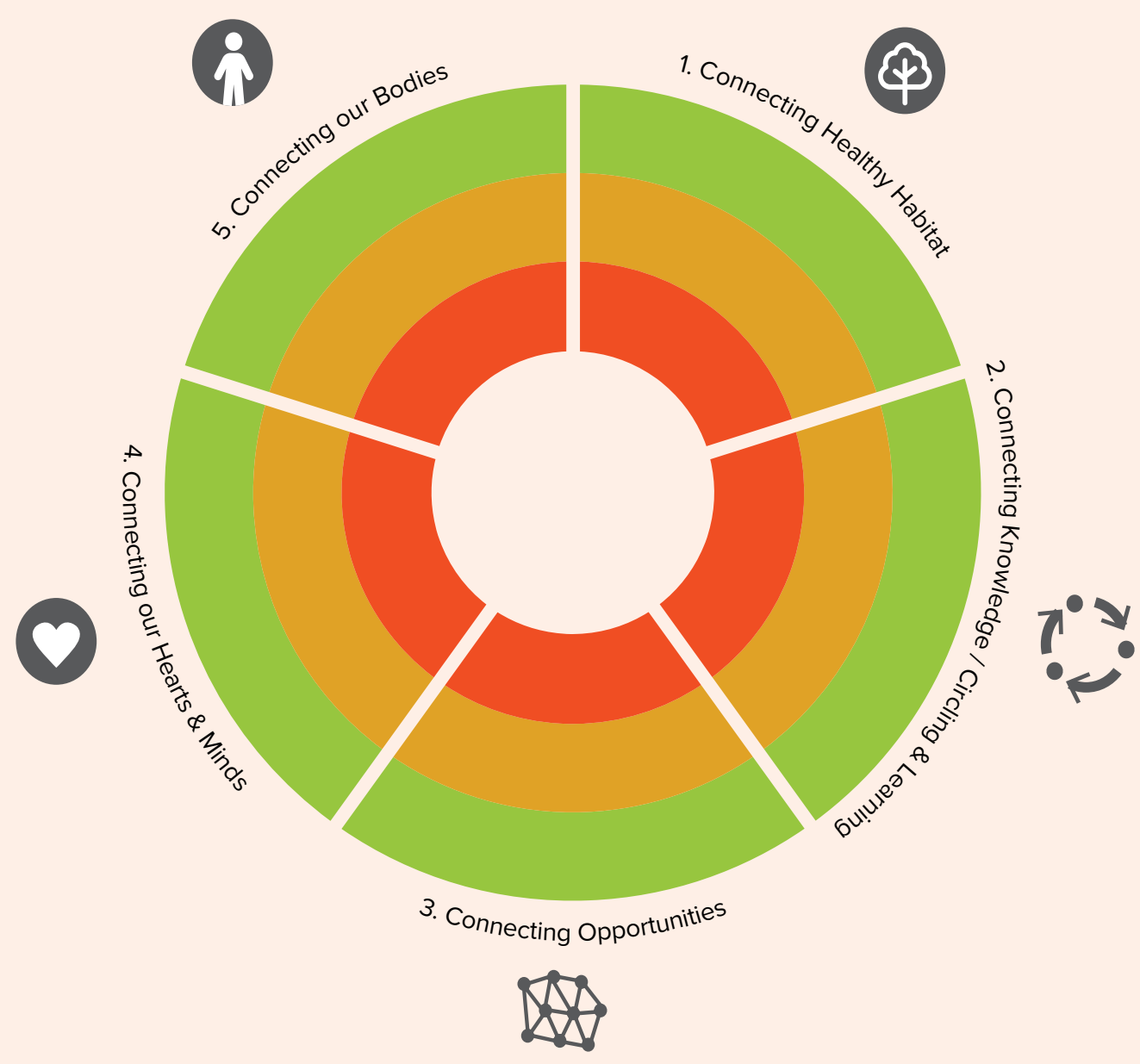

Figure 19: Evaluation Pillars of the DZCIB and a

Suggested Model to Visualize Thresholds of Impact

\section{Suggested Model for Assessing the Evaluation Pillars of the DZCIB}

Figure 19 is a suggested visual for the DZCIB outcome categories/evaluation pillars with space for thresholds to be set and visualized for the purpose of performance evaluation. This visual is colour-coded based on the following scheme: the green zone representing maximum threshold impact targets were achieved, the orange zone representing minimum threshold impact targets were not achieved, and the yellow zone representing targets achieved met minimum thresholds, but not maximum thresholds. This system can aid in project evaluation to place the project outcomes on this diagram within the appropriate colour zone for each respective evaluation pillar.

\section{Examples of DZCIB Pilot Habitat Projects and Impact to Date}

From 2019 to July 2021, the DZCIB pilot has supported 53 healthy landscape projects in the Deshkan Ziibi region resulting in numerous ecological, sociocultural, and economic benefits. To implement these 53 projects, Carolinian Canada developed agreements and partnerships with nine habitat partners: Chippewas of the Thames First Nation, Oneida Nation of the Thames, Thames Talbot Land Trust, Lower Thames Valley Conservation Authority, ALUS Canada, City of London, ReForest London, Camp Kee-Mo-Kee, and The Living Center. As part of these agreements, each habitat partner provided a significant funding match.

Thames Talbot Land Trust (TTLT) completed four habitat projects ranging from habitat creation and enhancement to community leadership. One of these projects occurred in February 2020 at Hawk Cliff Woods. At this site, TTLT removed invasive species from 22 acres of native meadow habitat and hosted 3M Canada, the DZCIB's outcome payer, for a seed collection event in the fall. 3M Canada's team of volunteers helped gather more than 15 buckets of seeds to grow native plants in southern Ontario. These seeds were then used at another one of TTLT's sites, Joany's Woods, to enhance native meadow plant species. 


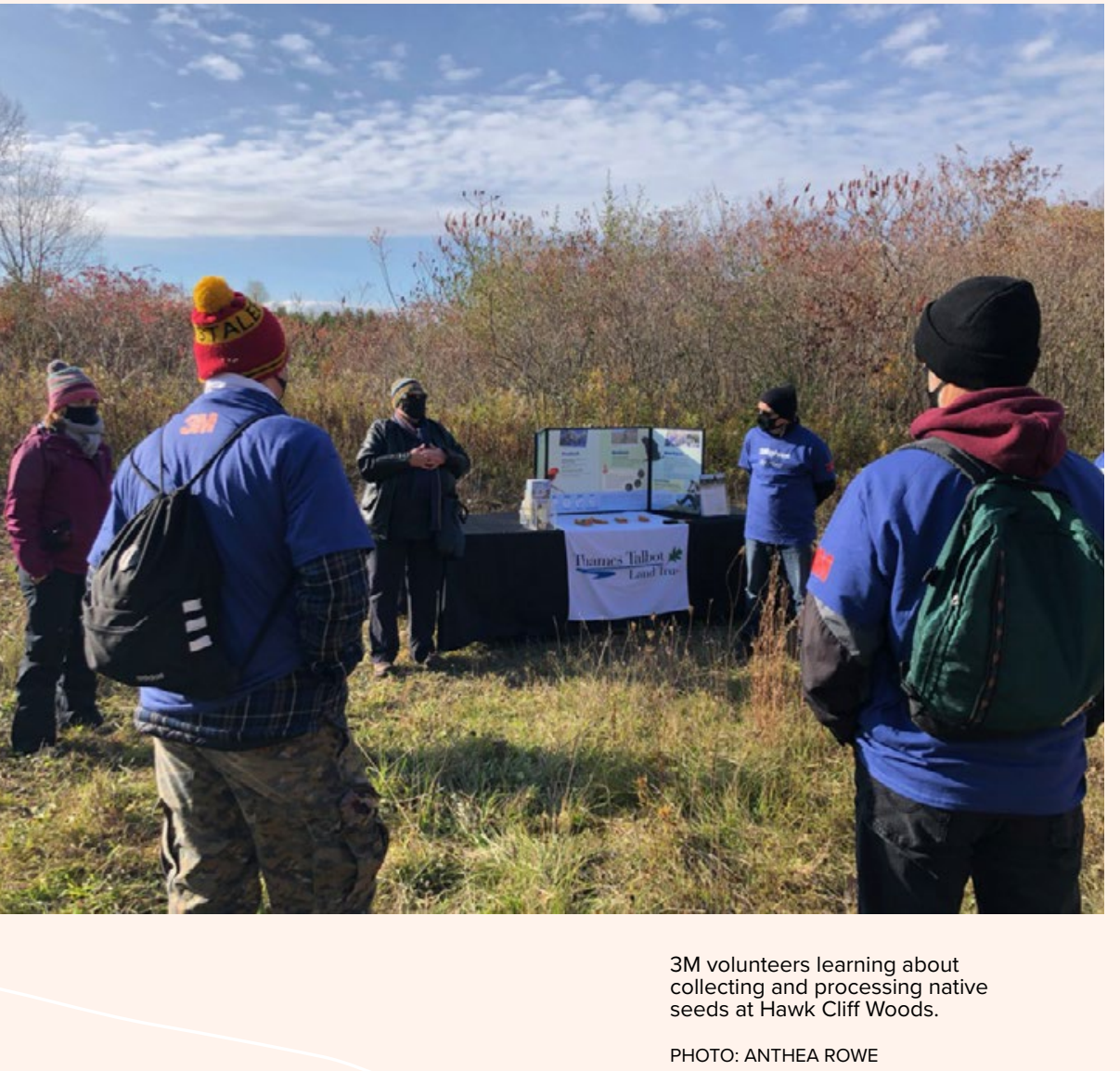

PHOTO: ANTHEA ROWE

"It was a rewarding experience to take part in the 3M Canada and Thames Talbot Land Trust Fall seed collection opportunity with my colleagues. The seeds we collected from native plants and wildflowers at the scenic Hawk Cliff Woods on the shore of Lake Erie had a positive impact on the environment by helping restore healthy landscapes across southwestern Ontario."

Soufiane Lamrabet, 3M Canada ${ }^{257}$

Working with ReForest London, the DZCIB pilot supported seven habitat projects in City of London parks. One of these projects occurred at Briscoe Woods in Fall 2020. At Briscoe Woods, 225 native trees and shrubs were planted by 42 volunteers along a walking trail increasing native habitat for the ecologically abundant area that is adjacent to The Coves Environmentally Significant Area.

Working with the Lower Thames Valley Conservation Authority (LTVCA) and Alternative Land Use Services (ALUS) Middlesex, the DZCIB pilot supported habitat projects on 36 sites in southern Ontario including woodland, wetland, and prairie sites. These projects included a wide variety of landowners including private landowners, Delaware Nation at Moraviantown, Chippewas of the Thames First Nation, and a youth group. A total of 41 hectares (101 acres) of native habitat improvements were achieved including woodland, wetland, and prairie habitats.

Working with Chippewas of the Thames First Nation as a habitat partner, the DZCIB pilot supported a farmland-river buffer creation through the LTVCA-ALUS partnership and the creation of a land-based learning program for Anishinaabensag Miikaanens (Little Anishinaabek Trail), a nature trail in the protected area behind 
PART 2 CAROLINIAN CANADA CONSERVATION IMPACT BOND

“Tree planting is the best feeling ever! I'm so happy ReForest London provides opportunities to give back to the land and the community. When I feel sad about climate change and other global issues I think of ReForest London and all the trees planted and I feel a little better. I feel motivated to do more! Not to mention it's super fun and something I can do with my friends safely during Covid!!!!!!"

J. H., ReForest London volunteer

the community's school. Educational materials, including species identification signs, will be made in both English and Anishinaabemowin to support the preservation and revitalization of the local Indigenous language.

These are merely a few examples of the many habitat projects that have been supported by the DZCIB. Throughout the DZCIB pilot thus far, 69 hectares (171 acres) of habitat in southern Ontario have been improved, 39,000+ native plants have been planted, and approximately 450 people have been engaged in high-quality learning and activities on the land. ${ }^{7}$

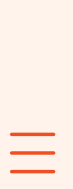

7 All figures presented are based on data collected on the DZCIB pilot up until July 2021. These figures are based on habitat partner reporting and have yet to be externally audited.

Restoration planting at Bebensee Tract.

PHOTO: DARIA KOSCINSKI

N.

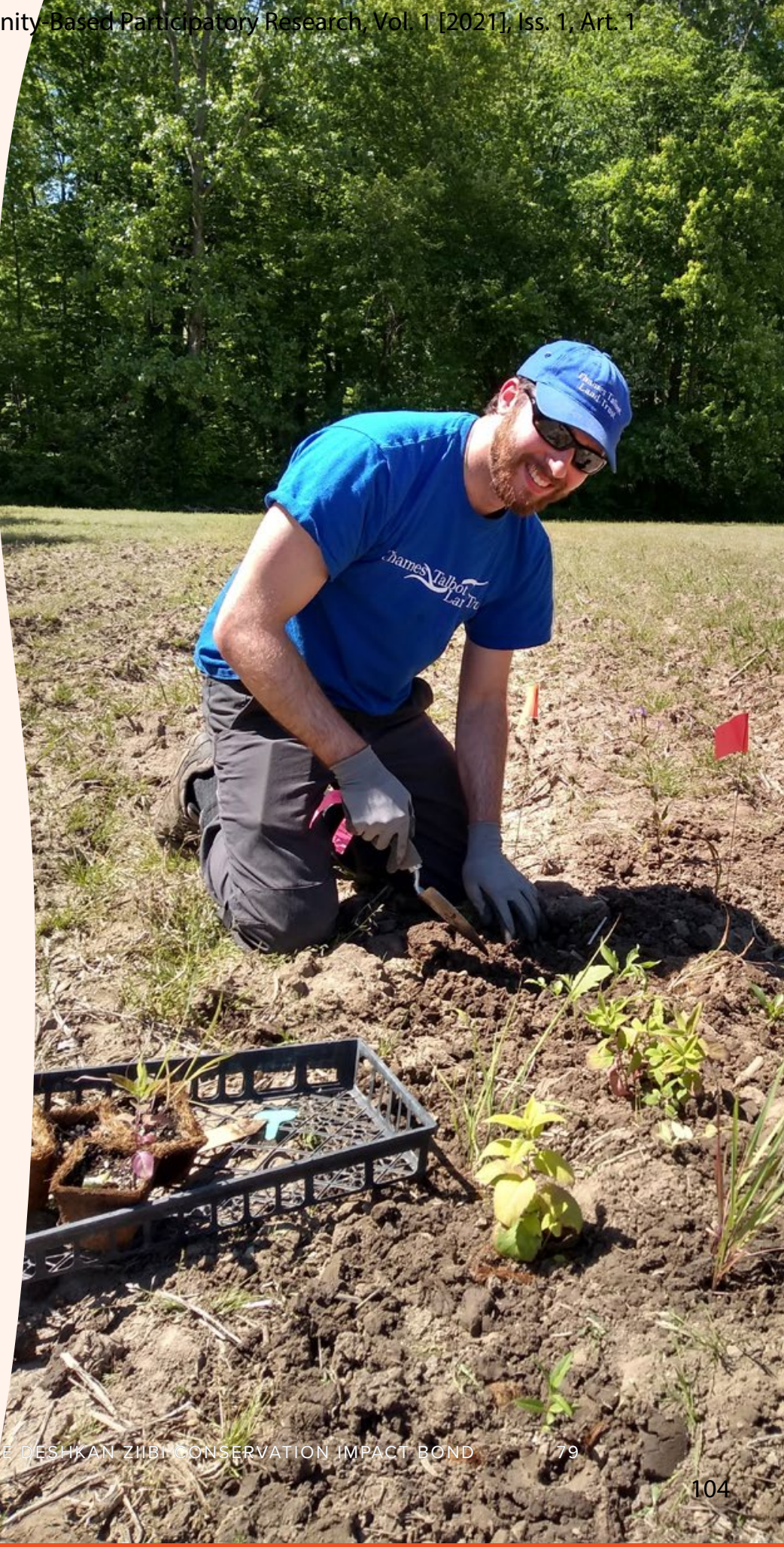




\section{Assessing the Impact of the Deshkan Ziibi Conservation Impact Bond}

» Impact assessment of the DZCIB aims to go beyond quan- 》 titative measures and incorporate qualitative measures and Indigenous knowledge to holistically assess impact.

» Five categories of impact were selected to capture the holistic impact of the bond with each category containing multiple metrics and one pay-for-success metric.
The collaborative approach to metric selection is integral as it allows for scalability of the bond to adapt to local communities while still honoring the essence of the CIB model. 


\section{The Cross-Cultural Collaborative Processes of the Deshkan Ziibi Conservation Impact Bond}

\section{Towards Plural Valuations \\ of Nature, Ecosystems, and \\ Ecosystem Services}

\begin{abstract}
The origins of the understanding that humans receive life-supporting and sustaining value from the natural world goes back millennia and is represented in most cultures and religions, some dating pre-recorded history. ${ }^{258}$ Throughout human history, experiences, stories, beliefs, and cultural traditions have shaped and influenced the ways in which individuals and communities perceive and interact with their internal and external environments around the world. Up until this last century, the aggregate of the diverse ways in which individuals live, explore, harvest, and develop their external environments have not had global planetary consequences that threatened the future life-support systems of our planet. However, that is no longer the case.
\end{abstract}

\begin{abstract}
Over the last few decades, amidst our intensifying biodiversity and climate crises, the valuation of nature, ecosystems, and ecosystem services has become one of the fastest growing areas of environmental research. ${ }^{259,}, 260$ How is nature being valued? How can we shift that valuation process to arrive at improved socio-ecological outcomes? It is apparent through the rapidly declining levels of natural capital over the years that nature has been improperly valued. ${ }^{261}$ Communities, institutions, and governing bodies, at both local and global scales, are seeking ways to conduct more robust valuations of nature to support improved policy and decision-making that will result in more just and sustainable socio-ecological outcomes. $262,263,264$
\end{abstract}

The DZCIB aims to adopt a plural valuation approach. This project joins a growing community of researchers and influential contributions to the field of ecosystem services, such as the Millennium Ecosystem Assessment, ${ }^{265}$ the Economics of Ecosystem Services and Biodiversity, ${ }^{266}$ and the Intergovernmental Panel on Biodiversity and Ecosystem Services, ${ }^{267}$ in the 
PART 2 CAROLINIAN CANADA CONSERVATION IMPACT BOND

global call to move towards the integration of value pluralism and incommensurability in nature and ecosystem service assessments. ${ }^{268,269,} 270$ We aim to challenge value assessors, decision makers, and policymakers to broaden their conceptualizations of 'nature' and its 'value' beyond a utilitarian, value monistic view and towards an interdisciplinary, integrative, value pluralistic view. ${ }^{271,272,273}$

\section{PLURAL VALUATION}

Plural valuation has been defined as a science-policy process focused on assessing the multiple values that human social actors attribute to nature and how this knowledge guides decision-making. ${ }^{274}$ The pluralistic approach to the valuation and assessment of nature, ecosystems, and ecosystem services incorporates diverse worldviews and human-nature relational models, both Western and Indigenous; spans value domains, ecological and sociocultural, including monetary and non-monetary; spans levels of societal organization, individual and group; and recognises multiple value systems, intrinsic, instrumental, and relational. ${ }^{275,276,277}$

Plural valuations of nature, ecosystems, and ecosystem services have been demonstrated and regarded as the most holistic and robust ecosystem assessment methodology for several reasons. First, it is grounded in an understanding of value pluralism and incommensurability that recognises that there are different and often conflicting value domains that are not reducible to one another nor to one ultimate value, such as money. $278,279,280$
Second, it enables greater epistemic justice by supporting an advancement in understanding and recognition of the diverse and multidimensional ways in which humans relate to and care for and about nature. ${ }^{281}$ The plural valuation process creates an ethical space for a diversity of perspectives and valuation languages to be expressed on their own terms facilitating a collective and organically evolving process of value formation. ${ }^{282}$

Third, as nature is valued in very different ways by individuals and groups with unequal levels of power, plural valuation makes visible the role that these power relations have in the production and distribution of benefits and burdens of nature and ecosystem services across social groups. ${ }^{283,284}$

Fourth, plural valuations recognise intrinsic, instrumental, and relational values embedded within human-nature relations and provides a framework for articulating human-nature relationships that transcend the dominant Western dichotomic model that often positions intrinsic and instrumental values of nature as a zero-sum trade-off. ${ }^{285,} 286$

The goal of embracing plural valuations and understanding the diversity of human-nature relational models is to engage in an assessment process that is aimed at reducing, transforming, and reconciling socio-ecological conflicts to arrive at a wiser and epistemologically broadened relationship with ourselves, one another, and our planet. ${ }^{287}$

The DZCIB aims to operationalize a plural valuation approach incorporating Indigenous and Western worldviews throughout the design of the financial instrument and favoring a form of relational accountability. ${ }^{288}$ 
PART 2 CAROLINIAN CANADA CONSERVATION IMPACT BOND

\section{Operationalizing Plural Valuations and Decolonizing Principles in the} DZCIB

Through the creation and the implementation of the DZCIB, the goal is to engage in an ongoing process of decolonization to deconstruct the biases towards a Western worldview through governance structures and thought processes which inhibit Indigenous ways. Beyond this process of decolonization, the goal is to engage in Indigenization: a process which aims to integrate and normalize Indigenous worldviews into the creation and processes of the DZCIB considering Indigenous value systems as diverse, yet with equal weighting of Western systems. Developing and engaging in collaborative relationships with Indigenous peoples that empowers Indigenous worldviews for the common goal of conservation, in a way which does not exploit Indigenous knowledge to support a profit agenda, is a guiding principle of the CIB model. There is potential for decolonization both with how the broader community is engaged with the $\mathrm{CIB}$, and the metrics and governance structure adopted by the bond.

\section{The following are evolving principles for driving a} decolonizing approach with the CIB model:

\section{LEARNING AND ENGAGEMENT}

» Ensure partners involved with the CIB are educated on the Indigenous peoples with whom they are working. Ensure partners are aware of the colonial legacy of Canada and sensitive to the colonial undertones of their approaches and systems (i.e., imposing Western values on Indigenous peoples).

" Be open to learning about Indigenous worldviews. Seek Indigenous input and co-creation throughout the process, aiming to integrate these worldviews into the structure of the $\mathrm{CIB}$ rather than simply meeting a requirement for consultation. Understand the strengths of diverse worldviews that can shape how we perceive conservation and value the impacts of the bond.

» Understand and honor the differences among the First Nations within the Carolinian Zone involved in the bond. Ensure representation from different communities of people, avoiding the microaggression of considering the perspectives of one First Nation to be representative of all First Nations. 
PART 2 CAROLINIAN CANADA CONSERVATION IMPACT BOND

\section{RESPECT AUTONOMY AND CREATE ETHICAL SPACE}

»Create space for Indigenous worldviews within the structure of the bond. The impact measurement framework and pay-for-success metrics must seek to consider and combine Indigenous and Western worldviews. This includes an impact measurement framework that legitimizes lived experiences, ceremony, and storytelling to communicate non-financial impacts.

" Respect the autonomy of Indigenous communities and engage them respectfully; different approaches to Western ways should not be viewed as inferior. Leverage the strengths of Indigenous leaders involved in the bond, understanding how best to engage with their communities.

» Understand that all habitat projects take place on traditional territory and facilitate connections to support Indigenous leadership, recognizing Indigenous land sovereignty.

COMMUNICATION AND RELATIONSHIP-BUILDING

» Create a platform and opportunity for Indigenous voices to be heard and valued when creating the bond. Facilitate and encourage relationship-building among partners.

» Strive for open communication among partners of the bond, be collaborative, and aim for consensus in governance decisions.

\section{Some of the ways in which the DZCIB has aimed to incorporate the above decolonizing principles include:}

\section{LEARNING AND ENGAGEMENT}

»A series of Indigenous-led workshops aimed to decolonize the thought processes of individuals involved in the bond and open hearts and minds to embracing diverse worldviews and relationships with nature. Involved in these workshops is time for collaborative brainstorming on the integration of learnings to the processes of the DZCIB to ensure a process of continuous reflection and improvement.

» Honoring Indigenous worldviews through the adoption of a plural valuation approach. Evaluating the impact of the DZCIB brings together Indigenous and Western worldviews including recognizing the relational value of nature; taking a holistic approach to community health; and taking into consideration principles of responsibility to relations in the past, present, and future.

\section{RESPECT AUTONOMY AND CREATE ETHICAL SPACE}

»Consensus-based decision making to honor Indigenous decision-making traditions. This approach gives space for all voices and perspectives to be heard and considered before arriving at a decision. During team meetings, individuals are encouraged to share their thoughts and ideas and space is given for diverse perspectives to be included in the discussions. 
PART 2 CAROLINIAN CANADA CONSERVATION IMPACT BOND

» Creating space for storytelling and honoring Indigenous forms of knowledge creation and transmission. During assessment of impact, storytelling and oral forms of information dissemination are valued with the same weight as quantitative assessments of ecosystem health. This is to honor Indigenous oral traditions and experiential ways of knowing.

COMMUNICATION AND RELATIONSHIP-BUILDING

» Starting the development of the CIB with a conversation over several months among First Nations and other partners in ethical space.

» Contributing to the broader goal of reconnecting people and the ecosystems in which they are embedded. The evaluation of impact of the DZCIB does not only consider ecological indicators of ecosystem health in isolation, but also includes assessing community holistic health of reconciling peoples and ecosystems.

\section{Ongoing Collaboration and Relationship-Building}

Each partner in the DZCIB - including First Nations, multinational corporations, impact investors, non-profit organizations, and academic researchers - came together due to their shared interest in land restoration and conservation; however, everyone brought forward different perspectives on the issues being faced and, as a result, proposed unique solutions. In trying to reconcile these diverse perspectives into holistic landscape projects, the CIB operated as a "boundary object", an object that facilitates communication across different social worlds, ${ }^{289}$ to facilitate sharing and collaboration across sectors, cultures, and generations. From wide-scale native plant restoration projects and creation of native seed orchards to connecting people's hearts and minds through ceremony and educational workshops, the diversity of partners supported the creation of community-driven habitat projects that aim to have the greatest impact on improving ecological and socio-cultural outcomes.

Bebensee Tract in fall 2019.
Once active farmland, this site

Once active farmland, this site
was restored with the planting

of native seeds.

PHOTO: DARIA KOSCINSK 
"Cross-cultural dialogues help us to see that there are as many ways of seeing, hearing, feeling, and understanding as there are members in a group." ${ }^{290}$

Melanie Goodchild 291

Building trust among partners across various sectors is crucial to the facilitation of a cross-sectoral instrument. One of the most unique and transformational aspects of the DZCIB, as stated by many of the participants, is the social platform that it builds for partners to engage with, and learn from, one another. Through ongoing collaboration, group workshops, and monthly check-in meetings, relationships have been built among many people that, despite their diverse individual backgrounds, come together for the conservation and restoration of the land and life-support mechanisms upon which all lives rely. Every month, the Deshkan Ziibi Leadership Team comes together to reconnect, share news, and discuss ongoing development and management topics related to the DZCIB.

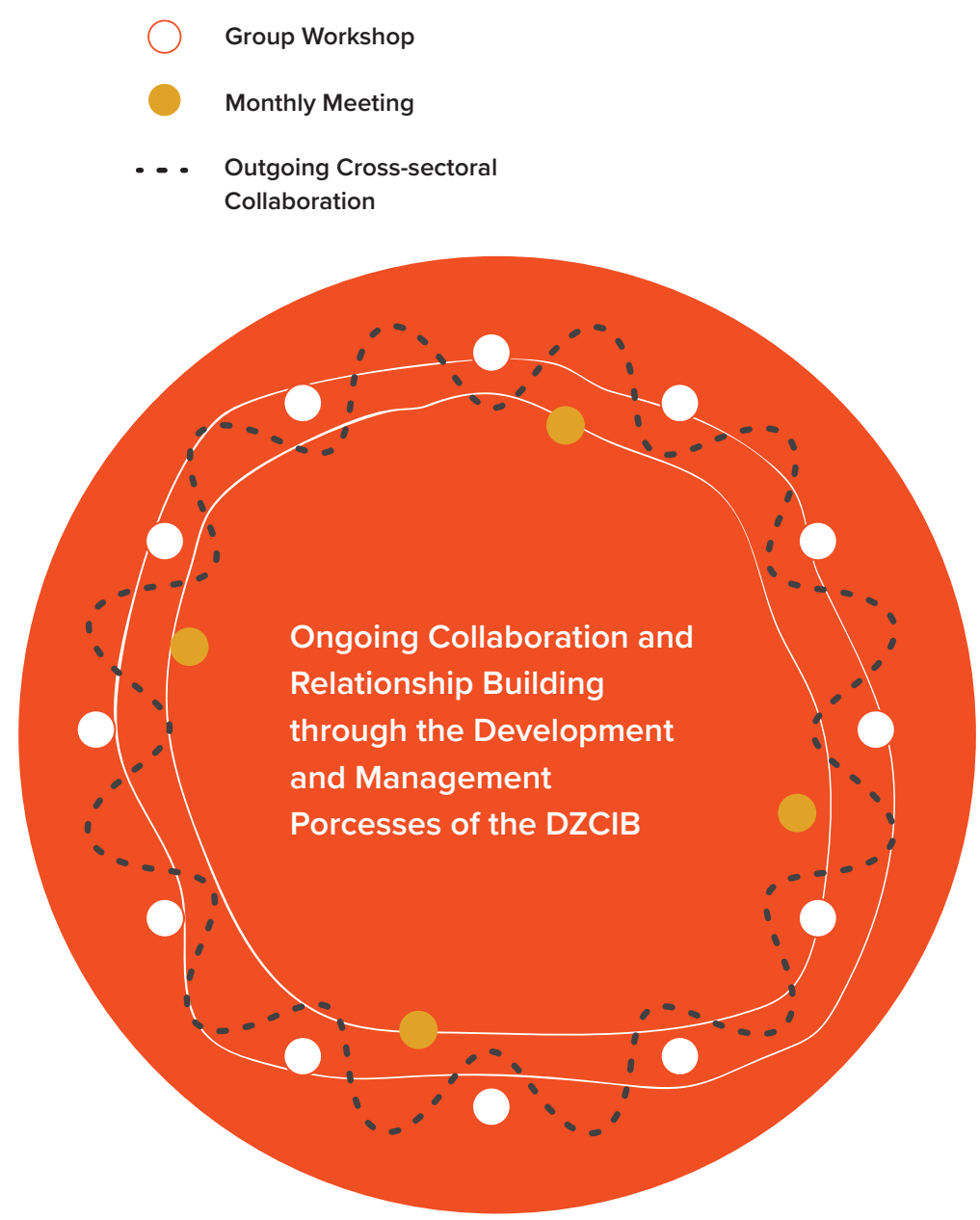

Figure 20: Ongoing Collaboration and Relationship Building Through the Development and Management Processes of the DZCIB 
PART 2 CAROLINIAN CANADA CONSERVATION IMPACT BOND

\section{DZCIB Connecting knowledge / Circling and Learning Workshops}

As the development and management process of the bond progressed, sessions were held to expand knowledge, reflect on specific topics, facilitate collaboration, form relationships, and build capacity toward shared goals.

\begin{tabular}{|c|c|c|c|}
\hline 2019 & \multicolumn{3}{|l|}{2020} \\
\hline $\begin{array}{l}\text { February: Shifting the Paradigm } \\
\text { Forum } 2019 \text { - Growing Healthy } \\
\text { Landscapes } \\
\text { This forum was presented by Car- } \\
\text { olinian Canada, WWF-Canada, the } \\
\text { Royal Ontario Museum, and VERGE } \\
\text { Capital. The forum focused on fos- } \\
\text { tering cross-sector collaboration to } \\
\text { ecosystem work, green investment, } \\
\text { and native plants to create healthy } \\
\text { landscapes and resilient communities } \\
\text { in southern Ontario. }\end{array}$ & $\begin{array}{l}\text { March: Shifting the Paradigm } \\
\text { Forum } 2020 \text { - Nature Works! } \\
\text { Restoring our Future by } 2030 \\
\text { This forum was hosted through a } \\
\text { collaborative initiative between } \\
\text { Carolinian Canada and WWF- } \\
\text { Canada. The forum was on taking } \\
\text { action to support nature-based } \\
\text { solutions during the UN Decade } \\
\text { of Ecosystem Restoration and the } \\
\text { role of conservation finance. } 120 \\
\text { people attended the forum. }\end{array}$ & $\begin{array}{l}\text { November: Uncovering the } \\
\text { Regenerative Capability of the } \\
\text { DZCIB Workshop } \\
\text { This workshop brought together } \\
\text { the Leadership Team and practi- } \\
\text { tioners from Regenesis group }{ }^{292} \\
\text { to explore and discuss different } \\
\text { perspectives on the regenerative } \\
\text { capability of the DZCIB project. }\end{array}$ & $\begin{array}{l}\text { December: Decolonizing the DZCIB } \\
\text { Workshop \#1 } \\
\text { This workshop was facilitated by } \\
\text { Leslee White-Eye, former Chief of } \\
\text { the Chippewas of the Thames First } \\
\text { Nation, and attended by members of } \\
\text { the DZCIB Leadership Team. Leslee } \\
\text { shared pre-readings, principles of } \\
\text { the Anishinaabe worldview, and } \\
\text { guided the group through exercises } \\
\text { centered around decolonizing the } \\
\text { work of the DZCIB project. }\end{array}$ \\
\hline \multicolumn{4}{|l|}{2021} \\
\hline $\begin{array}{l}\text { March: Impact Assessment Workshop } \\
\text { This workshop was facilitated by Dr. } \\
\text { Diane-Laure Arjaliès to update the } \\
\text { Leadership Team on the bond's impact } \\
\text { metrics and evaluation framework } \\
\text { and receive everyone's feedback, } \\
\text { perspectives, and ideas. This work- } \\
\text { shop resulted in the selection of the } \\
\text { DZCIB's five pay-for-success metrics. }\end{array}$ & $\begin{array}{l}\text { March: Decolonizing the DZCIB } \\
\text { Workshop \#2 } \\
\text { This workshop was facilitated by } \\
\text { Leslee White-Eye and attended by } \\
\text { members of the Leadership Team. } \\
\text { This workshop was a follow-up to } \\
\text { Decolonizing the DZCIB Workshop } \\
\text { \#1 and discussed how to implement } \\
\text { the teachings shared by Leslee into } \\
\text { practice. }\end{array}$ & $\begin{array}{l}\text { July: Habitat Restoration in the Spirit } \\
\text { This workshop was facilitated by } \\
\text { Leslee White-Eye and was attended } \\
\text { by members of the Leadership Team } \\
\text { and habitat partners of the DZCIB. } \\
\text { The purpose of this session was } \\
\text { to have a deeper dialogue about } \\
\text { infusing practices into the work of } \\
\text { the Deshkan Ziibi CIB to live out the }\end{array}$ & $\begin{array}{l}\text { and Practice of Reconciliation Workshop } \\
\text { intentions of reconciliation and to ex- } \\
\text { tend the dialogue to include habitat } \\
\text { partners. This workshop centered } \\
\text { around Anishinaabek principles and } \\
\text { practices in land relations and man- } \\
\text { agement, and ways to improve the } \\
\text { quality of land relations in conserva- } \\
\text { tion work. }\end{array}$ \\
\hline
\end{tabular}




\section{The Cross-Cultural and Collaborative Processes of the Deshkan Ziibi Conservation Impact Bond}

» The DZCIB aims to operationalize a plural valuation approach.

» A goal of the CIB was to engage in the processes of decolonization and Indigenization by integrating Indigenous worldviews and values through the design and implementation of the bond.
» The processes of the DZCIB facilitate an environment of cross-sectoral and cross-cultural relationship building which unite actors from diverse backgrounds through underlying common goals. 


\section{| Reflections and Next Steps}

\section{Scaling the Carolinian Canada CIB to Other Contexts}

The CIB is a flexible model that allows for adaptation to local contexts using ecological and Indigenous principles that apply globally. The funding provided by the CIB is intended to support the goals of the community in a regenerative process that respects the diversity of the local environment on a complex landscape (connecting rural, urban, Indigenous, cultural, and wild spaces), rather than restricting local projects by imposing a uniform structure through which to operate.

When scaling the Carolinian Canada CIB, the goal is not only to scale "up", but also to scale "out" and "deep", ${ }^{293}$ by prioritizing community involvement, connecting diverse healthy landscapes, and committing to building relationships over rapid growth. The principles of community involvement, healthy landscapes and relationship-building have been key features of the development and implementation of the DZCIB.

\section{"The bond feels co-developed and we have taken the time to build relationships and learn. In the early stages, we were not focused on the bond, but the partners."}

Emma Young, Chippewas of the Thames First Nation 


\section{Adapting to Evolving Conditions and Considerations for the Future}

The development and implementation processes of the DZCIB highlighted a number of external conditions which provided challenges and opportunities for future implementations of the CIB model. Uncertainties and challenges operating within broader systems are inevitable. This section will provide a reflection on the environmental and social conditions and challenges within the finance industry that are important considerations for the development and implementation of future CIB projects.

ENVIRONMENTAL AND SOCIAL CONDITIONS

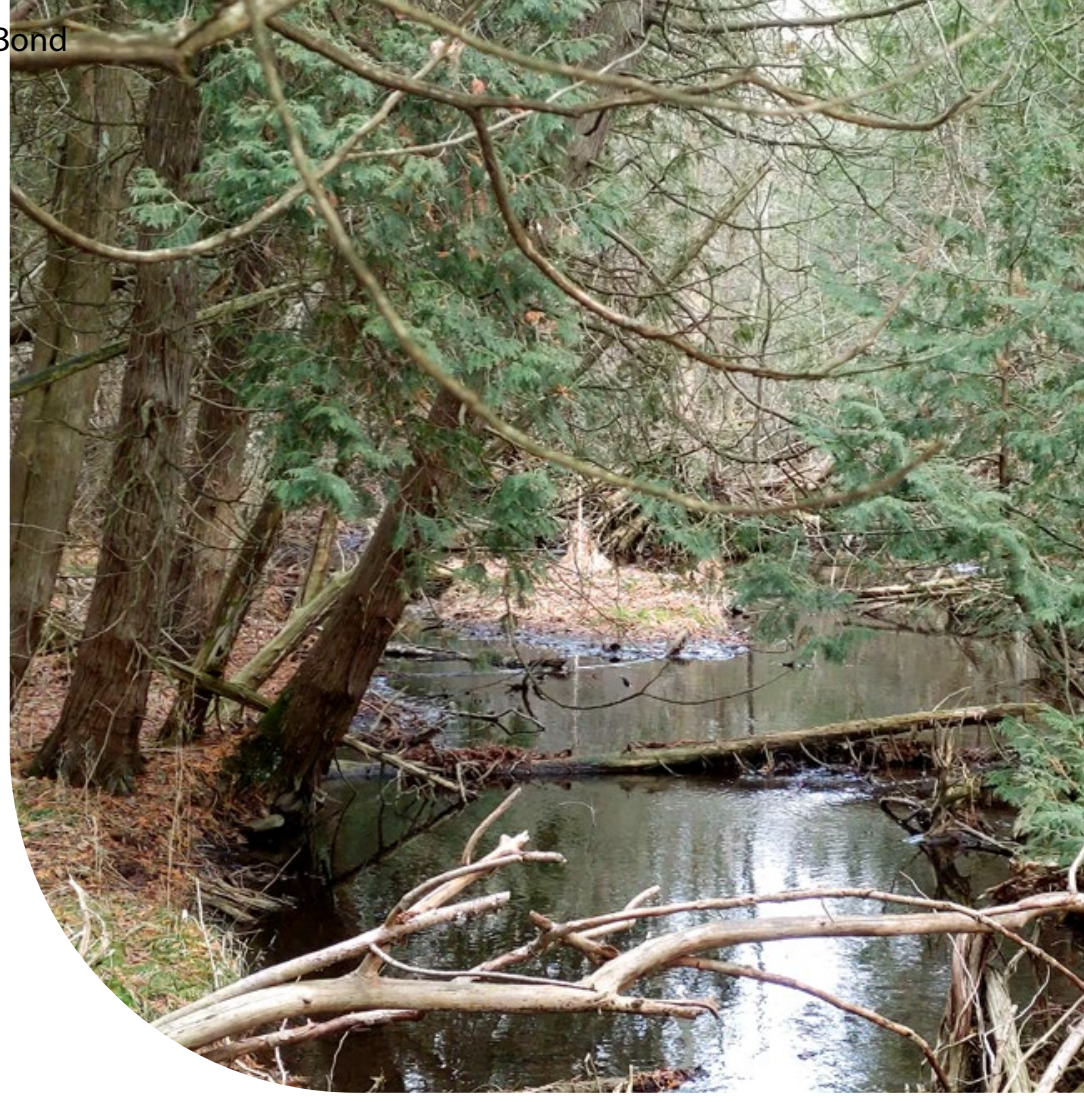

Coldwater stream flowing through Ross's Woods, Oxford County.

PHOTO: REBECCA LAUNCHBURY

\section{TABLE 3: THE ENVIRONMENTAL AND SOCIAL CONDITIONS TO CONSIDER FOR FUTURE IMPLEMENTATIONS OF THE CIB}

\begin{tabular}{ll}
\hline CONSIDERATIONS & DESCRIPTION AND FUTURE STEPS \\
\hline Changing climate & $\begin{array}{l}\text { The changing climate is resulting in increased intensity, severity, and frequency of extreme weather } \\
\text { events including extreme temperature, precipitation, floods, drought, and wildfires. Moving forward, future } \\
\text { implementations of the CIB model need to consider how climate change affects habitat project outcomes and } \\
\text { partners, notably investors who are providing the upfront capital and rely on the achievement of specific outcomes } \\
\text { to receive their return. This aspect also creates a significant opportunity for nature-based services as highlighted } \\
\text { by studies that identify natural infrastructure as a key strategy to prevent and mitigate flooding and drought. } \\
\text { Outcomes focused on the co-benefits of habitat conservation, protection, and restoration projects that can } \\
\text { sequester carbon and support resiliency through adaptive landscapes may provide opportunities in the next phase } \\
\text { of the project. }\end{array}$ \\
\end{tabular}


Deshkan Ziibi Conservation Impact Bond Project: On Conservation Finance, Decolonization, and Community-Based Participatory Research, Vol. 1 [2021], Iss. 1, Art. 1

PART 2 CAROLINIAN CANADA CONSERVATION IMPACT BOND

\author{
CONSIDERATIONS $\quad$ DESCRIPTION AND FUTURE STEPS
}

The COVID-19

pandemic

The COVID-19 pandemic introduced new considerations for the CIB model moving forward. First, the ongoing pandemic may detract from attention on the ecological crises. Therefore, the CIB model should aim to position itself as a tool to increase the resilience of our societies while reducing the risk of increasingly disastrous events that are expected to come from climate change and biodiversity collapse. Second, the pandemic halted and interrupted a few of the DZCIB's planned activities in 2020 and presented barriers for communication among partners. Therefore, the CIB model needs to plan for potential future interruptions and create adaptation strategies. The pandemic also fueled innovation to create new opportunities such as the Oneida Nations of the Thames garden project that has been adapted more widely and continued beyond the pandemic. One of the benefits of a flexible CIB design was demonstrated during the pandemic when it quickly accommodated due to timing flexibility provided by the investment and pooling of impact provided by the Healthy Landscape Portfolio.

Shifting societal

value(s)
The CIB offers a potential tool to pilot and sustain conservation, restoration, and reconciliation work amidst the shifting tides of public opinion. Societal value(s) is/are often short-term/ephemeral whereas climate change is longterm and increasing. Future implementations of the CIB model need to maintain engaged with shifting societal value(s) and their alignment with the CIB's goals to inform communications and maximize impact.

CHALLENGES WITHIN THE FINANCE INDUSTRY

\title{
TABLE 4: THE CHALLENGES WITHIN THE FINANCIAL INDUSTRY TO CONSIDER FOR FUTURE IMPLEMENTATIONS OF THE CIB
}

CONSIDERATIONS

Misalignment between

financing cycle and

restoration benefits

that accrue over long

periods of time

\section{DESCRIPTION AND FUTURE STEPS}

A misalignment exists between the CIB model financing cycle of three years and the benefits of ecological restoration projects that accrue over long periods of time (e.g., as a forest grows). Future implementations of the CIB model need to remain aware of this as they pursue long-term sustainable outcomes and communicate project evaluations with partners. 
Attracting large-scale investment with partners speaking different 'languages'
Attracting large-scale investment to implement future CIB models is challenging when working with such a diverse group of partners. Investors, Western scientists, and Indigenous knowledge keepers work within different paradigms, and thus, do not communicate in the same 'language' Future CIB model implementations should aim to connect with external partners in the "language" that resonates with them. For example, communicating how the CIB model supports achieving the Paris Agreement or goals to reach "net zero by 2030". A blended finance approach can involve a variety of investors that will commit capital with outcome goals and risk-adjusted return requirements.

\section{Balancing the} complexity of valuation with the need for standardization
As discussed in the plural valuation section, valuation of nature is incredibly complex and is strongly influenced by who is valuing. However, in order to scale funding for nature-based solutions to global markets, financiers will be looking for standardization and a consistent set of principles and metrics for these projects. This will also include a standardization in the approaches that are used for project valuation. It is important that the CIB model recognizes the need to balance both the complexity and unique features of local contexts with the need for standardization. It is also important that the CIB model remains engaged with market developments that are currently unfolding around investing in nature. For example, the Coalition for Climate Resilient Investment is currently working on developing a standardized taxonomy to integrate physical climate risks that can be understood by the investment community to attract private investment capital.

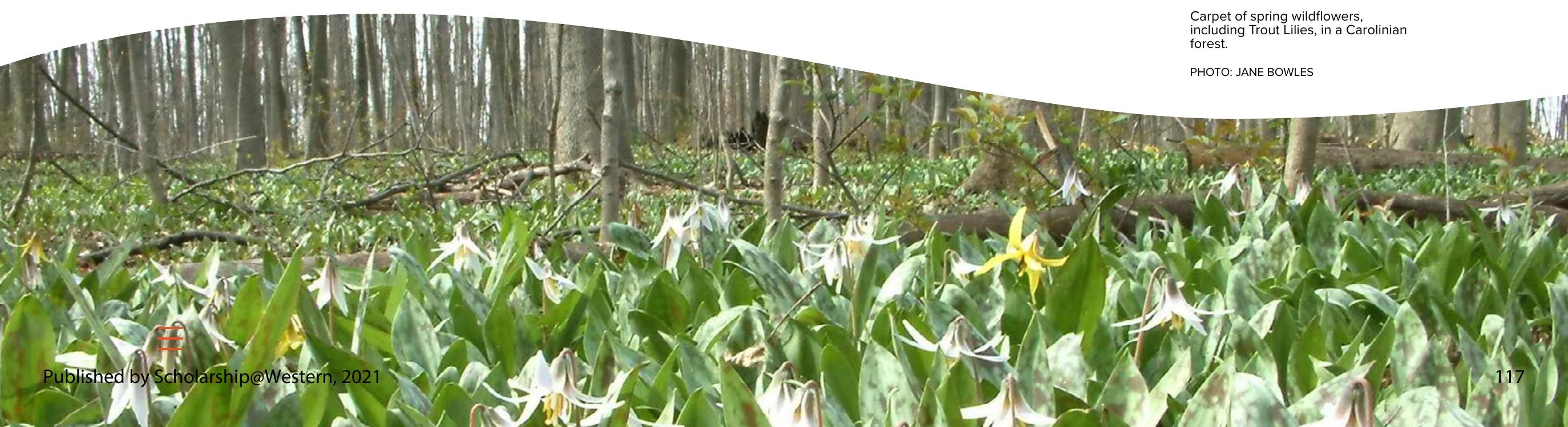




\section{KEY TAKEAWAYS}

\section{Reflections and Next Steps}

» The DZCIB pilot project will be scaled to other settings within the Carolinian Zone.

" When scaling, the goal is to capture the essence and principles of the CIB model while allowing for adaptations to local contexts.
» Reflections on lessons learned from the design and implementation of the DZCIB pilot project can be applied to future implementations of the CIB model.

»External conditions which influence the success of the CIB must be considered. 


\section{Concluding Reflection}

\section{FIRST LIGHT BY PETER BLUE CLOUD 294}

Figure 21: "First Light", a Two-Row Poem by Peter Blue Cloud
First light, a dark outline of a mountain peak and pines their morning scent

carried on first breezes,

stars a naked brilliance

pulsing to coyote cries

And keening chorus,

a cricket's tentative chirping, long pauses,

the fall of an oak leaf

a bird's sudden question,

that deepest blue of sky

And now the stars turn

brighter,

a sliver of moon

followed by a star

And then the pink of morning

sky as vast and open

as a child's dreaming,

a carpet of leaves, hazy

grey to mist of yellow

the oak growing a cliff face

reaching out for balance,

a dog bark crawling over a hill, a snapping conversation of twigs and branches in fire,

I wrap myself in morning as echoes

$$
\text { of a silly dream }
$$

linger my mind

And I smile to it,

my urine splashes the ground

sending up an acrid steam,

a long, ribbed cloud I reach for,

$$
\text { I want to }
$$

Soar on hawk wings and whistle

An all-consuming pride,

I smell the pine and cedar and the damp morning soil,

$$
\text { a flicker calls, }
$$

my feet are hooves

I run,

taking great, soaring

$$
\text { leaps }
$$

above the trees, over hills to meet

the sun. evening

too

will

call,

sleep

again

the
mind

mind

dreaming,

mind

a

ation

of

n

mind

Creation

space,

mind

is

space

void

crowded

lodge,

mind

memory

of

a

way,

people

seeking

a

law,

law

of

lasting

peace. (Clans 96-97) 
Indigenous poet, Peter Blue Cloud, presents the above poem in two columns. The column on the left emphasizes the living and dynamic nature of Creation and the right column presents ongoing thoughts or realizations throughout the poem. ${ }^{295}$ In this two-row style of presentation, the reader of the poem is challenged on how to read a poem laid out in this manner. Should the poem be read column by column? Should the poem be read line by line? In this process, it is inevitable that the reader confronts their individual thoughts, habits, assumptions, and ways of making meaning. ${ }^{296}$

The sense of balance that emerges with the two columns being presented together mirrors the idea of balance present in the Two Row Wampum, which is about balance in intercultural relationships. ${ }^{297}$

\section{Figure 22: Two-Row Wampum 299}

The oral history of the Two Row Wampum as presented by Grand River Cayuga Chief, Chief Thomas, ${ }^{298}$ says that the Two Row Wampum was created as a friendship and peace agreement between the Haudenosaunee Confederacy and Dutch merchants. The Dutch suggested putting the agreement in writing, and the Haudenosaunee created the Two Row Wampum belt as an alternative way of recording this treaty that would last longer than paper (See Figure 22).

The Two Row Wampum presents two parallel lines of purple beads. This was to symbolize two ways of travel: the Dutch via sailing ship, and the Haudenosaunee via canoe. Despite these independent modes of travel, both groups could travel down the same river in tandem. Beyond modes of transportation, this imagery symbolizes an acknowledgment of the different ways of knowing and living among the Dutch and the Haudenosaunee peoples, yet these do not hinder their ability to travel in the same direction side-by-side without interfering with each other's individual ways of life. The three rows of

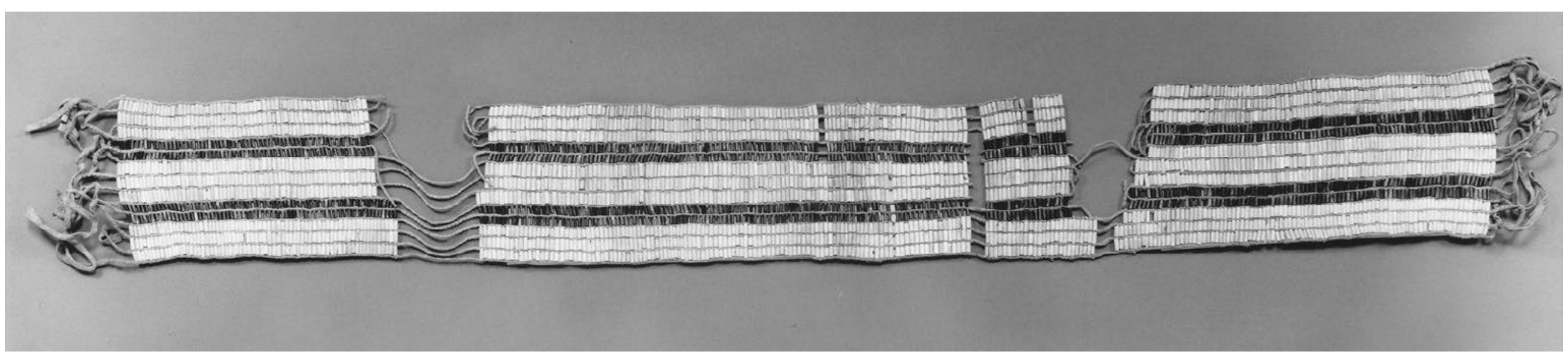


white beads in the centre represent peace, friendship, and respect that exists in the space between these two groups. The lines of beads continue to the edge of the belt and, when the belt is tied, form an eternal circle. This represents that, just as there is no end to the river, so too is their relationship ongoing. Maintaining the Two Row Wampum belt includes continuous care such as dusting and repolishing the beads, just as maintaining relationships also requires ongoing care and action.

The symbolism of duality present in the two-row poem and the symbolism of respectful and peaceful coexistence in the Two Row Wampum are ideas to which the authors of this report wanted to draw the reader's attention. Just as the reader was challenged to confront their assumptions and habits of thought and meaning-making through the Peter Blue Cloud two-row poem, so has the reader been challenged throughout this report to be open to diverse worldviews, ways of valuing nature, and conservation financing models. Although the poem presents two distinct columns, they are still related thoughts that together form a holistic story. This mirrors the sentiment of bringing together Indigenous and Western ways of knowing within this project. The Two Row Wampum symbolizes the acknowledgment of different ways of knowing and living that still can travel in the same direction in a relationship of peace, friendship, and respect without interfering with each other's ways of life. These values also underpin the relationships between the Indigenous and non-Indigenous partners involved with the creation and implementation of the DZCIB. Space is created for Indigenous and Western worldviews to co-exist within this project and travel in the same direction to the common goal of supporting healthy landscapes and reconciling people and ecosystem for the well-being of all Creation. 


\section{List of References}

1 Bartlett, C., Marshall, M., \& Marshall, A. (2012). Two-Eyed Seeing and other lessons learned within a co-learning journey of bringing together indigenous and mainstream knowledges and ways of knowing. Journal of Environmental Studies and Sciences, 2, 331-340. https://doi.org/10.1007/s13412-012-0086-8

2 Truth and Reconciliation Commission of Canada. (2015). Honouring the truth, reconciling for the future: summary of the final report of the Truth and Reconcilation Commission of Canada. Truth and Reconciliation Commission of Canada.

3 Antoine, A., Mason, R., Mason, R., Palahicky, S., \& Rodriguez de France, C. (2018). Pulling together: a guide for curriculum developers. Victoria, BC: BCcampus. https://opentextbc.ca/indigenizationcurriculumdevelopers/chapter/ indigenization-decolonization-and-reconciliation/

4 Tuck, E., \& Yang, K. W. (2012). Decolonization is not a metaphor. Decolonization: Indigeneity, Education \& Society, 1(1), 1-40.

5 Tuck, E., \& Yang, K. W. (2012). Decolonization is not a metaphor. Decolonization: Indigeneity, Education \& Society, 1(1), 1-40.

6 Antoine, A., Mason, R., Mason, R., Palahicky, S., \& Rodriguez de France, C. (2018). Pulling together: a guide for curriculum developers. Victoria, BC: BCcampus. https://opentextbc.ca/indigenizationcurriculumdevelopers/chapter/ indigenization-decolonization-and-reconciliation/

7 Excerpts from Brunette, C., \& Richmond, C. (2019). Guide for working with Indigenous students: interdisciplinary development initiative (IDI) in applied Indigenous scholarship. Western University.

8 Wallerstein, N. B., \& Duran, B. (2006). Using community-based participatory research to address health disparities. Health Promotion Practice, 7(3), 312-323. https://doi.org/10.1177/1524839906289376
9 Tobias, J. K., \& Richmond, C. (2016). Gimiigiwemin: Putting knowledge translation into practice with Anishinaabe communities. Wellness-based Indigenous Health Research and Promising Practices, 11(1). https://doi.org/10.18357/ijih111201616019

10 Louis, R. P. (2007). Can you hear us now? Voices from the margin: Using Indigenous methodologies in geographic research. Geographical Research, 45(2), 130-139. https://doi.org/10.1111/j.1745-5871.2007.00443.x

11 Wallerstein, N. B., \& Duran, B. (2006). Using community-based participatory research to address health disparities. Health Promotion Practice, 7(3), 312-323. https://doi.org/10.1177/1524839906289376

12 Ball, J., \& Janyst, P. (2008). Enacting research ethics in partnerships with Indigenous communities in Canada: "Do it in a good way." Journal of Empirical Research on Human Research Ethics, 3(2), 33-51.

https://doi.org/10.1525/jer.2008.3.2.33

13 Tobias, J. K., Richmond, C. A. M., \& Luginaah, I. (2013). Community-based participatory research (CBPR) with Indigenous communities: producing respectful and reciprocal research. Journal of Empirical Research on Human Research Ethics, 8(2), 129-140. https://doi.org/10.1525/jer.2013.8.2.129

14 Kosciolek, K., Kwan, N., Longaphy, C., \& Wilson, R. (2020). Financing conservation: how conservation financing could be used to protect Canada's ecosystems. Nature Conservancy of Canada and Rally Assets. https://rallyassets.com/ wp-content/uploads/2020/11/Financing-Conservation.pdf. 
15 Pörtner, H. O., Scholes, R. J., Agard, J., Archer, E., Arneth, A., Bai, X., Barnes, D., Burrows, M., Chan, L., Cheung, W. L., Diamond, S., Donatti, C., Duarte, C., Eisenhauer, N., Foden, W., Gasalla, M. A., Handa, C., Hickler, T., Hoegh-Guldberg, O., Ichii, K., Jacob, U., Insarov, G., Kiessling, W., Leadley, P., Leemans, R., Levin, L., Lim, M., Maharaj, S., Managi, S., Marquet, P. A., McElwee, P., Midgley, G., Oberdorff, T., Obura, D., Osman, E., Pandit, R., Pascual, U., Pires, A. P. F., Popp, A., ReyesGarcía, V., Sankaran, M., Settele, J., Shin, Y. J., Sintayehu, D. W., Smith, P., Steiner, N., Strassburg, B., Sukumar, R., Trisos, C., Val, A. L., Wu, J., Aldrian, E., Parmesan, C., Pichs-Madruga, R., Roberts, D. C., Rogers, A. D., Díaz, S., Fischer, M., Hashimoto, S., Lavorel, S., Wu, N., Ngo, H. T. (2021). IPBES-IPCC co-sponsored workshop report on biodiversity and climate change. IPBES and IPCC. DOI:10.5281/zenodo.4782538

16 Steffen, W., Crutzen, P. J., \& McNeill, J. R. (2007). The Anthropocene: are humans now overwhelming the great forces of nature. A Journal of the Human Environment, 36(8), 614-621.

https://doi.org/10.1579/0044-7447(2007)36[614:TAAHNO]2.0.CO;2

17 Rockström, J., Steffen, W., Noone, K., Persson, Å., Chapin, F. S., Lambin, E. F. Lenton, T. M., Scheffer, M., Folke, C., Schellnhuber, H. J., Nykvist, B., de Wit, C. A., Hughes, T., van der Leeuw, S., Rodhe, H., Sörlin, S., Snyder, P. K., Costanza, R., Svedin, U., Falenmark, M., Karlberg, L., Corell, R. W., Fabry, V. J., Hansen, J., Walker, B., Liverman, D., Richardson, K., Crutzen, P., \& Foley, J. A. (2009). A safe operating space for humanity. Nature, 461, 472-475.

https://doi.org/10.1038/461472a

18 Steffen, W., Broadgate, W., Deutsch, L., Gaffney, O., \& Ludwig, C. (2015). The trajectory of the Anthropocene: the great acceleration. The Anthropocene Review. https://doi.org/10.1177/2053019614564785

19 WWF. (2020). Living Planet Report 2020 - Bending the curve of biodiversity loss. Almond, R. E. A., Grooten, M. \& Petersen, T. (Eds). WWF, Gland, Switzerland.
20 WWF. (2020). Living Planet Report 2020 - Bending the curve of biodiversity loss. Almond, R.E.A., Grooten M., \& Petersen, T. (Eds). WWF, Gland, Switzerland.

21 WWF. (2020). Living Planet Report 2020 - Bending the curve of biodiversity loss. Almond, R.E.A., Grooten M. and Petersen, T. (Eds). WWF, Gland, Switzerland

22 Rockström, J., Steffen, W., Noone, K., Persson, Å., Chapin, F. S., Lambin, E. F., Lenton, T. M., Scheffer, M., Folke, C., Schellnhuber, H. J., Nykvist, B., de Wit, C. A., Hughes, T., van der Leeuw, S., Rodhe, H., Sörlin, S., Snyder, P. K., Costanza, R., Svedin, U., Falenmark, M., Karlberg, L., Corell, R. W., Fabry, V. J., Hansen, J., Walker, B., Liverman, D., Richardson, K., Crutzen, P., \& Foley, J. A. (2009). A safe operating space for humanity. Nature, 461, 472-475. https://doi.org/10.1038/461472a

${ }^{23}$ Steffen, W., Richardson, K., Rockström, J., Cornell, S. E., Fetzer, I., Bennett, E. M., Biggs, R., Carpenter, S. R., de Vries, W., de Wit, C. A., Folke, C., Gerten, D., Heinke, J., Mace, G. M., Persson, L. M., Ramanathan, V., Reyers, B., \& Sörlin, S. (2015). Planetary boundaries: guiding human development on a changing planet. Science, 347(6223). https://doi.org/10.1126/science.1259855

${ }^{24}$ Rockström, J., Steffen, W., Noone, K., Persson, Å., Chapin, F. S., Lambin, E. F., Lenton, T. M., Scheffer, M., Folke, C., Schellnhuber, H. J., Nykvist, B., de Wit, C. A., Hughes, T., van der Leeuw, S., Rodhe, H., Sörlin, S., Snyder, P. K., Costanza, R., Svedin, U., Falenmark, M., Karlberg, L., Corell, R. W., Fabry, V. J., Hansen, J., Walker, B., Liverman, D., Richardson, K., Crutzen, P., \& Foley, J. A. (2009). A safe operating space for humanity. Nature, 461, 472-475.

https://doi.org/10.1038/461472a

25 Steffen, W., Richardson, K., Rockström, J., Cornell, S. E., Fetzer, I., Bennett, E. M., Biggs, R., Carpenter, S. R., de Vries, W., de Wit, C. A., Folke, C., Gerten, D., Heinke, J., Mace, G. M., Persson, L. M., Ramanathan, V., Reyers, B., \& Sörlin, S. (2015). Planetary boundaries: guiding human development on a changing planet. Science, 347(6223). https://doi.org/10.1126/science.1259855 
${ }^{26}$ Steffen, W., Richardson, K., Rockström, J., Cornell, S. E., Fetzer, I., Bennett, E. M., Biggs, R., Carpenter, S. R., de Vries, W., de Wit, C. A., Folke, C., Gerten, D., Heinke, J., Mace, G. M., Persson, L. M., Ramanathan, V., Reyers, B., \& Sörlin, S. (2015). Planetary boundaries: guiding human development on a changing planet. Science, 347(6223). https://doi.org/10.1126/science.1259855

27 Steffen, W., Richardson, K., Rockström, J., Cornell, S. E., Fetzer, I., Bennett, E. M., Biggs, R., Carpenter, S. R., de Vries, W., de Wit, C. A., Folke, C., Gerten, D., Heinke, J., Mace, G. M., Persson, L. M., Ramanathan, V., Reyers, B., \& Sörlin, S. (2015). Planetary boundaries: guiding human development on a changing planet. Science, 347(6223). https://doi.org/10.1126/science.1259855

${ }^{28}$ Meyer W. B. (1999). Biosphere. In: Environmental Geology. Encyclopedia of Earth Science. Springer, Dordrecht. https://doi.org/10.1007/1-4020-4494-1_40

29 Dasgupta, P. (2021). The Economics of Biodiversity: The Dasgupta Review. (London: HM Treasury)

30 Dasgupta, P. (2021). The Economics of Biodiversity: The Dasgupta Review. (London: HM Treasury)

31 Pörtner, H. O., Scholes, R. J., Agard, J., Archer, E., Arneth, A., Bai, X., Barnes, D., Burrows, M., Chan, L., Cheung, W. L., Diamond, S., Donatti, C., Duarte, C., Ei senhauer, N., Foden, W., Gasalla, M. A., Handa, C., Hickler, T., Hoegh-Guldberg, O., Ichii, K., Jacob, U., Insarov, G., Kiessling, W., Leadley, P., Leemans, R., Levin, L., Lim, M., Maharaj, S., Managi, S., Marquet, P. A., McElwee, P., Midgley, G., Oberdorff, T., Obura, D., Osman, E., Pandit, R., Pascual, U., Pires, A. P. F., Popp, A., ReyesGarcía, V., Sankaran, M., Settele, J., Shin, Y. J., Sintayehu, D. W., Smith, P., Steiner, N., Strassburg, B., Sukumar, R., Trisos, C., Val, A. L., Wu, J., Aldrian, E., Parmesan, C., Pichs-Madruga, R., Roberts, D. C., Rogers, A. D., Díaz, S., Fischer, M., Hashimoto, S., Lavorel, S., Wu, N., Ngo, H. T. (2021). IPBES-IPCC co-sponsored workshop report on biodiversity and climate change. IPBES and IPCC. DOI:10.5281/zenodo.4782538
32 Hooper, D. U., Chapin III, F. S., Ewel, J. J., Hector, A., Inchausti, P., Lavorel, S., Lawton, J. H., Lodge, D. M., Loreau, M., Naeem, S., Schmid, B., Setälä, H., Symstad, A. J., Vandermeer, J. \& Wardle, D. A. (2005). Effects of biodiversity on ecosystem functioning: a consensus of current knowledge. Ecological Monographs, 75(1), 3-35. https://doi.org/10.1890/04-0922

33 Hooper, D. U., Chapin III, F. S., Ewel, J. J., Hector, A., Inchausti, P., Lavorel, S., Lawton, J. H., Lodge, D. M., Loreau, M., Naeem, S., Schmid, B., Setälä, H., Symstad, A. J., Vandermeer, J. \& Wardle, D. A. (2005). Effects of biodiversity on ecosystem functioning: a consensus of current knowledge. Ecological Monographs, 75(1), 3-35. https://doi.org/10.1890/04-0922

34 Ceballos, G., Ehrlich P. R., \& Raven P. H. (2020). Vertebrates on the brink as indicators of biological annihilation and the sixth mass extinction. Proceedings of the National Academy of Sciences of the United States of America, 117(24), 13596-13602. https://doi.org/10.1073/pnas.1922686117

35 WWF. (2020). Living Planet Report 2020 - Bending the curve of biodiversity loss. Almond, R.E.A., Grooten M., \& Petersen, T. (Eds). WWF, Gland, Switzerland.

${ }^{36}$ Ceballos, G., Ehrlich P. R., \& Raven P. H. (2020). Vertebrates on the brink as indicators of biological annihilation and the sixth mass extinction. Proceedings of the National Academy of Sciences of the United States of America, 117(24), 13596-13602. https://doi.org/10.1073/pnas.1922686117

37 Ripple, W. J., Wolf, C., Newsome, T. M., Barnard, P., Moomaw, W. R. (2020). World Scientists' Warning of a Climate Emergency. BioScience, 70(1), 8-12. https://doi.org/10.1093/biosci/biz088

38 Rockström, J., Steffen, W., Noone, K., Persson, Å., Chapin, F. S., Lambin, E. F., Lenton, T. M., Scheffer, M., Folke, C., Schellnhuber, H. J., Nykvist, B., de Wit, C. A., Hughes, T., van der Leeuw, S., Rodhe, H., Sörlin, S., Snyder, P. K., Costanza, R., Svedin, U., Falenmark, M., Karlberg, L., Corell, R. W., Fabry, V. J., Hansen, J., Walker, B., Liverman, D., Richardson, K., Crutzen, P., \& Foley, J. A. (2009). A safe operating space for humanity. Nature, 461, 472-475. https://doi.org/10.1038/461472a 
39 Ritchie, H. \& Roser, M. (2020). $\mathrm{CO}_{2}$ and Greenhouse Gas Emissions. Published online at OurWorldInData.org.

https://ourworldindata.org/co2-and-other-greenhouse-gas-emissions

40 IPCC. (2014). Climate Change 2014: Synthesis Report. Contribution of Working Groups I, II and III to the Fifth Assessment Report of the Intergovernmental Panel on Climate Change [Core Writing Team, R. K. Pachauri and L. A. Meyer (eds.)]. IPCC, Geneva, Switzerland, 151.

41 Ceballos, G., Ehrlich P. R., \& Raven P. H. (2020). Vertebrates on the brink as indicators of biological annihilation and the sixth mass extinction. Proceedings of the National Academy of Sciences of the United States of America, 117(24), 13596-13602. https://doi.org/10.1073/pnas.1922686117

42 IPCC. (2014). Summary for policymakers. In: Climate Change 2014: Impacts, Adaptation, and Vulnerability. Part A: Global and Sectoral Aspects. Contribution of Working Group II to the Fifth Assessment Report of the Intergovernmental Panel on Climate Change [Field, C. B., V. R. Barros, D. J. Dokken, K. J. Mach, M. D. Mastrandrea, T. E. Bilir, M. Chatterjee, K. L. Ebi, Y. O. Estrada, R. C. Genova, B. Girma, E. S. Kissel, A. N. Levy, S. MacCracken, P. R. Mastrandrea, and L. L. White (eds.)]. Cambridge University Press, Cambridge, United Kingdom and New York, NY, USA, 1-32.

43 Rockström, J., Steffen, W., Noone, K., Persson, Å., Chapin, F. S., Lambin, E. F., Lenton, T. M., Scheffer, M., Folke, C., Schellnhuber, H. J., Nykvist, B., de Wit, C. A., Hughes, T., van der Leeuw, S., Rodhe, H., Sörlin, S., Snyder, P. K., Costanza, R., Svedin, U., Falenmark, M., Karlberg, L., Corell, R. W., Fabry, V. J., Hansen, J., Walker, B., Liverman, D., Richardson, K., Crutzen, P., \& Foley, J. A. (2009). A safe operating space for humanity. Nature, 461, 472-475. https://doi.org/10.1038/461472a

${ }^{44}$ Pörtner, H. O., Scholes, R. J., Agard, J., Archer, E., Arneth, A., Bai, X., Barnes, D., Burrows, M., Chan, L., Cheung, W. L., Diamond, S., Donatti, C., Duarte, C., Eisenhauer, N., Foden, W., Gasalla, M. A., Handa, C., Hickler, T., Hoegh-Guldberg, O., Ichii, K., Jacob, U., Insarov, G., Kiessling, W., Leadley, P., Leemans, R., Levin,
L., Lim, M., Maharaj, S., Managi, S., Marquet, P. A., McElwee, P., Midgley, G., Oberdorff, T., Obura, D., Osman, E., Pandit, R., Pascual, U., Pires, A. P. F., Popp, A., ReyesGarcía, V., Sankaran, M., Settele, J., Shin, Y. J., Sintayehu, D. W., Smith, P., Steiner, N., Strassburg, B., Sukumar, R., Trisos, C., Val, A. L., Wu, J., Aldrian, E., Parmesan, C., Pichs-Madruga, R., Roberts, D. C., Rogers, A. D., Díaz, S., Fischer, M., Hashimoto, S., Lavorel, S., Wu, N., Ngo, H. T. (2021). IPBES-IPCC co-sponsored workshop report on biodiversity and climate change. IPBES and IPCC. DOI:10.5281/zenodo.4782538

45 Pörtner, H. O., Scholes, R. J., Agard, J., Archer, E., Arneth, A., Bai, X., Barnes, D., Burrows, M., Chan, L., Cheung, W. L., Diamond, S., Donatti, C., Duarte, C., Eisenhauer, N., Foden, W., Gasalla, M. A., Handa, C., Hickler, T., Hoegh-Guldberg, O., Ichii, K., Jacob, U., Insarov, G., Kiessling, W., Leadley, P., Leemans, R., Levin, L., Lim, M., Maharaj, S., Managi, S., Marquet, P. A., McElwee, P., Midgley, G., Oberdorff, T., Obura, D., Osman, E., Pandit, R., Pascual, U., Pires, A. P. F., Popp,

A., ReyesGarcía, V., Sankaran, M., Settele, J., Shin, Y. J., Sintayehu, D. W., Smith, P., Steiner, N., Strassburg, B., Sukumar, R., Trisos, C., Val, A. L., Wu, J., Aldrian, E., Parmesan, C., Pichs-Madruga, R., Roberts, D. C., Rogers, A. D., Díaz, S., Fischer, M., Hashimoto, S., Lavorel, S., Wu, N., Ngo, H. T. (2021). IPBES-IPCC co-sponsored workshop report on biodiversity and climate change. IPBES and IPCC. DOI:10.5281/zenodo.4782538

46 United Nations Decade on Ecosystem Restoration. (2021). About the UN Decade. Decade on Restoration.

https://www.decadeonrestoration.org/about-un-decade

47 Dasgupta, P. (2021). The Economics of Biodiversity: The Dasgupta Review. (London: HM Treasury)

48 WWF. (2020). Living Planet Report 2020 - Bending the curve of biodiversity loss. Almond, R.E.A., Grooten M., \& Petersen, T. (Eds). WWF, Gland, Switzerland.

49 Dasgupta, P. (2021). The Economics of Biodiversity: The Dasgupta Review. (London: HM Treasury) 
Deshkan Ziibi Conservation Impact Bond Project: On Conservation Finance, Decolonization, and Community-Based Participatory Research, Vol. 1 [2021], Iss. 1, Art. 1

50 Wackernagel, M., \& Rees, W. E. (1997). Perceptual and structural barriers to investing in natural capital: economics from an ecological footprint perspective. Ecological Economics, 20(1), 3-24.

https://doi.org/10.1016/S0921-8009(96)00077-8

51 David Suzuki Foundation. (2021). What is natural capital? David Suzuki Foundation. https://davidsuzuki.org/what-you-can-do/what-is-natural-capital//

52 David Suzuki Foundation. (n.d.). What is natural capital?. David Suzuki Foundation. https://davidsuzuki.org/what-you-can-do/what-is-natural-capital/

53 Díaz, S., Pascual, U., Stenseke, M., Martín-López, B., Watson, R. T., Molnár, Z., Hill, R., Chan, K. M. A., Baste, I. A., Brauman, K. A., Polasky, S., Church, A., Lonsdale, M., Larigauderie, A., Leadley, P. W., van Oudenhoven, A. P. E., van de Plaat, F., Schröter, M., Lavorel, S., Aumeeruddy-Thomas, Y., Bukvareva, E., Davies, K., Demissew, S., Erpul, G., Failler, P., Guerra, C. A., Hewitt, C. L., Keune, H., Lindley, S., \& Shirayama, Y. (2018). Assessing nature's contributions to people. Science, 359(6373), 270-272. https://doi.org/10.1126/science.aap8826

54 Natural Capital Coalition. (2016). Natural Capital Protocol. Capitals Coalition https://capitalscoalition.org/capitals-approach/natural-capital-protocol/?fwp_filter_tabs=guide_supplement

55 Dasgupta, P. (2021). The Economics of Biodiversity: The Dasgupta Review. (London: HM Treasury)

56 Dasgupta, P. (2021). The Economics of Biodiversity: The Dasgupta Review. (London: HM Treasury)

57 Global Commission on Adaptation. (2019). Adapt Now: A Global Call for Leadership on Climate Resilience. Global Commission on Adaptation. https://files.wri.org/s3fs-public/uploads/GlobalCommission_Report_FINAL.pdf

58 Global Commission on Adaptation. (2019). Adapt Now: A Global Call for Leadership on Climate Resilience. Global Commission on Adaptation. https://files.wri.org/s3fs-public/uploads/GlobalCommission_Report_FINAL.pdf
59 Global Commission on Adaptation. (2019). Adapt Now: A Global Call for Leadership on Climate Resilience. Global Commission on Adaptation. https://files.wri.org/s3fs-public/uploads/GlobalCommission_Report_FINAL.pdf

60 WWF. (2020). Living Planet Report 2020 - Bending the curve of biodiversity loss. Almond, R.E.A., Grooten M., \& Petersen, T. (Eds). WWF, Gland, Switzerland.

61 Banerjee, B. S., \& Arjaliès, D-L. (2021). Celebrating the end of enlightenment: organization theory in the age of the Anthropocene and Gaia (and why neither is the solution to our ecological crisis). Organization Theory. https:// doi.org/10.1177/26317877211036714

62 United Nations Climate and Environment. (2021). 2021: Critical year to 'reset our relationship with nature' - UN chief. UN News. https://news.un.org/en/ story/2021/02/1085382

63 Wildcat, M., McDonald, M., Irlbacher-Fox, S., \& Coulthard, G. (2014). Learning from the land: Indigenous land based pedagogy and decolonization. Decolonization: Indigeneity, Education \& Society, 3(3)

${ }^{64}$ Ballantyne, E. F. (2014). Dechinta Bush University: Mobilizing a knowledge economy of reciprocity, resurgence and decolonization. Decolonization: Indigeneity, Education \& Society, 3(3), 67-85

65 Ballantyne, E. F. (2014). Dechinta Bush University: Mobilizing a knowledge economy of reciprocity, resurgence and decolonization. Decolonization: Indigeneity, Education \& Society, 3(3), 76-77

${ }^{66}$ Banerjee, B. S., \& Arjaliès, D-L. (2021). Celebrating the end of enlightenment: organization theory in the age of the Anthropocene and Gaia (and why neither is the solution to our ecological crisis). Organization Theory. https:// doi.org/10.1177/26317877211036714

67 History.com Editors. (2020). Enlightenment. History.

https://www.history. com/topics/british-history/enlightenment 
68 Marshall, P. (2015). Nature's web: Rethinking our place on earth. Routledge

69 Marshall, P. (2015). Nature's web: Rethinking our place on earth. Routledge.

70 Winter, D. D. N. (1996). Ecological psychology: healing the split between planet and self. HarperCollins College Publishers.

71 Fleischacker, S. (2020). Adam Smith's Moral and Political Philosophy. The Stanford Encyclopedia of Philosophy. Metaphysics Research Lab, Stanford University. https://plato.stanford.edu/entries/smith-moral-political/

72 Jonsson, F. A. (2012). The Industrial Revolution in the Anthropocene. The Journal of Modern History, 84(3), 679-696. https://doi.org/10.1086/666049

73 Winter, D. D. N. (1996). Ecological psychology: healing the split between planet and self. HarperCollins College Publishers.

74 Sandifer, P. A., Sutton-Grier, A. E., \& Ward, B. P. (2015). Exploring connections among nature, biodiversity, ecosystem services, and human health and well-being: opportunities to enhance health and biodiversity conservation. Ecosystem Services, 12, 1-15. https://doi.org/10.1016/j.ecoser.2014.12.007

75 Zylstra, M. J., Knight, A. T., Esler, K. J., \& Le Grange, L. L. (2014). Connectedness as a core conservation concern: an interdisciplinary review of theory and a call for practice. Springer Science Reviews, 2, 119-143.

https://doi.org/10.1007/s40362-014-0021-3

76 Chawla, L. \& Cushing, D. F. (2007). Education for strategic environmental behavior. Environmental Education Research, 13(4), 437-452. https://doi. org/10.1080/13504620701581539

77 Raygorodetsky, G. (2018). Indigenous peoples defend Earth's biodiversity but they're in danger. National Geographic. https://www.nationalgeographic. com/environment/article/can-indigenous-land-stewardship-protect-biodiversity

78 Mitchell, S. (2018). Sacred Instructions: Indigenous Wisdom for Living Spirit-Based Change. North Atlantic Books.
79 Haudenosaunee Confederacy. (n.d.). Values. Haudenosaunee Confederacy. Retrieved June 21, 2021, from https://www.haudenosauneeconfederacy.com/ values/

80 Toledo, V. M. (2013). Indigenous peoples and biodiversity. Encyclopedia of Biodiversity, 3, 269-278. https://doi.org/10.1016/B978-0-12-384719-5.00299-9

81 Schuster, R., Germain, R. R., Bennett, J. R., Reo, N. J., \& Arcese, P. (2019). Vertebrate biodiversity on indigenous-managed lands in Australia, Brazil, and Canada equals that in protected areas. Environmental Science \& Policy, 101, 1-6. https://doi.org/10.1016/j.envsci.2019.07.002

82 Tauli-Corpuz, V. (2016). Statement of Ms. Victoria Tauli-Corpuz, Special Rapporteur on the Rights of Indigenous Peoples, at the 71st session of the General Assembly. United Nations Human Rights Office of the High Commissioner. https://www.ohchr.org/en/NewsEvents/Pages/DisplayNews.aspx?NewsID=20748\&LangID=E

83 Stephenson J., Berkes F., Turner N. J., and Dick J. (2012). Biocultural conservation of marine ecosystems: examples from New Zealand and Canada. Indian Journal of Traditional Knowledge, 13(2): 257-265.

84 Turner, N. (2014). Ancient pathways, ancestral knowledge: ethnobotany and ecological wisdom of Indigenous peoples of northwestern North America. McGill-Queen's University Press, Montréal, Québec.

85 IPBES. (2019). Global assessment report on biodiversity and ecosystem services of the Intergovernmental Science-Policy Platform on Biodiversity and Ecosystem Services. Brondizio, E. S., Settele, J., Díaz, S., \& Ngo, H. T. (editors). IPBES secretariat, Bonn, Germany. https://doi.org/10.5281/zenodo.3831673

${ }^{86}$ Fligg, R. A., \& Robinson, D. T. (2020). Reviewing First Nation land management regimes in Canada and exploring their relationship to community well-being. Land Use Policy, 90, 104245. https://doi.org/10.1016/j.landusepol.2019.104245 
87 Descola, P. (2013). Beyond Nature and Culture. University of Chicago Press.

${ }^{88}$ Kellert, S. R., \& Wilson, E. O. (1993). The Biophilia Hypothesis. Island Press.

${ }^{89}$ Marshall, P. (2015). Nature's web: Rethinking our place on earth. Routledge.

90 Lehmann, S. (2019). Reconnecting with nature: developing urban spaces in the age of climate change. Emerald Open Research, 1.

91 Donald, D. (2016). Chapter three: from what does ethical relationality flow? An "Indian" Act in Three Artifacts. The Ecological Heart of Teaching Radical Tales of Refuge and Revival for Classrooms and Communities, 478, 10-16.

92 Kerr, J., \& Ferguson, K. A. (2021). Ethical relationality and Indigenous storywork principles as methodology: addressing settler-colonial divides in inner-city educational research. Qualitative Inquiry, 27(6), 706-715. https://doi. org/10.1177/1077800420971864

${ }_{93}$ Deloria, V. (1999). Spirit \& Reason: The Vine Deloria, Jr., Reader. Fulcrum Publishing.

94 Deloria, V. (1999). Spirit \& Reason: The Vine Deloria, Jr., Reader. Fulcrum Publishing

95 Jacobs, S., Zafra-Calvo, N., Gonzalez-Jimenez, D., Guibrunet, L., Benessaiah, K., Berghöfer, A., Chaves-Chaparro, J., Díaz, S., Gomez-Baggethun, E., Lele,

S., Martín-López, B., Masterson, V. A., Merçon, J., Moersberger, H., Muraca, B., Norström, A., O'Farrell, P., Ordonez, J. C., Prieur-Richard, A-H., Rincón-Ruiz, A., Sitas, N., Subramanian, S. M., Tadesse, W., van Noordwijk, M., Pascual, U., \& Balvanera, P. (2020). Use your power for good: Plural valuation of nature - the Oaxaca statement. Global Sustainability, 3. https://doi.org/10.1017/sus.2020.2

96 Photo by Lukasz Szmigiel on Unsplash

${ }^{97}$ Kari-Oca 2 Declaration. (2012). Kari-Oca 2 Declaration. Indigenous Environmental Network. http:// www.ienearth.org/kari-oca-2-declaration
98 See a reflective essay on relational accounting: Arjaliès, D-L., (2020). What Trees Taught Me About COVID-19: On Relational Accounting and Other Magic. Forthcoming in the Accounting, Auditing \& Accountability Journal (AAAJ). https://ssrn.com/abstract=3652440

99 Watson, J. E. M., Venter, O., Lee, J., Jones, K. R., Robinson, J. G., Possingham, H. P., \& Allan, J. R. (2018). Protect the last of the wild. Nature, 563, 27-30. https://doi.org/10.1038/d41586-018-07183-6

${ }^{100}$ Soto-Navarro, C., Ravilious, C., Arnell, A., de Lamo, X., Harfoot, M., Hill, S. L. L., Wearn, O. R., Santoro, M., Bouvet, A., Mermoz, S., Le Toan, T., Xia, J., Liu, S., Yuan, W., Spawn, S. A., Gibbs, H. K., Ferrier, S., Harwood, T., Alkemade, R., Schipper, A. M., Schmidt-Traub, G. (2020). Mapping co-benefits for carbon storage and biodiversity to inform conservation policy and action. Philosophical Transactions of the Royal Society. http://doi.org/10.1098/rstb.2019.0128

101 Olmsted, P. (2021). Invest in Nature: Scaling Conservation Finance in Canada for a Smart Economy. Smart Prosperity Institute.

https://institute.smartprosperity.ca/sites/default/files/Nature_Report.pdf

${ }^{102}$ Smith, R. B. (2020). Enhancing Canada's Climate Change Ambitions with Natural Climate Solutions. Vedalia Biological Inc. Galiano, Canada. http://doi.org/10.13140/RG.2.2.18243.02088

${ }^{103}$ Environment and Climate Change Canada. (2020). United Nations Framework Convention on Climate Change. Government of Canada. https://www. canada.ca/en/environment-climate-change/corporate/international-affairs/partnerships-organizations/united-nations-framework-climate-change.html

${ }^{104}$ Environment and Climate Change Canada. (2020). Convention on Biological Diversity. Government of Canada. https://www.canada.ca/en/environment-climate-change/corporate/international-affairs/partnerships-organizations/biological-diversity-convention.html

105 United Nations. (2011). Strategic Plan for Biodiversity 2011-2020. United Nations Decade on Biodiversity. https://www.cbd.int/undb/media/factsheets/ undb-factsheet-sp-en.pdf 
106 United Nations. (2011). Strategic Plan for Biodiversity 2011-2020. United Nations Decade on Biodiversity.

https://www.cbd.int/undb/media/factsheets/undb-factsheet-sp-en.pdf

107 The Pathway Team. (2020). Pathway to Canada Target 1, biodiversity, conser vation. Conservation 2020.

https://www.conservation2020canada.ca/the-pathway

108 The Pathway Team. (2020). Pathway to Canada Target 1, biodiversity, conservation. Conservation 2020.

https://www.conservation2020canada.ca/the-pathway

109 The Pathway Team. (2020). Pathway to Canada Target 1, biodiversity, conservation. Conservation 2020

https://www.conservation2020canada.ca/the-pathway

110 WWF Canada. (2020). WWF-Canada applauds Canada's commitment to Leader's Pledge for Nature and High Ambition Coalition for Nature and People. WWF. https://wwf.ca/media-releases/leaders-pledge-for-nature-high-ambitioncoalition-for-nature-and-people/

111 Environment and Climate Change Canada. (2020). Canada joins the High Ambition Coalition for Nature and People [News release]. Government of Canada. https://www.canada.ca/en/environment-climate-change/news/2020/09/ canada-joins-the-high-ambition-coalition-for-nature-and-people.htmll

112 High Ambition Coalition for Nature and People. (2021). High Ambition Coalition for Nature and People. One Planet Summit. https://www.oneplanetsummit. $\mathrm{fr} / \mathrm{en} /$ coalitions-82/high-ambition-coalition-nature-and-people-190

113 International Institute for Sustainable Development. (2021). UN Biodiversity Conference (CBD COP 15) (Part 1). SDG Knowledge Hub.

http://sdg.iisd.org/events/2020-un-biodiversity-conference/

114 Government of Canada. (2016). Paris Agreement. Government of Canada. https://www.canada.ca/en/environment-climate-change/services/climate-change/paris-agreement.html
115 Walsh, M., \& Graney, E. (2021). Canada announces goal of cutting greenhouse gas emissions by up to 45 per cent by 2030 . The Globe and Mail. https://www.theglobeandmail.com/politics/article-canada-to-cut-greenhousegas-emissions-by-up-to-45-per-cent-by-2030/

116 Government of Canada. (2021). Net-Zero Emissions by 2050. Government of Canada. https://www.canada.ca/en/services/environment/weather/climatechange/climate-plan/net-zero-emissions-2050.html

117 Department of Finance Canada. (2021). Government of Canada highlights Budget 2021 investments to create a healthy environment for a healthy economy. Government of Canada. https://www.canada.ca/en/department-finance/ news/2021/04/government-of-canada-highlights-budget-2021-investments-tocreate-a-healthy-environment-for-a-healthy-economy.html

118 Department of Finance Canada. (2021). Government of Canada highlights Budget 2021 investments to create a healthy environment for a healthy econ omy. Government of Canada. https://www.canada.ca/en/department-finance/ news/2021/04/government-of-canada-highlights-budget-2021-investments-tocreate-a-healthy-environment-for-a-healthy-economy.html

${ }^{119}$ Nature United. (2021). Federal budget makes new commitments to protect 25\% of Canada's ecosystems. Nature United. https://www.natureunited.ca/ newsroom/2021-federal-budget-climate-change-natural-solutions/

${ }^{120}$ IUCN. (2021). Nature-based solutions for people and planet. IUCN. https:// www.iucn.org/theme/nature-based-solutions

121 Seddon, N., Sengupta, S., García-Espinosa, M., Hauler, I., Herr, D. and Rizvi, A.R. (2019). Nature-based Solutions in Nationally Determined Contributions:

Synthesis and recommendations for enhancing climate ambition and action by 2020. Gland, Switzerland and Oxford, UK: IUCN and University of Oxford.

122 Wells, J. V. (2020). Overlap between carbon stores and intact boreal woodland caribou ranges in Canada's boreal forest. Encyclopedia of the World's Biomes, 3, 279-286. https://doi.org/10.1016/B978-0-12-409548-9.12444-3 
Deshkan Ziibi Conservation Impact Bond Project: On Conservation Finance, Decolonization, and Community-Based Participatory Research, Vol. 1 [2021], Iss. 1, Art. 1

${ }^{123}$ Carlson, M., Chen, J., Elgie, S., Henschel, C., Montenegro, Á., Roulet, N., Scott, N., Tarnocai, C., \& Wells, J. (2011). Maintaining the role of Canada's forests and peatlands in climate regulation. The Forestry Chronicle, 86(4), 434-443. https://doi.org/10.5558/tfc86434-4

124 Townsend, J., Moola, F., \& Craig, M. K. (2020). Indigenous Peoples are critical to the success of nature-based solutions to climate change. FACETS, 551-556. https://doi.org/10.1139/facets-2019-0058

${ }^{125}$ Wilson, K. (2018). Pulling Together: Foundations Guide. Victoria, BC: BCcampus. https:// opentextbc.ca/indigenizationfoundations/

126 obinson, A. (2018). Turtle Island. The Canadian Encyclopedia.

https://www.thecanadianencyclopedia.ca/en/article/turtle-island

${ }^{127}$ Report of the Royal Commission on Aboriginal Peoples. (1991). Royal Commission on Aboriginal Peoples. https://www.bac-lac.gc.ca/eng/discover/aboriginal-heritage/royal-commission-aboriginal-peoples/Pages/final-report.aspx

${ }^{128}$ Government of Canada. (2008). Treaties and Agreements. Government of Canada. https://www.rcaanc-cirnac.gc.ca/eng/1100100028574/1529354437231

${ }^{129}$ Neimanis, V. P. (2011). Crown Land. The Canadian Encyclopedia.

https:// www.thecanadianencyclopedia.ca/en/article/crown-land

${ }^{130}$ Government of Ontario. (2015). Crown Land. Ontario.

https://www.ontario.ca/page/crown-land

${ }^{131}$ Statistics Canada. (2011). Distribution of First Nations people, First Nations people with and without registered Indian status, and First Nations people with registered Indian status living on or off reserve, Canada, provinces and territories. Statistics Canada. https://www12.statcan.gc.ca/nhs-enm/2011/as-sa/99011-x/2011001/tbl/tbl03-eng.cfm

132 Wilson, K. (2018). Pulling Together: Foundations Guide. Victoria, BC: BCcampus. https:// opentextbc.ca/indigenizationfoundations/
133 United Nations. (2015). United Nations Declaration on the Rights of Indigenous Peoples. Department of Economic and Social Affairs. https://www.un.org/ development/desa/indigenouspeoples/declaration-on-the-rights-of-indigenous-peoples.html/

${ }^{134}$ Faguy, Y. (2021). A new beginning. CBC/ABC National. http://nationalmagazine.ca/en-ca/articles/law/in-depth/2021/a-new-beginning

135 Harper, S. (2008). Statement of apology to former students of Indian Residential Schools [Presentation]. Government of Canada. https://www.rcaanc-cirnac.gc.ca/eng/1100100015644/1571589171655

136 Truth and Reconciliation Commission of Canada. (2015). Truth and Reconciliation Commission of Canada: Calls to Action. Truth and Reconciliation of Canada.

137 Government of Canada. (2018). Overview of a Recognition and Implementation of Indigenous Rights Framework [Archived]. Government of Canada. https://www.rcaanc-cirnac.gc.ca/eng/1536350959665/1539959903708

${ }^{138}$ Wildcat, M., McDonald, M., Irlbacher-Fox, S., \& Coulthard, G. (2014). Learning from the land: Indigenous land based pedagogy and decolonization. Decolonization: Indigeneity, Education \& Society, 3(3).

139 Truth and Reconciliation Commission of Canada. (2015). Canada's Residential Schools: Reconciliation: The Final Report of the Truth and Reconciliation Commission of Canada, Volume 6. Montreal; Kingston; London; Chicago: McGill-Queen's University Press.

140 Indigenous Circle of Experts. (2018). We Rise Together: achieving pathway to Canada target 1 through the creation of Indigenous Protected and Conserved Areas in the spirit and practice of reconciliation. Indigenous Circle of Experts.

141 Conservation through Reconciliation Partnership. (2021). Conservation through Reconciliation. Conservation through Reconciliation Partnership. https://conservation-reconciliation.ca 
142 Williams-Davidson, T., \& Sarra, J. (2021). Haida law of gina 'waadluxan gud ad kwaagiida and Indigenous rights in conservation finance. https://ccli.ubc. ca/resource/haida-law-of-gina-waadluxan-gud-ad-kwaagiida-and-indigenousrights-in-conservation-finance/

${ }^{143}$ United Nations. (2007). United Nations Declaration on the Rights of Indigenous Peoples. United Nations. https://www.un.org/development/desa/indigenouspeoples/declaration-on-the-rights-of-indigenous-peoples.html

${ }^{144}$ Meyers, D., Bohorquez, J., Cumming, T., Emerton, L., Heuvel, O.v.d., Riva, M., \& Victurine, R. (2020). Conservation Finance: A Framework. Conservation Finance Alliance. www.cfalliance.org. DOI: 10.13140/RG.2.2.14186.88000

${ }^{145}$ Meyers, D., Bohorquez, J., Cumming, T., Emerton, L., Heuvel, O.v.d., Riva, M., \& Victurine, R. (2020). Conservation Finance: A Framework. Conservation Finance Alliance. www.cfalliance.org. DOI: 10.13140/RG.2.2.14186.88000

${ }^{146}$ Meyers, D., Bohorquez, J., Cumming, T., Emerton, L., Heuvel, O.v.d., Riva, M., \& Victurine, R. (2020). Conservation Finance: A Framework. Conservation Finance Alliance. www.cfalliance.org. DOI: 10.13140/RG.2.2.14186.88000

${ }^{147}$ Clark, R., Reed, J., \& Sunderland, T. (2018). Bridging funding gaps for climate and sustainable development: pitfalls, progress and potential of private finance. Land Use Policy, 71, 335-346. https://doi.org/10.1016/j.landusepol.2017.12.013

148 Olmsted, P. (2021). Invest in Nature: Scaling Conservation Finance in Canada for a Smart Economy. Smart Prosperity Institute. https://institute.smartprosperity.ca/sites/default/files/Nature_Report.pdf

149 Olmsted, P. (2021). Invest in Nature: Scaling Conservation Finance in Canada for a Smart Economy. Smart Prosperity Institute. https://institute.smartprosperity.ca/sites/default/files/Nature_Report.pdf

${ }^{150}$ Deutz, A., Heal, G. M., Niu, R., Swanson, E., Townshend, T., Li, Z., Delmar, A., Meghji, A., Sethi, S. A., \& Tobin-de la Puente, J. (2020). Financing Nature: closing the global biodiversity financing gap. The Paulson Institute, the Nature Conservancy, and the Cornell Atkinson Center for Sustainability. http://rgdoi. net/10.13140/RG.2.2.26226.32968
151 Tobin-de la Puente, J., and Mitchell, A. W. (2021). The Little Book of Investing in Nature. Global Canopy: Oxford.

152 Tobin-de la Puente, J., and Mitchell, A. W. (2021). The Little Book of Investing in Nature. Global Canopy: Oxford.

153 Tobin-de la Puente, J., and Mitchell, A. W. (2021). The Little Book of Investing in Nature. Global Canopy: Oxford.

154 Parker, C., Cranford, M., Oakes, N., Leggett, M. (2012). The Little Biodiversity Finance Book. Global Canopy Programme, Oxford.

155 Deutz, A., Heal, G. M., Niu, R., Swanson, E., Townshend, T., Li, Z., Delmar, A., Meghji, A., Sethi, S. A., \& Tobin-de la Puente, J. (2020). Financing Nature: closing the global biodiversity financing gap. The Paulson Institute, the Nature Conservancy, and the Cornell Atkinson Center for Sustainability. http://rgdoi. net/10.13140/RG.2.2.26226.32968

156 Parker, C., Cranford, M., Oakes, N., Leggett, M. (2012). The Little Biodiversity Finance Book. Global Canopy Programme, Oxford.

157 Deutz, A., Heal, G. M., Niu, R., Swanson, E., Townshend, T., Li, Z., Delmar, A., Meghji, A., Sethi, S. A., \& Tobin-de la Puente, J. (2020). Financing Nature: closing the global biodiversity financing gap. The Paulson Institute, the Nature Conservancy, and the Cornell Atkinson Center for Sustainability. http://rgdoi. net/10.13140/RG.2.2.26226.32968

158 Kosciolek, K., Kwan, N., Longaphy, C., \& Wilson, R. (2020). Financing conservation: how conservation financing could be used to protect Canada's ecosystems. Nature Conservancy of Canada and Rally Assets. https://rallyassets.com/ wp-content/uploads/2020/11/Financing-Conservation.pdf.

159 Deutz, A., Heal, G. M., Niu, R., Swanson, E., Townshend, T., Li, Z., Delmar, A., Meghji, A., Sethi, S. A., \& Tobin-de la Puente, J. (2020). Financing Nature: closing the global biodiversity financing gap. The Paulson Institute, the Nature Conservancy, and the Cornell Atkinson Center for Sustainability. http://rgdoi. net/10.13140/RG.2.2.26226.32968 
Deshkan Ziibi Conservation Impact Bond Project: On Conservation Finance, Decolonization, and Community-Based Participatory Research, Vol. 1 [2021], Iss. 1, Art. 1

${ }^{160}$ World Bank Group. (2020). Mobilizing Private Finance for Nature. World Bank Group.

161 Tobin-de la Puente, J., and Mitchell, A. W. (2021). The Little Book of Investing in Nature. Global Canopy: Oxford.

162 Task Force on Climate-related Financial Disclosures. (2020). Climate change presents financial risk to the global economy. TCFD. https://www.fsb-tcfd.org/

163 Taskforce on Nature-related Financial Disclosures. (2021). Delivering a risk management and disclosure framework for organisation to report and act on nature-related risks. TNFD. https://tnfd.info/

164 United Nations. (2015). Paris Agreement. United Nations

${ }^{165}$ Conventional on Biological Diversity. (2020). Aichi Biodiversity Targets. Convention on Biological Diversity. https://www.cbd.int/sp/targets/

166 United Nations. (2015). Transforming our world: the 2030 Agenda for Sustainable Development. United Nations.

167 Tobin-de la Puente, J., and Mitchell, A. W. (2021). The Little Book of Investing in Nature. Global Canopy: Oxford.

${ }^{168}$ Meyers, D., Bohorquez, J., Cumming, T., Emerton, L., Heuvel, O.v.d., Riva, M., \& Victurine, R. (2020). Conservation Finance: A Framework. Conservation Finance Alliance. www.cfalliance.org. DOI: 10.13140/RG.2.2.14186.88000

169 UNDP. (2018). The BIOFIN Workbook 2018: Finance for Nature. The Biodiversity Finance Initiative. United Nations Development Programme: New York.

170 Meyers, D., Bohorquez, J., Cumming, T., Emerton, L., Heuvel, O.v.d., Riva, M., \& Victurine, R. (2020). Conservation Finance: A Framework. Conservation Finance Alliance. www.cfalliance.org. DOI: 10.13140/RG.2.2.14186.88000.
171 Meyers, D., Bohorquez, J., Cumming, T., Emerton, L., Heuvel, O.v.d., Riva, M., \& Victurine, R. (2020). Conservation Finance: A Framework. Conservation Finance Alliance. www.cfalliance.org. DOI: 10.13140/RG.2.2.14186.88000

172 Meyers, D., Bohorquez, J., Cumming, T., Emerton, L., Heuvel, O.v.d., Riva, M., \& Victurine, R. (2020). Conservation Finance: A Framework. Conservation Finance Alliance. www.cfalliance.org. DOI: 10.13140/RG.2.2.14186.88000

173 United Nations. (1997). Glossary of Environment Statistics. United Nations.

${ }^{174}$ Nature United. (2020). A Blueprint for Action: Conservation Finance to Support Canada's Target 1. Nature United. https://www.natureunited.ca/what-wedo/our-priorities/innovating-for-climate-change/a-blueprint-for-action-in-canada/

175 Nature United. (2020). A Blueprint for Action: Conservation Finance to Support Canada's Target 1. Nature United. https://www.natureunited.ca/what-wedo/our-priorities/innovating-for-climate-change/a-blueprint-for-action-in-canada/

${ }^{176}$ Nature United. (2020). A Blueprint for Action: Conservation Finance to Support Canada's Target 1. Nature United. https://www.natureunited.ca/what-wedo/our-priorities/innovating-for-climate-change/a-blueprint-for-action-in-canada/

177 Nature United. (2020). A Blueprint for Action: Conservation Finance to Support Canada's Target 1. Nature United. https://www.natureunited.ca/what-wedo/our-priorities/innovating-for-climate-change/a-blueprint-for-action-in-canada/

178 Meyers, D., Bohorquez, J., Cumming, T., Emerton, L., Heuvel, O.v.d., Riva, M., \& Victurine, R. (2020). Conservation Finance: A Framework. Conservation Finance Alliance. www.cfalliance.org. DOI: 10.13140/RG.2.2.14186.88000

${ }^{179}$ Meyers, D., Bohorquez, J., Cumming, T., Emerton, L., Heuvel, O.v.d., Riva, M., \& Victurine, R. (2020). Conservation Finance: A Framework. Conservation Finance Alliance. www.cfalliance.org. DOI: 10.13140/RG.2.2.14186.88000

180 Galloway, I. (2015). Perspectives on Impact Bonds: Scaling the social sector through innovation and impact bonds. Brookings 
181 Milburn, R. (2015). U.S.'s First Impact Bond a Bust. PENTA. https://blogs. barrons.com/penta/2015/07/15/u-s-s-first-impact-bond-a-bust/

182 Raven Indigenous Capital Partners. (2021). Outcomes financing. Raven Indigenous Capital Partners. https://ravencapitalpartners.ca/investments/outcomes-financing

${ }^{183}$ Raven Indigenous Capital Partners. (2021). Our Impact. Raven Indigenous Capital Partners. https://ravencapitalpartners.ca/about-us/our-impact

${ }^{184}$ Quantified Ventures. (2018). Sharing Risk, Rewarding Outcomes: The Environmental Impact Bond. Quantified Ventures. https://www.quantifiedventures. com/blog/what-is-an-environmental-impact-bond

185 Quantified Ventures. (2016). DC Water: First Ever Environmental Impact Bond. Quantified Ventures. https://www.quantifiedventures.com/dc-water

${ }^{186}$ Blue Forest Conservation. (2017). Forest Resilience Bond. Blue Forest. https://www.blueforest.org/forest-resilience-bond

187 Blue Forest Conservation. (2018). The Yuba Project. Blue Forest. https://www.blueforest.org/the-yuba-project

188 Zoological Society of London (ZSL). (n.d.). Rhino Impact Investment Project. Zoological Society of London. https://www.zsl.org/conservation/our-priorities/ wildlife-back-from-the-brink/animals-on-the-edge/rhino-impact-investment

189 UNDP Ecosystems and Biodiversity. (2018). Results for Rhinos: Using Innovative Financing to Achieve Conservation Outcomes. Exposure.

https:// undp-biodiversity.exposure.co/results-for-rhinos

${ }^{190}$ Sguazzin, A. (2021). World's First Wildlife Bond to Track Rhino Numbers in Africa. Bloomberg. https://www.bloomberg.com/news/articles/2021-03-24/ world-s-first-wildlife-bond-to-track-rhino-populations-in-africa

191 Meyers, D., Bohorquez, J., Cumming, T., Emerton, L., Heuvel, O.v.d., Riva, M., \& Victurine, R. (2020). Conservation Finance: A Framework. Conservation Finance Alliance. www.cfalliance.org. DOI: 10.13140/RG.2.2.14186.88000
192 United Nations Convention to Combat Desertification. (n.d.). An impact investment fund for land degradation neutrality. United Nations Convention to Combat Desertification. https://www.unccd.int/actions/impact-investment-fund-land-degradation-neutrality

193 Global Affairs Canada. (2021, January 11). Canada announces support to combat land degradation and desertification in developing countries. Government of Canada. https:// www.canada.ca/en/global-affairs/news/2021/01/canada-announces-support-to-combat-land-degradation-and-desertification-in-developing-countries. html

${ }^{194}$ HSBC Pollination Climate Asset Management. (2020). Nature is Capital. HSBC. https://www.assetmanagement.hsbc.co.uk/en/institutional-investor/ news-and-insights/climateassetmanagement-uk

195 The Centre for Land and Water Stewardship. (1994). The uniqueness of Carolinian Canada. Carolinian Canada. https://caroliniancanada.ca/legacy/FactSheets_CCUniqueness.htm

${ }^{196}$ WWF-Canada. (2017). New hope for at-risk wildlife with launch of habitat gardening program. WWF-Canada. https://wwf.ca/media-releases/new-hopefor-at-risk-wildlife-with-launch-of-habitat-gardening-program/

197 CAUT. (2021). Guide to Acknowledging First Peoples \& Traditional Territory CAUT. https://www.caut.ca/content/guide-acknowledging-first-peoples-traditional-territory

${ }^{198}$ Carolinian Canada. (2021). We live on traditional territories. Carolinian Canada. https://caroliniancanada.ca/

199 Native Land Digital. (2021). Native Land. Native Land Digital. Retrieved June 21, 2021 from https://native-land.ca/

200 The Centre for Land and Water Stewardship. (1994). The uniqueness of Carolinian Canada. Carolinian Canada. https://caroliniancanada.ca/legacy/FactSheets_CCUniqueness.htm 
Deshkan Ziibi Conservation Impact Bond Project: On Conservation Finance, Decolonization, and Community-Based Participatory Research, Vol. 1 [2021], Iss. 1, Art. 1

201 Jalava, J.V., Kanter, M. \& Hodgkiss, S. (2015). Be part of the big picture: Big picture report card discussion paper. Carolinian Canada Coalition

${ }^{202}$ The Centre for Land and Water Stewardship. (1994). The uniqueness of Carolinian Canada. Carolinian Canada. https://caroliniancanada.ca/legacy/ FactSheets_CCUniqueness.htm

203 alava J. V., Sorrill, P. J., Henson, J., and Brodribb, K. (2004). The big picture project: developing a natural heritage vision for Canada's southernmost ecological region. Carolinian Canada. http://longpointbiosphere.com/download/ Environment/2007-06-02-10-25-43.pdf

${ }^{204}$ Carolinian Canada. (2013). The Landowner Leaders Program. Carolinian Canada. https://caroliniancanada.ca/landowner-leaders

${ }^{205}$ Carolinian Canada. (n.d.) Carolinian Canada - A Special But Threatened Landscape. Carolinian Canada. https://caroliniancanada.ca/legacy/ConservationPrograms_greening_threatened.htm

${ }^{206}$ Carolinian Canada Coalition. (2019) Growing our green future together. Carolinian Canada Coalition. https://caroliniancanada.ca/about

${ }^{207}$ Carolinian Canada. (n.d.) What is the Big Picture? Carolinian Canada. https://caroliniancanada.ca/legacy/ConservationPrograms_BigPicture.htm

208 Government of Canada. (2014). Conserve Ontario's Carolinian Forests: Preserve Songbird Species at Risk, Chapter 1. Government of Canada. https:// www.canada.ca/en/environment-climate-change/services/migratory-bird-conservation/publications/ontario-carolinian-forests-preserve-songbird/chapter-1. htmll

${ }^{209}$ Crins, W. J., Gray, P. A., Uhlig, W. C., and Wester, M. C. (2009). The ecosystems of Ontario, part 1: ecozones and ecoregions. Ministry of Natural Resources Ontario
${ }^{210}$ Government of Canada. (2014). Conserve Ontario's Carolinian Forests: Preserve Songbird Species at Risk, Chapter 1. Government of Canada. https:// www.canada.ca/en/environment-climate-change/services/migratory-bird-conservation/publications/ontario-carolinian-forests-preserve-songbird/chapter-1. html

${ }^{211}$ Carolinian Canada Coalition. (2019) Growing our green future together. Carolinian Canada Coalition. https://caroliniancanada.ca/about

${ }^{212}$ Carolinian Canada Coalition. (2019) Growing our green future together. Carolinian Canada Coalition. https://caroliniancanada.ca/about

${ }^{213}$ Kanter, M. (2005). The future of species and ecosystems at risk in Carolinian Canada: are we on the right track? Parks Research Forum of Ontario.

${ }^{214}$ Kanter, M. (2005). The future of species and ecosystems at risk in Carolinian Canada: are we on the right track? Parks Research Forum of Ontario.

${ }^{215}$ Carolinian Canada Coalition. (2014). Carolinian Canada's timeline. Carolinian Canada Coalition. https://caroliniancanada.ca/carolinian-canada-timeline

${ }^{216}$ Eagles, P. F. J. \& Beechey, T. J. (1985). Critical Unprotected Natural Areas in the Carolinian Life Zone of Canada: Final Report. World Wildlife Fund Canada.

${ }^{217}$ Carolinian Canada Coalition. (2019) Growing our green future together. Carolinian Canada Coalition. https://caroliniancanada.ca/about

218 Jalava J. V., Sorrill, P. J., Henson, J., and Brodribb, K. (2004). The big picture project: developing a natural heritage vision for Canada's southernmost ecological region. Carolinian Canada. http://longpointbiosphere.com/download/ Environment/2007-06-02-10-25-43.pdf

${ }^{219}$ Environment Canada. (2005). Beyond islands of green: a primer for using conservation science to select and design community-based nature reserves. Environment Canada. 
${ }^{220}$ Jalava, J.V., Kanter, M. \& Hodgkiss, S. (2015). Be part of the big picture: big picture report card discussion paper. Carolinian Canada Coalition.

${ }^{221}$ Noss, R. F., O'Connell, M., \& D.D. Murphy. (1997). The science of conservation planning: habitat conservation under the Endangered Species Act. World Wildlife Fund and Is/and Press.

${ }^{222}$ Carolinian Canada. (n.d.) What is the Big Picture? Carolinian Canada. https:// caroliniancanada.ca/legacy/ConservationPrograms_BigPicture.htm

${ }^{223}$ Riley, J. L. \& Mohr, P. (1994). The natural heritage of southern Ontario's settled landscapes: A review of conservation and restoration ecology for land-use and landscape planning. Ontario Ministry of Natural Resources.

${ }^{224}$ Carolinian Canada. (n.d.) What is the Big Picture? Carolinian Canada. https:// caroliniancanada.ca/legacy/ConservationPrograms_BigPicture.htm

${ }^{225}$ Carolinian Canada. (2018). A Map to the Future: Carolinian Canada Strategic Plan. Carolinian Canada. https://caroliniancanada.ca/strategic-planning

${ }^{226}$ Carolinian Canada. (2018). Growing a green future together: strategic plan 2018-2023. Carolinian Canada.

${ }^{227}$ Carolinian Canada. (2021). Welcome to my wild. Carolinian Canada. https:// caroliniancanada.ca/

${ }^{228}$ Tallamy, D. W., \& Shropshire, K. J. (2009). Ranking lepidopteran use of native versus introduced plants. Conservation biology: the Journal of the Society for Conservation Biology, 23(4), 941-947.

${ }^{229}$ Environment Canada. (2013). How Much Habitat is Enough? Third edition. Environment Canada, Toronto, Ontario.

230 Jalava, J.V., Kanter, M. \& Hodgkiss, S. (2015). Be part of the big picture: big picture report card discussion paper. Carolinian Canada Coalition.
${ }^{231}$ Environment Canada. (2013). How Much Habitat is Enough? Third edition. Environment Canada, Toronto, Ontario.

${ }^{232}$ Conservation Standards. (2021). About Conservation Standards: helping conservation teams achieve lasting impact. Conservation Standards. https:// conservationstandards.org/about/

${ }^{233}$ Conservation Standards. (2021). About Conservation Standards: helping conservation teams achieve lasting impact. Conservation Standards. https:// conservationstandards.org/about/

${ }^{234}$ Nature United. (2021). Healthy Country Planning. Nature United. https://www. natureunited.ca/what-we-do/our-priorities/investing-in-people/healthy-country-planning/

${ }^{235}$ Ermine, W. (2007). The Ethical Space of Engagement. Indigenous Law Journal, 6(1), 193-201.

${ }^{236}$ Indigenous Circle of Experts. (2018). We Rise Together: achieving pathway to Canada target 1 through the creation of Indigenous Protected and Conserved Areas in the spirit and practice of reconciliation. Indigenous Circle of Experts.

${ }^{237}$ Carolinian Canada \& WWF Canada. (2020). Your Garden Can Help Native Species Thrive. In the Zone Gardens. https://inthezonegardens.ca/

${ }^{238}$ Carolinian Canada. (2013). The Landowner Leaders Program. Carolinian Canada. https://caroliniancanada.ca/landowner-leaders

${ }^{239}$ Von Bertalanffy, L. (1951). Problems of general system theory. Human Biology, 23(4), 302.

${ }^{240}$ Von Bertalanffy, L. (2010). General Systems Theory. The Science of Synthesis: Exploring the Social Implications of General Systems Theory, 103.

${ }^{241}$ Hofkirchner, W. (2019). Social relations: building on Ludwig von Bertalanffy. Systems Research and Behavioral Science, 36(3), 263-273. https://doi. org/10.1002/sres.2594 
${ }^{242}$ Beer, S. (1972). Brain of the firm: a development in management cybernetics. Herder and Herder.

${ }^{243}$ Beer, S. (1979). The heart of enterprise (Vol. 2). Chichester, England; New York: Wiley

${ }^{244}$ Mingers, J., \& White, L. (2010). A review of the recent contribution of systems thinking to operational research and management science. European Journal of Operational Research, 207(3), 1147-1161. https://doi.org/10.1016/j. ejor.2009.12.019

${ }^{245}$ Kennedy, S., Grewatsch, S., Liboni, L., \& Cezarino, L. O. (2021). A Systems Approach to Business Sustainability Education. Academy of Management Proceedings. https://doi.org/10.5465/AMBPP.2021.227

${ }^{246}$ Goodchild, M. (2021). Relational Systems Thinking: That's How Change is Going to Come, From Our Earth Mother. Journal of Awareness-Based Systems Change, 1(1), 75-103. https://doi.org/10.47061/jabsc.v1i1.577

${ }^{247}$ Goodchild, M. (2021). Relational Systems Thinking: That's How Change is Going to Come, From Our Earth Mother. Journal of Awareness-Based Systems Change, 1(1), 75-103. https://doi.org/10.47061/jabsc.v1i1.577

${ }^{248}$ Goodchild, M. (2021). Relational Systems Thinking: That's How Change is Going to Come, From Our Earth Mother. Journal of Awareness-Based Systems Change, 1(1), 75-103. https://doi.org/10.47061/jabsc.v1i1.577

${ }^{249}$ Goodchild, M. (2021). Relational Systems Thinking: That's How Change is Going to Come, From Our Earth Mother. Journal of Awareness-Based Systems Change, 1(1), 75-103. https://doi.org/10.47061/jabsc.v1i1.577

${ }^{250}$ The Center for Theory of Change. (2021) What is Theory of Change? https:// www.theoryofchange.org/what-is-theory-of-change/

${ }^{251}$ Arjaliès, D. L. \& Bansal T. (2020). Guidelines for Doing an Impact Assessment. Ivey Publishing
252 Kimmerer, R. W. (2013). Braiding sweetgrass: Indigenous wisdom, scientific knowledge and the teachings of plants. Milkweed Editions

${ }^{253}$ Kimmerer, R. W. (2013). Braiding sweetgrass: Indigenous wisdom, scientific knowledge, and the teachings of plants. Milkweed Editions.

${ }^{254}$ Yu H., Bansal, T. \& Arjaliès D-L. (2021). "What Global Crisis? How a Local Tibetan Business Notices Global Issues”. Unpublished working paper.

${ }^{255}$ Parlee, B., Manseau, M. \& Lutsel K'e Dene First Nation. (2005). Chapter 8: Understanding \& Communicating About Ecological Change: Denesoline Indicators of Ecosystem Health. Breaking Ice.

${ }^{256}$ Hatcher, A., Bartlett, C., Marshall, A., \& Marshall, M. (2009). Two-eyed seeing in the classroom environment: concepts, approaches, and challenges. Canadian Journal of Science, Mathematics, and Technology Education, 9(3), 141-153.

${ }^{257}$ Chartrand, R. (2021). How we're fighting climate change and promoting environmental conservation. Science Centre 3M Canada. https://sciencecentre.3mcanada.ca/articles/how-we-re-fighting-climate-change-and-promoting-environmental-conservation

${ }^{258}$ Victor, P. A. (2020). Cents and nonsense: a critical appraisal of the monetary valuation of nature. Ecosystem Services, 42, 101076. https://doi.org/10.1016/j. ecoser.2020.101076

259 Turner, K. R., Paavola, J., Cooper, P., Farber, S., Jessamy, V., \& Georgiou, S. (2003). Valuing nature: Lessons learned and future research directions. Ecological Economics, 46(3), 493-510. https://doi.org/10.1016/S0921-8009(03)00189-7

${ }^{260}$ Costanza, R., \& Kubiszewski, I. (2012). The authorship structure of "ecosystem services" as a transdisciplinary field of scholarship. Ecosystem Services, 1(1), 16-25. https://doi.org/10.1016/j.ecoser.2012.06.002

${ }^{261}$ Dasgupta, P. (2021). The Economics of Biodiversity: The Dasgupta Review. (London: HM Treasury) 
${ }^{262}$ Luck, G. W., Chan, K. M. A., Eser, U., Gómez-Baggethun, E., Matzdorf, B., Norton, B., \& Potschin, M. B. (2012). Ethical Considerations in On-Ground Applications of the Ecosystem Services Concept. BioScience, 62(12), 1020-1029. https://doi.org/10.1525/bio.2012.62.12.4

${ }^{263}$ Chaudhary, S., McGregor, A., Houston, D., \& Chettri, N. (2015). The evolution of ecosystem services: A time series and discourse-centered analysis. Environmental Science \& Policy, 54, 25-34. https://doi.org/10.1016/j.envsci.2015.04.025

${ }^{264}$ Zafra-Calvo, N., Balvanera, P., Pascual, U., Merçon, J., Martín-López, B., van Noordwijk, M., Mwampamba, T. H., Lele, S., Ifejika Speranza, C., Arias-Arévalo, P., Cabrol, D., Cáceres, D. M., O’Farrell, P., Subramanian, S. M., Devy, S., Krishnan, S., Carmenta, R., Guibrunet, L., Kraus-Elsin, Y., Moersberger, H., Cariño, J., \& Díaz, S. (2020). Plural valuation of nature for equity and sustainability: Insights from the Global South. Global Environmental Change, 63. https://doi. org/10.1016/j.gloenvcha.2020.102115

${ }^{265}$ Millennium Ecosystem Assessment. (2005). Ecosystems and human well-being: Synthesis. Island Press, Washington, DC

${ }^{266}$ TEEB. (2010). The Economics of Ecosystems and Biodiversity: Mainstreaming the Economics of Nature: A synthesis of the approach, conclusions, and recommendations of TEEB. The Economics of Ecosystems and Biodiversity. http:// teebweb.org/publications/teeb-for/synthesis/

${ }^{267}$ IPBES. (2015). Preliminary guide regarding diverse conceptualization of multiple values of nature and its benefits, including biodiversity and ecosystem functions and services (Deliverable 3(d)). Intergovernmental Science-Policy Platform on Biodiversity and Ecosystem Services.

${ }^{268} \mathrm{Himes}$, A., \& Muraca, B. (2018). Relational values: the key to pluralistic valuation of ecosystem services. Current Opinion in Environmental Sustainability, 35 $1-7$.
${ }^{269}$ Zafra-Calvo, N., Balvanera, P., Pascual, U., Merçon, J., Martín-López, B., van Noordwijk, M., Mwampamba, T. H., Lele, S., Ifejika Speranza, C., Arias-Arévalo, P., Cabrol, D., Cáceres, D. M., O’Farrell, P., Subramanian, S. M., Devy, S., Krishnan, S., Carmenta, R., Guibrunet, L., Kraus-Elsin, Y., Moersberger, H., Cariño, J., \& Díaz, S. (2020). Plural valuation of nature for equity and sustainability: Insights from the Global South. Global Environmental Change, 63. https://doi. org/10.1016/j.gloenvcha.2020.102115

270 Jacobs, S., Zafra-Calvo, N., Gonzalez-Jimenez, D., Guibrunet, L., Benessaiah, K., Berghöfer, A., Chaves-Chaparro, J., Díaz, S., Gomez-Baggethun, E., Lele, S., Martín-López, B., Masterson, V. A., Merçon, J., Moersberger, H., Muraca, B., Norström, A., O’Farrell, P., Ordonez, J. C., Prieur-Richard, A-H., Rincón-Ruiz, A. Sitas, N., Subramanian, S. M., Tadesse, W., van Noordwijk, M., Pascual, U., \& Balvanera, P. (2020). Use your power for good: Plural valuation of nature - the Oaxaca statement. Global Sustainability, 3. https://doi.org/10.1017/sus.2020.2

${ }^{271}$ Muradian, R. \& Pascual, U. (2018). A typology of elementary forms of human-nature relations: A contribution to the valuation debate. Current Opinion in Environmental Sustainability, 35. https://doi.org/10.1016/j.cosust.2018.10.014

272 Jacobs, S., Zafra-Calvo, N., Gonzalez-Jimenez, D., Guibrunet, L., Benessaiah, K., Berghöfer, A., Chaves-Chaparro, J., Díaz, S., Gomez-Baggethun, E., Lele, S., Martín-López, B., Masterson, V. A., Merçon, J., Moersberger, H., Muraca, B., Norström, A., O’Farrell, P., Ordonez, J. C., Prieur-Richard, A-H., Rincón-Ruiz, A., Sitas, N., Subramanian, S. M., Tadesse, W., van Noordwijk, M., Pascual, U., \& Balvanera, P. (2020). Use your power for good: Plural valuation of nature - the Oaxaca statement. Global Sustainability, 3. https://doi.org/10.1017/sus.2020.2

${ }^{273}$ Pascual, U., Phelps, J., Garmendia, E., Brown, K., Corbera, E., Martin, A., Gomez-Baggethun, E., \& Muradian, R. (2014). Social equity matters in payments for ecosystem services. Bioscience, 64(11), 1027-1036. https://doi.org/10.1093/ biosci/biu146 
${ }^{274}$ Rincón-Ruiz, A., Arias-Arevalo, P., Nuñez-Hernandez J. M., Cotler, H., Caso, M. A., Meli, P., Tauro, A., Akerberg, V. D. A., Avila-Foucat, V. S., Cardenas, J. P., Hernandez, L. A. C., Castro, L. G., Hernandez, V. A. C., Araque, A. C., Deschamps-Lomeli, J., Galeana-Pizaña, J. M., Mathamba, L. A. L., Pérez, L. M., Díaz, M. L. M., Marín, W., Ochoa, V., Sarmiento, M. A., Tauro, A., Timote, J. D., Cardozo, L. L., Acosta, A. T., \& Waldron, T. (2019). Applying integrated valuation of ecosystem services in Latin America: Insights from 21 case studies. Ecosystem Services, 36. https://doi.org/10.1016/j.ecoser.2019.100901

${ }^{275}$ Chan, K. M., Guerry, A. D., Balvanera, P., Klain, S., Satterfield, T., Basurto, X., Bostrom, A., Chuenpagdee, R., Gould, R., Halpern, B. S., Hannahs, N., Levine, J., Norton, B., Ruckelhaus, M., Russell, R., Tam, J., \& Woodside, U. (2012). Where are cultural and social in ecosystem services? A framework for constructive engagement. BioScience, 62(8), 744-756.

${ }^{276}$ Martín-López, B., Gómez-Baggethun, E., García-Llorente, M., \& Montes, C. (2014). Trade-offs across value-domains in ecosystem services assessment. Ecological Indicators, 37, 220-228. https://doi.org/10.1016/j.ecolind.2013.03.003

${ }^{277}$ Kenter, J. O., O’Brien, L., Hockley, N., Ravenscroft, N., Fazey, I., Irvine, K. N., Reed, M. S., Christie, M., Brady, E., Bryce, R., Church, A., Cooper, N., Davies, A., Evely, A., Everard, M., Fish, R., Fisher, J. A., Jobstvogt, N., Molloy, C., Orchard-Webb, J., Ranger, S., Ryan, M., Watson, V., Williams, S. (2015). What are shared and social values of ecosystems? Ecological Economics, 111, 86-99. https://doi.org/10.1016/j.ecolecon.2015.01.006

${ }^{278}$ O'Neill, J. (1996). Cost-benefit analysis, rationality, and the plurality of values. The Ecologist, 26(3), 98-103.

${ }^{279}$ Martinez-Alier, J., Munda, G., \& O’Neil, Jl. (1998). Weak comparability of values as a foundation for ecological economics. Ecological Economics, 26(3), 277-286. https://doi.org/10.1016/S0921-8009(97)00120-1

${ }^{280}$ Mason, E. (2013). Value pluralism. The International Encyclopedia of Ethics. https://doi.org/10.1002/9781444367072.wbiee575

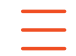

https://ir.lib.uwo.ca/impact-bond/vol1/iss1/1
${ }^{281}$ Arias-Arévalo, P., Gómez-Baggethun, E., \& Martín-López, B., \& Rincón, M. (2018). Widening the Evaluative Space for Ecosystem Services: A Taxonomy of Plural Values and Valuation Methods. Environmental Values, 27(1), 29-53.

${ }^{282}$ Himes, A., \& Muraca, B. (2018). Relational values: the key to pluralistic valuation of ecosystem services. Current Opinion in Environmental Sustainability, 35, $1-7$.

${ }^{283}$ Berbés-Blázquez, M., González, J. \& Pascual, U. (2016). Towards an ecosystem services approach that addresses social power relations. Current Opinion in Environmental Sustainability, 19. 134-143.

https://doi.org/10.1016/j.cosust.2016.02.003

${ }^{284}$ Jacobs, S., Zafra-Calvo, N., Gonzalez-Jimenez, D., Guibrunet, L., Benessaiah, K., Berghöfer, A., Chaves-Chaparro, J., Díaz, S., Gomez-Baggethun, E., Lele,

S., Martín-López, B., Masterson, V. A., Merçon, J., Moersberger, H., Muraca, B., Norström, A., O’Farrell, P., Ordonez, J. C., Prieur-Richard, A-H., Rincón-Ruiz, A. Sitas, N., Subramanian, S. M., Tadesse, W., van Noordwijk, M., Pascual, U., \& Balvanera, P. (2020). Use your power for good: Plural valuation of nature - the Oaxaca statement. Global Sustainability, 3. https://doi.org/10.1017/sus.2020.2

${ }^{285}$ Martinez-Alier, J., Anguelovski, I., Bond, P., Del Bene, D., Demaria, F., Gerber, J., Greyl, L., Healy, H., Marín-Burgos, V., Ojo, G., Porto, M., Rijnhout, L., Rodríguez-Labajos, B., Spangenberg, J., Temper, L., Warlenius, R., \& Yánez, I. (2014). Between activism and science: grassroots concepts for sustainability coined by Environmental Justice Organizations. Journal of Political Ecology, 21, 19-60.

${ }^{286}$ Muraca, B. (2016). Re-appropriating the ecosystem services concept for a decolonization of 'nature.' Rowan and Littlefield.

${ }^{287}$ Muradian, R. \& Pascual, U. (2018). A typology of elementary forms of human-nature relations: a contribution to the valuation debate. Current Opinion in Environmental Sustainability, 35, 8-14.

https://doi.org/10.1016/j.cosust.2018.10.014

${ }^{288}$ Arjaliès, D-L., (2020). What Trees Taught Me About COVID-19: On Relational Accounting and Other Magic. Forthcoming in the Accounting, Auditing \& Accountability Journal (AAAJ). https://ssrn.com/abstract=3652440 
${ }^{289}$ Star, S. L., \& Griesemer, J. R. (1989). Institutional ecology, translations' and boundary objects: Amateurs and professionals in Berkeley's Museum of Vertebrate Zoology, 1907-39. Social Studies of Science, 19(3), 387-420

${ }^{290}$ Goodchild, M. (2021). Relational Systems Thinking: That's How Change is Going to Come, From Our Earth Mother. Journal of Awareness-Based Systems Change, 1(1), 75-103. https://doi.org/10.47061/jabsc.v111.577

291 Goodchild, M. (2021). Relational Systems Thinking: That's How Change is Going to Come, From Our Earth Mother. Journal of Awareness-Based Systems Change, 1(1), 75-103. https://doi.org/10.47061/jabsc.v1i1.577

${ }^{292}$ Regenesis Group. (2021). Regenerative Development. https://regenesisgroup.com/

${ }^{293}$ The McConnell Foundation. (2021). Scaling Out, Scaling Up, Scaling Deep: Scaling Innovation. McConnell. https://mcconnellfoundation.ca/report/scaling-out-scaling-up-scaling-deep-scaling-innovation/

${ }^{294}$ Blue Cloud, Peter. (1995). Clans of Many Nations: Selected Poems. White Pine P. 1969- 94.
${ }^{295}$ Coleman, D. (2019). The Good Mind and Trans-Systemic Thinking in the Two-Row Poems of Mohawk Poet Peter Blue Cloud. Studies in American Indian Literatures, 31(1-2), 54-82. https://doi.org/10.5250/studamerindilite.31.1-2.0054

${ }^{296}$ Goodchild, M. (2021). Relational Systems Thinking: That's How Change is Going to Come, From Our Earth Mother. Journal of Awareness-Based Systems Change, 1(1), 75-103. https://doi.org/10.47061/jabsc.v111.577

${ }^{297}$ Coleman, D. (2019). The Good Mind and Trans-Systemic Thinking in the Two-Row Poems of Mohawk Poet Peter Blue Cloud. Studies in American Indian Literatures, 31(1-2), 54-82. https://doi.org/10.5250/studamerindilite.31.1-2.0054

${ }^{298}$ As cited in: Coleman, D. (2019). The Good Mind and Trans-Systemic Thinking in the Two-Row Poems of Mohawk Poet Peter Blue Cloud. Studies in American Indian Literatures, 31(1-2), 54-82. https://doi.org/10.5250/studamerindilite.31.1-2.0054

299 Two-Row Wampum Belt (Guswhenta or Kaswhenta)" by Six Nations Legacy Consortium Collection is licensed under CC BY-NC-ND 4.0. https://vitacollections.ca/sixnationsarchive/details.asp?ID=2687087. 
